\title{
Proteomics biomarkers for solid tumors: Current status and future prospects
}

Iwona Belczacka ${ }^{1,2}$, Agnieszka Latosinska ${ }^{1}$, Jochen Metzger ${ }^{1}$, David Marx ${ }^{3,4}$, Antonia Vlahou ${ }^{5}$, Harald Mischak $^{1^{*}}$, Maria Frantzi ${ }^{1}$

${ }^{1}$ Mosaiques-Diagnostics GmbH, Hannover, Germany

${ }^{2}$ University Hospital RWTH Aachen, Institute for Molecular Cardiovascular Research (IMCAR), Aachen, Germany

${ }^{3}$ Hôpitaux Universitaires de Strasbourg, Service de Transplantation Rénale, 67091 Strasbourg, France ${ }^{4}$ Laboratoire de Spectrométrie de Masse BioOrganique (LSMBO), University of Strasbourg, National Center for Scientific Research (CNRS), Institut Pluridisciplinaire Hubert Curien (IPHC) UMR 7178, 67000 Strasbourg, France

${ }^{5}$ Biotechnology Division, Biomedical Research Foundation, Academy of Athens (BRFAA), Athens, Greece

*Corresponding author:

Prof. Harald Mischak

Mosaiques Diagnostics GmbH

Hannover, Germany

Tel.: +49 (0) 51155474413

Fax: +49 (0) 55474431

E-mail:mischak@mosaiques-diagnostics.com 


\begin{abstract}
Cancer is a heterogeneous multifactorial disease, which continues to be one of the main causes of death worldwide. Despite the extensive efforts for establishing accurate diagnostic assays and efficient therapeutic schemes, disease prevalence is on the rise, in part, however, also due to improved early detection. For years, studies were focused on genomics and transcriptomics, aiming at the discovery of new tests with diagnostic or prognostic potential. However, cancer phenotypic characteristics seem most likely to be a direct reflection of changes in protein metabolism and function, which are also the targets of most drugs. Investigations at the protein level are therefore advantageous particularly in the case of in-depth characterization of tumor progression and invasiveness. Innovative high-throughput proteomic technologies are available to accurately evaluate cancer formation and progression and to investigate the functional role of key proteins in cancer. Employing these new highly sensitive proteomic technologies, cancer biomarkers may be detectable that contribute to diagnosis and guide curative treatment when still possible. In this review, the recent advances in proteomic biomarker research in cancer are outlined, with special emphasis placed on the identification of diagnostic and prognostic biomarkers for solid tumors. In view of the increasing number of screening programs and clinical trials investigating new treatment options, we discuss the molecular connections of the biomarkers as well as their potential as clinically useful tools for diagnosis, risk stratification and therapy monitoring of solid tumors.
\end{abstract}

Key words: Cancer, protein biomarkers, diagnosis, clinical proteomics, solid tumors 
Table of contents

I. INTRODUCTION

II. CURRENT STATUS OF CANCER DIAGNOSIS

III. LITERATURE SEARCH STRATEGY

IV. SYSTEMATIC REVIEW

A. Tissue proteomics studies subsequently verified in human body fluids

B. Studies in cell lines further verified in human biofluids

C. Studies performed in urine

D. Studies performed in serum/plasma

E. Studies performed in other biofluids

V. PROTEOMICS PLATFORMS IN CANCER RESEARCH

VI. FUNCTIONAL ANNOTATION OF MAIN BIOMARKER FINDINGS

VII. OUTLOOK AND FURTHER PERSPECTIVES

VIII. ACKNOWLEDGEMENTS

IX. ABBREVIATIONS

X. FIGURES

XI. TABLES

XII. SUPPLEMENTARY TABLES

XIII. REFERENCE LIST 


\section{INTRODUCTION}

Cancer is one of the main causes of death worldwide accounting for $21 \%$ of the overall mortality and is the second leading disease condition affecting people in developed countries(1). The number of new cancer cases reached 14.1 million in 2012 and is expected to rise to 23.6 million new cases in 2030(2). Despite the remarkable progress in cancer research and drug development, the long term survival of most cancer patients still remains poor (1). In most cases, this is attributed to diagnosis at an advanced stage of the malignancies and to limited guidance on the ideal treatment. To address this clinical challenge, research efforts have been (and still are) directed towards the identification of biomarkers for early diagnosis, prognosis and prediction of therapeutic response and towards the development of new treatment strategies targeting the underlying molecular pathology of the tumor.

To date, genomics approaches delivered important information about the cell's functional abilities and built the foundation for proteomics investigations. Proteomics complements the genomic approaches, providing additional information about the proteins as the main mediators of cell function, like their functionality, post-translational modifications, interaction with other biological molecules and their response to environmental factors (3-5).

In the last years, mass spectrometry (MS)-based proteomic technologies enabled the acquisition of large profiling datasets with very high precision and resolution (6) and we have now moved to an era, where MS is more widely applied, also as a valid alternative to the conventional immune-based approaches that target only single tumour antigens and are frequently compromised by low specificity and interference effects from the matrix (e.g. by compounds present in urine interfering with immunological detection) $(7,8)$.

The aim of this manuscript is to review the currently applied MS-based proteomic approaches in cancer biomarker research. Based on this aim, the most valid results from the studies involving cancer proteomics are presented, applied towards early cancer detection and its diagnosis, as well as patient stratification, prognosis, prediction of drug response and treatment monitoring. Subsequently, the main results are cross-correlated to investigate their associations with cancer evolution and progression.

We conclude the review with a discussion on the gaps and challenges of current oncoproteomics and propose suggestion on how to move forward.

\section{CURRENT STATUS OF CANCER DIAGNOSIS}

Cancer, as any disease is more likely to be treated successfully when diagnosed at its earliest stage (9). However, cancer can remain asymptomatic until late stage, particularly for certain primary cancer sites (10) and only few symptoms are cancer-specific, making timely diagnosis even more challenging (11). To increase the chances of detecting certain cancers at an early stage, screening programmes are recommended (9). Typical examples are described in Table 1. For several etiologies, cancer screening is initially performed by using imaging techniques like ultrasound x-ray examinations (e.g. mammography) or magnetic resonance imaging (MRI). While imaging techniques are helpful in 
detecting mass lesions or areas of abnormality, they are not well suited for early detection, as they frequently cannot distinguish cancerous from non-cancerous cells with high certainty. Furthermore, imaging does typically not inform about prognosis or enable prediction of therapeutic response. For most types of cancers, biopsies are used to establish definite diagnosis in case of uncertain imaging results. However, biopsies are obtained in an invasive manner and associated with significant complications (12). Therefore, application of non-invasive cancer biomarker tests would have a clear benefit in this field of cancer diagnostics.

Cancer biomarker tests have been and still are continuously developed using genetic and proteomic approaches. Genetic techniques provide information about gene mutations or aberrant gene expression based on the screening and quantification of specific DNA regions and/or mRNA transcripts. Several PCR- or microarray-based gene expression tests have been already introduced to clinical practice (Table 2). For instance, genetic testing for $B R C A 1 / B R C A 2$ mutations is recommended for the risk assessment in women with ovarian cancer (13). Moreover, the Fluorescence In Situ Hybridization (FISH) testing for HER2 gene amplification became an essential part of the clinical evaluation of breast cancer patients and accurate HER2 results are critical in selecting the best treatment strategy (Table 2) (14).

Several protein biomarkers are in use in clinical practice, some of them approved by the Food and Drug Administration (FDA), as further summarised in Table 2. Examples for protein biomarkers currently applied for cancer screening are the cancer antigen 125 (CA125), carcinoembryonic antigen (CEA) and prostate-specific antigen (PSA) (9). These proteins are generally assessed using immune-based assays like ELISA. Unfortunately, in most of the cases their clinical utility is limited due to suboptimal sensitivities and specificities especially for early cancer detection (15). With the advent of the postgenomic era, novel approaches like tandem mass spectrometry (MS/MS) have been introduced in clinical practice, for example for the quantification of metabolites in clinical samples (16), which in combination with the extensive ongoing biomarker discovery efforts raises hopes that their wider application in cancer diagnosis and monitoring may be feasible in the near future, and brings benefits for cancer patients.

\section{LITERATURE SEARCH STRATEGY}

For this systematic review, a literature search was performed by searching the Web of Science database with the following criteria (as also schematically presented in Figure 1): TOPIC: (tumor OR cancer) AND TOPIC: (proteom*) AND TOPIC: (marker OR biomarker). Only original articles published between 2010 and 2017 were taken into consideration. For each year, literature search was performed separately. According to these criteria, 4647 papers were retrieved. Between 2010 and 2016, we focused on publications cited at least five times per each year, whereas no citation threshold was applied for publications in 2017. After this step, 1056 manuscripts were retained and are all listed in Supplementary Table S1. Out of these, 500 articles were excluded as they were reviews, protocols, meeting abstracts, methodological and basic chemical research papers. Additionally, 61 articles were 
focused on experimental animal models only (mouse, rat, hamster, or zebrafish) and 222 were studies that were based solely on isolated cell lines and/or tissues and not subsequently verified in vivo in human body fluids. From the remaining 273 articles, 51 were excluded as they were not relevant to MS-based proteomics methodologies and seven articles that were focused on genomic and metabolomic technologies only. Moreover, 93 articles on topics not related to cancer where not taken into consideration. An additional exclusion criterion was the absence of independent validation of the candidate biomarkers $(n=43)$. Seven studies were excluded because the comparison was based on a very small number of investigated samples $(<5)$. Collectively, 72 manuscripts were considered for presentation and are categorized by the type of biological specimen under investigation and grouped based on the specific cancer type. An overview of the 72 selected studies, including performance characteristics, size of the study cohorts, applied methodologies and clinical application is provided in Supplementary Table S2. It should be emphasized that the presented manuscripts are based on the specific systematic search, but the presented list is clearly not exhaustive. However, the specific approach (to base the article on a well defined systematic review with clear criteria), is considered the most appropriate to investigate such a broad field, and helps avoiding introducing bias.

\section{SYSTEMATIC REVIEW}

\section{A. Tissue proteomics studies subsequently verified in human body fluids}

\section{Renal cell carcinoma}

Several studies reported initial findings based on tissue proteome analysis using MS, followed by verification in human body fluids. Non-invasive diagnostic biomarkers for detection of clear-cell type of renal cell carcinoma (ccRCC) were investigated by White et al (17). In this study, isobaric tag for relative and absolute quantitation (iTRAQ) labeling coupled with liquid chromatography-MS/MS (LC/MS-MS) was used to analyse tissue samples (tumor and adjacent non-malignant tissue) from ccRCC patients $(n=40)$. A total of 55 proteins were identified with significantly differential abundance, 15 of those with increased (iTRAQ ratios of $\geq 1.5$ ) and 40 with decreased abundance (iTRAQ ratios of $\leq 0.67)$ in ccRCC patients. Further analysis by unsupervised hierarchical clustering highlighted 39 proteins $(71 \%)$ as "secretory", revealing a potential to serve as diagnostic biomarkers for ccRCC. $\alpha$ enolase (ENO1), neuroblast differentiation-associated protein AHNAK (AHNAK), heat shock protein beta-1 (HSP27), and $10 \mathrm{kDa}$ heat shock protein (HSPE1) were selected for further verification in the discovery cohort by Western Blot (WB). The expressions of AHNAK, ENO1, and HSP27 were found with significantly increased expression ( $\boldsymbol{p}<0.002, \boldsymbol{p}<0.01$, and $\boldsymbol{p}<0.01$, respectively) in ccRCC compared to adjacent non-malignant tissues, whereas HSPE1 was significantly downregulated in ccRCC $(\boldsymbol{p}<0.002)$. HSP27 was further validated by ELISA conducted in an independent small set of urine $(n=17)$ samples and found significantly elevated in primary ccRCC patients compared those with no malignancy $(\boldsymbol{p}<0.05)(17)$. 


\section{Colorectal cancer}

Two studies on colorectal cancer (CRC) were performed starting from discovery in colon cancer tissue with the findings to be further investigated for their utility as biomarkers in plasma and serum specimens. Hamelin et al. compared protein expression levels between CRC tissue and adjacent non-malignant colon mucosa using two-dimensional (2D) differential gel electrophoresis (2D-DIGE) and matrix assisted laser desorption ionization-time of flight mass spectrometry (MALDI-TOF-MS) (18). The differential expression of glutathione-S-transferase Pi (GST-Pi), ENO1, T-complex protein 1 subunit $\beta$ (TCP1 $\beta$ ) and leukocyte elastase inhibitor (LEI) proteins detected by 2D-DIGE was confirmed by WB in the tissue samples, and in the case of HSP60 by ELISA in serum. Following analysis of sera of 112 patients with CRC and 90 healthy controls, HSP60 levels discriminated CRC from controls with an area under the curve (AUC) value of 0.70. In combination with the serum markers CEA and cancer antigen 19-9 (CA19-9), an increased AUC value of 0.77 was reached $(\boldsymbol{p}<0.001)$ (18). Surinova et al. performed proteomic profiling of microdissected human primary tumor epithelia compared to adjacent nonmalignant mucosa ( $\mathrm{n}=16$ each) using liquid chromatography coupled to tandem mass spectrometry (LCMS/MS) to characterize tumor-associated secreted and cell surface glycoproteins (19). In total, 303 candidates were retrieved and further quantified initially in plasma samples from 19 CRC patients using selected reaction monitoring (SRM), as targeted proteomic approach. Further evaluation of the 303 biomarker candidates was conducted in two independent cohorts. In the first cohort consisting of 66 plasma samples from healthy controls, 34 patients with benign lesions and 100 CRC patients, a biomarker signature comprised of ceruloplasmin, serum paraoxonase/arylesterase 1 (PON1), serpin peptidase inhibitor, clade A (SERPINA3), leucine-rich alpha-2-glycoprotein (LRG1), and tissue inhibitor of metalloproteinases 1 (TIMP1) was established. Further validation of this biomarker signature in an independent set of plasma samples from 50 healthy controls, 17 benign lesions, and 202 CRC patients exhibited an AUC of 0.84 for the discrimination of CRC patients from the control groups (19).

\section{Pancreatic cancer}

Kosanam et al. analysed four pancreatic ductal adenocarcinoma (PDAC) tissue samples and corresponding adjacent non-malignant tissues, identifying a total of 2190 nonredundant proteins (20). Among these, 344 proteins were exclusively detected in PDAC, out of which 67 were identified as membranous and secretory proteins released from extracellular receptors by Gene Ontology (GO) analysis. The 67 selected proteins were scored based on cellular origin, mRNA expression levels, average LFQ (label free quantification) values in PDAC tissues and identification in previously profiled proteomes of malignant pancreatic ascitic fluids. The top four ranked candidates were laminin 2 (LAMC2), desmoplakin (DSP), Golgi membrane protein-1 (GP73) and desmoglein-2 (DSG2), which were further investigated in serum from 20 pancreatic cancer patients and 20 patients with benign pancreatic cysts using ELISA. The analysis showed that serum levels of LAMC2 and DSG2 were significantly increased in PDAC patients $(\boldsymbol{p}<0.05)$, whereas the DSP and GP73 changes did not reach 
statistical significance. Further comparison with the current standard for PDAC diagnosis - CA19-9, revealed potential added benefits of LAMC2 (20).

Tomaino et al. investigated specific post-translational modifications of Enolase that trigger the production of autoantibodies in PDAC patients (21). Enolase was isolated from PDAC tissues and further characterized by two dimensional electrophoresis (2DE) and WB, in order to determine the expression of six different isoforms (ENOA1,2,3,4,5,6). Two isoforms were exclusively present in cancer tissue only, while the remaining 4 isoforms (ENO3,4,5 and 6) presented a 2-fold increase in PDAC compared to normal pancreatic tissues. 62\% of PDAC patients produced circulating autoantibodies (Aab) against the two enolase isoforms (ENOA1,2), whereas such reactivity was observed in only $4 \%$ of non-PDAC and $9 \%$ chronic pancreatitis serum samples. Phosphorylation of all six ENOA isoforms was investigated by LC-MS/MS, revealing a unique phosphorylation site for ENOA1,2 isoforms at serine 419. Aab against ENOA1,2 were investigated in a set of 268 serum samples (120 PDAC serum samples, 40 healthy subjects, 50 non-PDAC, 46 chronic pancreatitis patients and 12 patients with autoimmune diseases). In this study, the Aab enabled discrimination of PDAC patients from controls with sensitivity and specificity of $62 \%$ and $97 \%$, respectively (21).

\section{Prostate cancer}

Pang et al. reported potential biomarkers for diagnosis of prostate cancer (PCa)-derived lymph-node metastasis (LNM) using 2D-DIGE and MALDI-TOF-MS (22). Among 58 identified proteins that were differentially expressed in tissues from PCa patients with LNM in comparison to benign prostatic hyperplasia (BPH) patients, six were relevant to cancer metastasis based on their function: epidermal fatty acid-binding protein (e-FABP5), mitochondrial methylcrotonoyl-CoA carboxylase beta chain (MCCC2), inorganic pyrophosphatase 2 mitochondrial (PPA2), ezrin, stomatin like protein 2 (SLP2) which were upregulated, while smooth muscle protein (SM22) found to be downregulated in the cancer tissue (22). The differential expression of these proteins was further confirmed by WB and immunohistochemistry (IHC). Additionally, the serum levels of e-FABP5 were determined in 20 patients with localized PCa, 20 LNM PCa patients and 30 patients with BPH by ELISA, showing significantly higher levels of e-FABP5 in the LNM PCa patients than in BPH patients $(\boldsymbol{p}<0.01)$, indicating that e-FABP5 might be a promising biomarker candidate for the diagnosis of LNM PCa (22).

\section{Esophageal squamous cell carcinoma}

Protein expression profiles of 30 esophageal squamous cell carcinoma (ESCC) tissues and paired adjacent non-malignant tissues were analysed using 2DE and MALDI-TOF-MS (23). Among 47 deregulated proteins, heat shock protein 70 (HSP70) and high-mobility group box-1 (HMGB1) induced autoantibody response in ESCC and displayed higher abundance levels in ESCC compared to the adjacent non-malignant tissues. In 69 patients with ESCC and 79 healthy individuals, antibodies targeting HSP70 were significantly increased in ESCC $(\boldsymbol{p}<0.01)$, whereas antibodies for HMGB1 displayed no significant difference between ESCC and normal controls (23). 
Hou et al. applied a combination of sequential window acquisition of all theoretical fragment ion mass spectra (SWATH) and multiple-reaction monitoring (MRM) to discover and verify ESCC-related protein biomarkers in 10 ESCC tissues samples paired with adjacent non-malignant tissue (24). The authors quantified 1758 proteins. Of these, 467 proteins (260 being upregulated and 207 downregulated) exhibited nominal significant quantitative differences between the ESCC and adjacent non-malignant tissue $(\boldsymbol{p}<0.05)$. After evaluation of the SWATH MS signals of the upregulated proteins, 116 were selected and further assessed with MRM in ten paired individual ESCC serum samples collected preand post-tumor excision surgery. Of the 116 target proteins, 42 were detected in serum samples. Eleven proteins showed significantly lower abundances post-operation $(\boldsymbol{p}<0.05)$, and satisfactory MRM signals whereas the rest of the proteins exhibited no significant change in the abundance. For these 11 proteins, their abundance was further assessed individually: seven proteins were consistently of lower abundance in most sera (>80\%) post-operation, whereas the other four proteins were excluded from the final biomarker list due to the higher variability $(50-60 \%)$ in their abundance changes. Of the 7 biomarker candidates, glutathione s-transferase omega-1 (GSTO1), histone H4, fibronectin and thrombospondin-1 (THBS1) were previously described as potential serum biomarkers for ESCC, whereas three other proteins: serpin B9 (SERPINB9), dynamin-2 (DNM2) and galectin-3- binding protein (LG3BP) were identified as novel ESCC-related potential biomarkers (24).

\section{Bladder cancer}

Chen et al. combined laser capture microdissection, iTRAQ labeling and LC-MS/MS to profile proteomic changes in four surgically resected primary bladder cancer tissues and adjacent non-malignant tissues (25). Based on the iTRAQ results, seven candidate biomarkers, namely carbonic anhydrase 2 (CA2), phosphoglycerate kinase 1 (PGK1), 14-3-3 protein sigma (SFN), 4F2 cell-surface antigen heavy chain (SLC3A2), stathmin (STMN1), transgelin-2 (TAGLN2), and thioredoxin (TXN). All were overexpressed in at least three out of four microdissected tissue specimens and were subjected for further verification by IHC. Three of the candidates, SLC3A2, STMN1, and TAGLN2, were found significantly overexpressed in cancer cells in comparison to non-cancerous bladder epithelial cells $(\boldsymbol{p}<0.001)$. Further investigation in urine samples by ELISA revealed that STMN1 and TAGLN2 were significantly increased in urine of bladder cancer patients ( $\mathrm{n}=104$ for STMN1 and $\mathrm{n}=137$ for TAGLN2) compared to those presenting with hernia ( $\mathrm{n}=48$ for STMN1 and $n=68$ for TAGLN2), exhibiting AUCs values of 0.67 and 0.70 , respectively (25).

\section{B. Studies in cell lines further verified in human biofluids}

\section{Lung cancer and Non-small cell lung cancer}

Promising biomarker candidates have been investigated in several studies involving cell lines, followed by validation in human body fluids. Farlow et al. used 2DE and WB analysis followed by MS/MS to identify autoantibodies as biomarkers for the detection of non-small cell lung cancer (NSCLC) (26). Cell extracts from the HCC827 lung adenocarcinoma cell line were subjected to WB and probed 
individually either with pooled sera from control or NSCLC patients ( $\mathrm{n}=10$ per group). The candidate autoantigens that were recovered from the 2D WB were identified by MS/MS. Fifteen of these proteins and an additional set of 10 potential autoantigens (NY-ESO, p53, peroxiredoxin, triosephosphate isomerase, tecoverin, 3-oxoacid CoA transferase, survivin, c-Myc, annexin II, and ubiquillin 1), selected from a literature search were chosen to be investigated on a Luminex platform with sera from a larger cohort of patients $(n=117$ NSCLC, $n=32$ chronic obstructive pulmonary disorder/asthma, $n=31$ osteoarthritis patients with no history on lung diseases or cancer, $n=16$ resected patients with nonneoplastic nodules). A panel of 6 autoantibodies with reactivity against inosine-5'-monophosphate dehydrogenase (IMPDH), phosphoglycerate mutase, ubiquillin 1, annexin I, annexin II or heat shock protein 70-9B (HSP70-9B) was found to be highly discriminative (AUC=0.93) for NSCLC with the serum levels of these 6 autoantibodies each significantly higher in NSCLC comparing to controls $(\boldsymbol{p}<0.05)(26)$.

Birse et al. integrated LC-MS/MS analyses from freshly resected lung tumor specimens ( $n=13)$, extracts from lung cancer cell lines ( $n=17)$, and conditioned media collected from lung cancer cell lines $(n=7)$ to identify candidate diagnostic biomarkers for lung cancer (27). By integrating the discoveries from the three parallel analyses, a pool of 179 candidate markers was defined. From these, eight proteins: tissue factor pathway inhibitor (TFPI), midkine (MDK), osteopontin (OPN), matrix metalloproteinase-2 (MMP2), TIMP1, CEA, cytokeratin-19 fragment (CYFRA 21-1) and squamous cell carcinoma antigen (SCC-Ag) were selected for further validation by ELISA in an independent set of serum samples collected from NSCLC stage I patients ( $\mathrm{n}=94)$ and individuals with smoking history $(\mathrm{n}=189)$. Levels of CEA, MDK, MMP2, SLPI, TIMP1, and TFPI were significantly higher in serum from subjects with NSCLC $(\boldsymbol{p}<0.001)$. Furthermore, an eight-marker model (TFPI, MDK, OPN, MMP2, TIMP1, CEA, CYFRA 21-1, SCC-Ag) was tested in an independent study, including 50 high risk smokers as reference controls and 50 patients with lung cancer. The eight-marker model distinguished patients with malignant lesions from all smokers with an AUCvalue of 0.78 (27).

Yu et al. compared the proteome of malignant pleural effusions (MPE) ( $n=13)$ obtained from patients with lung adenocarcinoma with the secretome from three adenocarcinoma cell lines using SDS-PAGE combined to LC-MS/MS to identify potential pleural effusion biomarkers originating from malignant cells (28). The approach enabled the identification of 107 biomarker candidates. The candidates were shortlisted based on biological significance in tumorigenesis, novelty, and availability of a commercial ELISA kit. Based on these criteria, four potential candidates: alpha-2-HS glycoprotein (AHSG), angiotensin, cystatin-C, and insulin-like growth factor-binding protein 2 (IGFBP2), were subjected to further validation by ELISA in an independent set of 187 pleural effusion samples. IGFBP2 showed significantly increased levels in patients with malignancy $(n=68)$, compared to those with non-malignant pleural effusion $(n=119) \quad(\boldsymbol{p}<0.001)$. Furthermore, the potential of IGFBP2 as a pleural effusion biomarker was compared with CEA levels in the same validation cohort. The AUC value for IGFBP2 
was 0.76 and 0.78 for CEA. The combination of IGFBP2 and CEA exhibited higher performance with an AUC of 0.85 (28).

Cerciello et al. employed MS-based Cell Surface Capture (CSC) technology and SRM to analyse the glycosylated proteome of two epithelioid and two biphasic malignant pleural mesothelioma (MPM) cell lines, two NSCLC (lung adenocarcinoma) and two non-cancerous pleural cell lines (29). After enrichment of N-linked glycoproteins, $668 \mathrm{~N}$-glycopeptides were detected, representing more than 350 glycoproteins. Further analysis focused only on those glycopeptides that exhibited higher abundance in MPM cell lines compared to two NSCLC and the two non-cancerous pleural cell lines. This resulted in shortlisting of $125 \mathrm{~N}$-glycopeptides that were selected for detailed analysis by SRM. SRM assays for 51 $\mathrm{N}$-glycopeptides could be established. In a set of enriched (for glycopeptides) serum samples from MPM $(\mathrm{n}=25)$, healthy individuals $(\mathrm{n}=25)$ and NSCLC subjects $(\mathrm{n}=25), 10$ of these $\mathrm{N}$-glycopeptides were found in MPM to be significantly different between the groups: four $\mathrm{N}$-glycopeptides were significantly higher in their abundance compared to healthy individuals and six N-glycopeptides, showed higher abundance when compared to NSCLC. By evaluation of their predictive ability using ROC curves allowed proposing a multiplexed panel of six MPM candidate biomarkers demonstrated the best discriminatory performance for MPM. The marker panel includes intercellular adhesion molecule 1 (ICAM1), basement membrane-specific heparan sulfate proteoglycan core protein (HSPG2), anthrax toxin receptor 1 (ANTXR1), PON1, hypoxia up-regulated protein 1 (HYOU1) and THBS1, all with higher abundance in MPM compared to NSCLC patients $(\boldsymbol{p}<0.05)$. The six glycopeptide panel was validated in an independent set of 87 sera (enriched for N-glycopeptides) from MPM $(n=30)$, healthy individuals $(n=29)$ and NSCLC patients ( $\mathrm{n}=28)$ and discriminated MPM from healthy individuals with an AUC value of 0.94, while the panel failed to discriminate MPM from NSCLC (29).

\section{Head and neck cancer/oral squamous cell carcinoma}

Ralhan et al. investigated conditioned media from head and neck cancer/oral squamous cell carcinoma (HNOSCC) cell lines from different sites: tongue exemplified by SCC4, mouth exemplified by HSC2, glottis larynx by SCC38 and AMOSIII representing buccal mucosa. As a result of the LC-MS/MS analysis, 140 unique proteins were identified, of which 122 proteins were classified as secretory proteins by Ingenuity® Pathway Analysis (IPA). Of these, five proteins were considered for further verification based on their presence in previous iTRAQ studies (30-32) as well as due to their biological relevance and prognostic value. These 5 proteins, ENO1, peptidyl prolyl isomerase A, 14-3-3 zeta, 14-3-3 delta and heterogeneous ribonucleoprotein $\mathrm{K}$ were found to be increased in the sera of additional set of HNOSCC patients by WB analysis ( $n=12$ HNOSCC patients and $n=12$ healthy controls) (33).

Using Multidimensional protein identification technology (MudPIT) analysis, Sepiashvili et al. identified 90 putative protein biomarkers that are secreted or shed to the extracellular space and significantly over-expressed in head and neck cell carcinoma (HNSCC) cell lines relative to the normal oral epithelial cell line $(\boldsymbol{p}<0.05)(34)$. Further short lists of potential biomarker candidates were based on differences in IHC staining intensities of head and neck cancer tissues (HNC) compared to normal 
oral mucosal tissues using Human Protein Atlas expression profiling in two previously published microarray expression data sets for primary human HNC differences in secretion mechanisms (canonical or noncanonical secretion pathways or released from exosomes), a literature search for biomarkers with relevance for HNSCC progression, and the development of new antibodies for IHC and ELISA screening purposes. The top 5 ranked biomarker candidates urokinase (PLAU), insulin-like growth factor binding protein 7 (IGFBP7), metalloproteinase 14 (MMP14), THBS1 and transforming growth factor, beta-induced (TGFBI) were investigated using qRT-PCR and WB in HNSCC and the normal oral epithelial cell line. All five proteins were verified as being upregulated both on the mRNA and protein levels. Subsequently the expression levels of the five candidates were determined in HNSCC tissues ( $n=39)$ by IHC. Expression of PLAU, IGFBP7, MMP14 and THBS1 was significantly higher in relapsed comparing to non-relapsed HNSCC tissues $(\boldsymbol{p}=0.02, \boldsymbol{p}=0.04, \boldsymbol{p}=0.004$ and $\boldsymbol{p}=0.09$, respectively), whereas TGFBI show no such differences. As further demonstrated by ELISA, PLAU and IGFBP7 levels were significantly increased in the plasma of HNSCC patients $(n=27)$ compared to healthy individuals $(n=14)(\boldsymbol{p}=0.01$ and $\boldsymbol{p}=0.0002$, respectively), whereas MMP14 and THBS1 levels were similar in both groups of plasma samples (34).

\section{Colorectal cancer}

Four proteomics studies were conducted to identify potential biomarkers for detection of CRC using a combination of cell line and body fluid analysis. Xue et al. compared the secretomes of the primary CRC cell line SW480 and its metastatic variant SW620 using LC-MS/MS. The authors identified 145 potentially discriminating proteins, based on a threshold of 1.5 -fold change in secretion levels between two cell lines (35). For further assessment by WB, the proteins growth/differentiation factor 15 (GDF15), trefoil factor 3 (TFF3), anterior gradient protein 2 homolog (AGR2), protein-glutamine gamma-glutamyltransferase 2 (TGM2) and neutrophil gelatinase-associated lipocalin (NGAL) and IGFBP7 were selected because they exhibited high fold changes in differential expression between SW620 and SW480 in combination with the availability of commercial antibodies. GDF15, TFF3 and AGR2 were clearly detected in conditioned media of SW620, whereas little or no immunoreactivity was observed in SW480. TGM2, LCN2 and IGFBP7 were observed in the supernatant from SW480 and reduced or undetectable in SW620. TFF3 and GDF15 were selected for further ELISA analysis of serum samples from 144 CRC patients and 156 healthy controls. Serum levels of both proteins were significantly higher in metastatic colorectal cancer in comparison to healthy controls $(\boldsymbol{p}<0.0001)$. In addition, ROC analysis confirmed that serum TFF3 and GDF15 are significantly (AUC $=0.73$ and AUC $=0.89$, respectively) associated with colorectal cancer metastasis (35). Barderas et al. used SILAC (stable isotope labeling by/with amino acids in cell culture) followed by LC-MS/MS to compare the protein content of conditioned serum-free medium from the highly metastatic KM12SM CRC cell line with that of the parental, poorly metastatic KM12C cell line (36). Among 155 proteins showing >1.5fold change, GDF15, calprotectin (S100A8/A9), and SERPINI1 (Serpin Family I Member 1) were further investigated in serum of $40 \mathrm{CRC}$ patients and 20 normal controls and found to be discriminative 
for highly metastatic CRC with AUC values of 0.75 (S100A8/A9), 0.81 (GDF15), and 0.82 (SERPINI). The AUC for a combined classifier when integrating S100A8/A9, SERPINI1, and GDF15 was 0.88, corresponding to a sensitivity of $95 \%$ and specificity of $60 \%$ for CRC metastasis (36). In a third study, LC-MS/MS was used in combination with iTRAQ labeling to study the secretome of two gastric cancer cell lines, AGS, derived from a primary gastric tumor, and MKN7, derived from a gastric cancer lymph node metastasis (37). Comparative proteome analysis revealed 43 proteins different in abundance between the AGS and MKN7 secretome, with granulin (GRN) demonstrating the most prominent change. GRN was further investigated in serum samples $(\mathrm{n}=78)$ by ELISA and exhibited an AUC of 0.71 for the discrimination of early stage gastric cancer patients from healthy individuals (37). Yao et al. applied a lectin affinity-based approach to compare the secretome of CRC tumor tissues with adjacent non-malignant tissues to identify potential biomarkers, using GeLC-MS/MS (separation by SDS-PAGE, sliced in 5-20 lanes, followed by in-gel digest and LC-MS/MS analysis) (38). Based on label-free spectral counting, 123 differentially expressed secreted proteins were identified. Among them, EGFcontaining fibulin-like extracellular matrix protein 2 (EFEMP2) was one of the top 10 upregulated proteins and was further selected to be investigated at the tissue level by IHC and in serum using ELISA. EFEMP2 expression levels were higher in CRC tissues $(n=88)$ compared to colorectal adenoma tissues $(n=19)(\boldsymbol{p}<0.05)$ and non-malignant tissues $(n=16)(\boldsymbol{p}<0.01)$. Consistently with the IHC results, the serum levels of EFEMP2 were significantly increased in samples from CRC patients at different stages $(\mathrm{n}=122)$ in comparison to 79 healthy controls $\left(\boldsymbol{p}=2.00 \times 10^{-13}\right)$ and 14 samples from a population presenting colorectal adenoma $(\boldsymbol{p}=0.003)(38)$.

\section{Prostate cancer}

Several groups employed LC-MS/MS to identify biomarkers for prostate cancer (PCa) diagnosis (39, 40). Saraon et al. compared the secretome of androgen-independent (PC3, DU145, PPC1, LNCaP-SF, and 22Rv1), androgen-dependent ( $\mathrm{LNCaP}$ and $\mathrm{VCaP}$ ) and non-cancerous immortalized prostate epithelial (RWPE) cell lines using LC-MS/MS (40). Among the identified proteins, protein S (PROS1) was consistently elevated in the secretome of all androgen-independent PCa cell lines with no detectable secretion in non-cancerous and androgen-dependent cell lines. Further evaluation by ELISA in seminal plasma samples from PCa patients revealed that PROS1 was significantly elevated $(\boldsymbol{p}<0.05)$ in seminal plasma of patients with high-grade/intermediate $\mathrm{PCa}(\mathrm{n}=13)$ in comparison to patients with low-grade $\mathrm{PCa}(\mathrm{n}=8)$. The AUC of PROS 1 in distinguishing benign (negative biopsy and prostatitis) and low-grade PCa from intermediate/high-grade PCa in seminal plasma was 0.88 (40). Fujita et al. investigated urinary extracellular vesicles (EVs) from patients with high Gleason PCa in comparison to benign controls ( $\mathrm{n}=6$ PCa and $n=12$ patients with negative biopsy), using quantitative label-based proteomics (iTRAQ-LCMS/MS) (39). In this approach, 4710 proteins were identified, and 3528 proteins were quantified. Among them, 11 proteins were identified with increased abundance in the EVs from patients with PCa compared to those with negative biopsy (ratio >1.5) and were selected for further assessment using SRM/MRM in an independent set of 29 urine samples ( $\mathrm{n}=18 \mathrm{PCa}, \mathrm{n}=11$ patients with negative biopsy). 
The urinary levels of fatty acid binding protein 5 (FABP5) were significantly higher in the cancer group than in the negative group $(\boldsymbol{p}=0.009)$ and FABP5 abundance was significantly associated with Gleason score $(p$ for trend $=0.011)(39)$.

\section{Bladder cancer}

In the case of bladder cancer (BCa), Chen et al. analysed proteins from urinary exosomes of patients with $\mathrm{BCa}$ or hernia as controls ( $\mathrm{n}=18$ samples, 9 per group), using LC-MS/MS. A total of 107 proteins were selected as candidate biomarkers and further assessed in urine samples $(n=48)$ from BCa or hernia patients and patients presenting with urinary tract infection/hematuria, using LC-MRM-MS analysis. Twenty four proteins were found to be differentially abundant between $\mathrm{BCa}$ and hernia patients $(\boldsymbol{p}<0.05)$. Among them, tumor-associated calcium-signal transducer 2 (TACSTD2) concentrations were higher in urinary microparticles from $\mathrm{BCa}$ patients compared to hernia controls (6.5-fold change, $\boldsymbol{p}=0.02$ ) but not significantly different between hernia and urinary tract infection/hematuria patients $(\boldsymbol{p}=0.396)$, revealing a possible role for TACSTD2 in bladder tumorigenesis. Upregulation of TACSTD2 was further confirmed by ELISA in an independent set of 221 urine samples ( 81 hernia patients, 40 low grade/early stage $\mathrm{BCa}, 63$ high grade/early stage $\mathrm{BCa}$ and 37 high grade/advanced stage $\mathrm{BCa}$ ). TACSTD2 discriminated all cancer subgroups from hernia patients with an AUC value of 0.80 (41).

GeLC-MS/MS was used to identify proteins released into culture media by cell lines in the context of urothelial bladder cancer (UBC): the immortalised 'normal' urothelial UROtsa cell line, MGH-U3, RT4, SW-780 (grade 1 UBC cell lines) and RT112, VM-CUB1, 5637, T-24, HB-CLS2 (grade 2 UBC cell lines) (42). To induce secretion and shedding, the cells were treated with phorbol myristate acetate (PMA). In total, 2078 proteins were identified in the conditioned media. Thirty nine proteins exhibited a $>2$-fold increased and 6 proteins a $>2$-fold decreased abundance in response to PMA in more than 4 cell lines. These secretome data were further compared with immunohistochemistry data from the Human Protein Atlas. This approach enabled the identification of five potential candidates: epidermal growth factor receptor (EGFR), glucose-6-phosphate dehydrogenase (G6PD), peroxiredoxin 6, LY6/PLAUR domain containing 3 and fibulin 1, with the EGFR being unique in that it was the only one of these 5 proteins that was identified in the cancer cell line secretomes and not in the immortalised 'normal' urothelial UROtsa cell line. EGFR was subsequently evaluated by ELISA in urine from 60 noncancer control subjects and from patients with $\mathrm{BCa}$ and long-term clinical follow-up $(\mathrm{n}=436)$. EGFR levels were significantly higher in urine from the patients with pT1 or pT2 UBC in comparison to noncancer controls ( $\boldsymbol{p}<0.003$ and $\boldsymbol{p}<0.001$, respectively) and associated with UBC-specific survival in both, non-muscle invasive and muscle-invasive BCa (Hazard Ratio [HR]=6.9, 90\% CI 4.7-10.1, $\boldsymbol{p}<0.001$ ) $(42)$.

\section{Breast cancer}

Mange et al. compared the secretome of four genetically-related breast cancer cell lines: MCF10A (nontumorigenic), MCF10NeoT (premalignant; tumorigenic), MCF10DCIS (tumorigenic and locally invasive) and MCF10CA1d (tumorigenic), using iTRAQ labeling coupled with LC-MS/MS (43). Of the 
903 proteins initially identified, five breast cancer-specific protein marker candidates, namely leukemia inhibitory factor (LIF), follistatin (FST), IGFBP2, kallikrein 6 (KLK6) and tissue-type plasminogen activator (tPA), were shortlisted based on the selection for secreted proteins and differences in gene expression and immunohistochemical staining of breast cancer tissues. The differential abundance of these proteins in plasma was further evaluated by ELISA in two independent approaches, involving 56 and 353 samples, respectively. Serum levels of FST and KLK6 were significantly higher in breast cancer patients than healthy controls $(\boldsymbol{p}<0.05)(43)$.

De Marchi et al. used a previously identified four-protein-based classifier (44) composed of: programmed cell death protein 4 (PDCD4), cingulin (CGN), Ras GTPase-activating protein-binding protein 2 (G3BP2), and ovarian carcinoma immuno-reactive antigen domain containing protein 1 (OCIAD1) to assess the prediction of tamoxifen treatment outcomes using 38 breast cancer whole tissue lysates (WTLs) (25 samples from patients with good treatment outcome and 13 samples from patients with poor treatment outcome) by iMRM (MRM coupled with immunoprecipitation). Only PDCD4 and CGN were found to be significantly different between the patients with poor compared to good treatment outcomes. Furthermore, the 4-protein signature was assessed in an independent set of 24 patient-derived immuno-enriched serum samples before and after tamoxifen therapy: CGN and OCIAD1 were significantly decreased and G3BP2 was significantly increased in their expression levels after tamoxifen treatment, whereas PDCD4 showed no significant change between the two time points (44).

\section{Oral squamous cell carcinoma}

To identify biomarker candidates involved in progression and metastasis of oral squamous cell carcinoma (OSCC), the secretome of two OSCC cell lines were profiled using GeLC-MS/MS (45). Six hundred sixty six proteins were detected in the secretome of both cell lines. To select proteins specific for OSCC, all proteins also secreted by nasopharyngeal carcinoma cells were excluded, resulting of a restricted list of 114 protein marker candidates. These proteins were investigated for association with OSCC in the Oncomine database (46), resulting in the definition of 19 candidates as potentially associated with OSCC. After additional literature review, the candidates were shortlisted to a final list of 10 proteins: cellular retinoic acid-binding protein 2 (CRABP2), eukaryotic translation initiation factor 3 subunit J (EIF3J), flavin reductase, guanine nucleotide-binding protein subunit $\beta 2$-like 1 (RACK1), guanylate-binding protein 1 (GBP1), myosin light polypeptide 6 (MYL6), phosphoglycerate mutase 1 (PGAM1), Rho-GDP-dissociation inhibitor 2 (GDIR), glucose transporter member 1 (GLUT1), tropomyosin 3 chain (TPM3). Among them, GBP1 was selected as the most promising candidate biomarker due to its selective expression in head-and-neck cancer and complete absence in tissue sections of oral mucosa and nasopharynx, as reported in the Human Protein Atlas. Further evaluation of GBP1 was conducted by ELISA in serum of OSCC patients $(n=38)$ compared to healthy individuals $(n=37)$. In this study, GBP1 levels discriminated OSCC patients from controls with an AUC value of $0.76(45)$. 


\section{Hepatocellular carcinoma}

Based on the hypothesis that the Notch pathway is a main driver in cell proliferation and is involved in hepatocellular carcinoma (HCC), Giovanni et al. compared the culture media of HepG2 cells with Notch 1 depleted cells (applying short hairpin oligonucleotides targeting different Notch 1 exons) (47). Using LC-MS/MS, 89 proteins were found significantly altered, 37 at increased and 52 at decreased levels following Notch 1 depletion $(\boldsymbol{p}<0.05)$. Biological function and pathway analysis of the deregulated proteins was performed by employing the DAVID functional annotation tool (48). PAI-3, Intercellular adhesion molecule 5 (ICAM-5), THBS1 were selected as biomarker candidates as their roles are established in cancer. In addition, soluble E-Cadherin (CDH1), even though not detected in the proteome analysis, it was also selected by the authors for validation in WB due to its essential role in Notch 1regulated epithelial-mesenchymal-transition. WB analysis indeed revealed that $\mathrm{CDH} 1$ expression was downregulated in Notch 1 depleted cells, whereas PAI-3 and ICAM-5 were overexpressed. The WB result did not confirm increased THBS1 expression in Notch 1 depleted cells as compared to HepG2 cells, nevertheless it was selected for further validation as it is being critically involved in cell adhesion. Further assessment of PAI-3, ICAM-5, THBS1 and CDH1 was conducted by ELISA in an independent small set of serum samples from 7 cirrhosis, 7 early and 7 advanced stage HCC patients. PAI-3, CDH1 and THBS1 discriminated HCC from cirrosis, whereas CDH1 and ICAM-5 discriminated early from advanced stage HCC $(\boldsymbol{p}<0.05)$ (47).

\section{Studies investigating multiple cancer types}

In a study conducted by Wu et al., the secretomes of 23 human cancer cell lines derived from 11 cancer types were analysed using GeLC-MS/MS (49). A total of 4584 non-redundant proteins (with an average of 1300 proteins per cell line) were identified. Biomarker candidates were selected based on three strategies: a) proteins selectively secreted by one cancer type only, b) proteins released by most cancer cell lines (named as pan-cancer biomarkers), and c) proteins putatively linked to biological processes related to cancer. The determined protein expression profiles were further investigated by immunohistochemistry using Human Protein Atlas data to select biomarker candidates that were concomitantly detected by secretome and IHC analysis. As a result, six out of to 137 biomarker candidates were identified to be selective for one particular tumor type and 94 could be attributed to the group of pan-cancer markers. From the six highly cancer type-specific protein biomarker candidates, 4 were validated in a set of 178 plasma samples by ELISA, namely monocyte differentiation antigen CD14, stromal cell-derived factor 1 (SDF-1), cathepsin L1 and interferon-induced 17-kDa protein (ISG15). CD14 plasma levels were significantly higher in liver cancer ( $\mathrm{n}=44, \boldsymbol{p}<0.0117)$, SDF-1 plasma levels were significantly higher in lung cancer $(\mathrm{n}=44, \boldsymbol{p}<0.0007)$, and both, cathepsin L1 and ISG15 were significantly higher in nasophageal carcinoma ( $n=45, \boldsymbol{p}<0.01$ and $\boldsymbol{p}<0.02)$, compared to healthy controls $(n=45)(49)$. 


\section{Studies performed in urine}

\section{Bladder cancer}

Urine appears especially well suited to provide information on the development and progression of tumors in the urothelial tract. With the aim to identify urinary biomarkers associated with bladder cancer, Chen et al. assessed a set of 17 previously discovered protein markers by iTRAQ in urine samples of patients with $\mathrm{BCa}$ or non-cancerous diseases (i.e. urinary tract infection or hematuria) $(\mathrm{n}=156)$ using LC-MRM (50). Twelve proteins were found upregulated in BCa compared to hernia and urinary tract infection $(\boldsymbol{p}<0.05)$. Based on hierarchical clustering analysis, a six-protein marker panel was generated, including afamin, adiponectin, complement $\mathrm{C} 4$ gamma chain, apolipoprotein A-II, ceruloplasmin, and prothrombin, all being upregulated in cancer. In independent validation, the six-protein marker panel discriminated patients with $\mathrm{BCa}(\mathrm{n}=76)$ from those with hernia and urinary tract infection $(\mathrm{n}=80)$ with an AUC value of $0.81(50)$.

In a similar approach, a six-protein marker panel for $\mathrm{BCa}$ consisting of different types of apolipoprotein (APOA1, APOA2, APOB, APOC2, APOC3, and APOE) was established by Chen et al. using iTRAQLC-MS/MS (51). The urinary levels of all six apolipoproteins were subsequently measured in a set of urine samples from $\mathrm{BCa}$ patients $(\mathrm{n}=63)$ and hernia patients $(\mathrm{n}=48)$ by Human Apolipoprotein Kit. As a result, the levels of six proteins were significantly increased in $\mathrm{BCa}$ hernia in comparison to hernia $(\boldsymbol{p}<0.001$ and AUC $>0.70)$. Furthermore, the authors identified serum amyloid A-4 protein (SAA4) and pro-epidermal growth factor (proEGF) as additional $\mathrm{BCa}$ biomarkers. Both candidates were differentially regulated in BCa patients, resulting in AUC of 0.68 and 0.71 for SAA4 and ProEGF, respectively (51). Increased urinary levels of APOA1 in BCa were also supported in a subsequent study by Chen et al. using iTRAQ labeling coupled with LC-MS/MS (52). The result was further confirmed by ELISA resulting in a sensitivity of $95 \%$ and specificity of $92 \%$ (at a cut off value of $11.16 \mathrm{ng} / \mathrm{mL}$ ) for $\mathrm{BCa}$ diagnosis in a cohort of $\mathrm{n}=151$ individuals ( $\mathrm{n}=76$ cases and $\mathrm{n}=75$ controls) (52). Yang et al. investigated the association of glycoproteins with $\mathrm{BCa}(53)$. In brief, urine samples from $\mathrm{BCa}$ patients $(\mathrm{n}=54)$ and non-cancerous controls $(\mathrm{n}=46)$ were analysed using a proteomics strategy combining dual lectin-affinity chromatography and LC-MS/MS. Alpha-1-antitrypsin (A1AT) was identified as a promising $\mathrm{BCa}$ biomarker candidate. For validation, urinary levels of A1AT1 were measured by ELISA in an independent cohort of 70 samples ( 35 cancer cases and 35 non-cancer controls). Increased urinary A1AT levels discriminated BCa patients from the controls with a sensitivity of $74 \%$ and a specificity of $80 \%(\boldsymbol{p}<0.001)(53)$. A1AT was also proposed as biomarker for BCa by Linden et al. (54). In the same study, the authors identified additional BCa-associated proteins including leucine-rich alpha-2glycoprotein (LRG1), fibrinogen beta chain (FGB) and apolipoprotein E (APOE) in pooled samples from BCa patients $(\mathrm{n}=6)$ and controls $(\mathrm{n}=6)$ using LC-MS/MS and subsequent verification by WB $(n=42)$. These protein candidates were described to be significantly upregulated in bladder cancer comparing to controls $(\boldsymbol{p}<0.05)(54)$. However, because APOA1 and A1AT are highly abundant plasma proteins that likely reflect proteinuria $(55,56)$ rather than being specific $\mathrm{BCa}$ biomarkers, the diagnostic 
value of both, and also other highly abundant plasma proteins (e.g. APOE) for detecting BCa remains highly questionable.

A multi-marker approach for bladder cancer detection was presented by Frantzi et al., based on urinary peptide profiling by capillary electrophoresis coupled mass spectrometry (CE-MS) (57). In a multicentre study including 1357 patients recruited in five clinical centers, two biomarker panels, consisting of 116 and 106 peptides were developed to detect primary $(n=721)$ and recurrent bladder cancer $(n=636)$ respectively, aiming at non-invasive diagnosis of patients with first presentation of $\mathrm{BCa}$ and those under surveillance. Independent validation in respective cohorts resulted in AUC values of 0.87 and 0.75 , respectively (57). Peptide fragments from various collagen chains, APOA1, fibrinogen alpha chain (FGA) and beta-2-microglobulin (B2M) were found to be increased in their urinary abundance in the BCa patients, while those of basement membrane-specific heparan sulfate proteoglycan (HSPG2) and histidine-rich glycoprotein (HRG1) peptides were found to be decreased (57).

\section{Renal cell carcinoma}

The same approach (CE-MS) was applied for the discovery of renal cell carcinoma (RCC)-specific biomarkers, analysing urine samples from patients with RCC $(n=40)$ compared to non-diseased controls (n=68) (58). Eighty six urinary peptides were found associated with RCC, 40 of which were identified by MS/MS sequencing. A classifier based on all 86 peptides was evaluated in an independent set of 76 samples (30 RCC cases and 46 normal controls), resulting in $80 \%$ sensitivity and $87 \%$ specificity in RCC detection (58). Among the peptides included in the classifier were B2M and CD99 antigen (both downregulated in RCC), as well as fragments of the collagen chains type I alpha 1 (COL1A1), type I alpha 2 (COL1A2) and type III alpha 1 (COL3A1), FGB, deleted in human brain tumor protein 1 (DMBT1), and haemoglobin subunit beta (HGB), all of which were upregulated in RCC in comparison to controls. Protease prediction analysis using the in silico protease prediction software tool Proteasix (59) indicated a set of proteases being potentially involved in RCC progression, most prominently cathepsins and kallikreins (58).

\section{Cholangiocarcinoma}

To identify biomarkers for cholangiocarcinoma (CC) as a non-invasive alternative to endoscopy of the biliary tracts, Metzger et al. applied CE-MS for urinary peptide profiling of 14 patients with CC, 13 patients with PSC and 14 patients with other benign biliary disorders (BBD) (60). Forty two peptides were selected to establish a peptide marker pattern which in an independent set of 123 patients discriminated CC cases from the PSC and BBD controls with an AUC value of 0.87 (60). The proposed 42-peptide marker pattern was composed mostly of peptide collagen chains (COL1A1, COL1A2, COL3A1) but also included peptides from CD99 antigen, kininogen-1, and OPN. The urinary levels of COL3A1, kininogen-1 and OPN were upregulated, whereas CD99 was downregulated in CC cases compared to PSC and BBD controls (60). 


\section{Breast cancer}

Gajbhiye et al. investigated urinary protein markers that could discriminate HER2-positive breast cancer patients $(n=24)$ from healthy individuals $(n=24)$ using 2D-DIGE, iTRAQ-LC-MS/MS and SWATH (61). Using those three complementary approaches, 183 proteins were identified to be differentially expressed between the case and control groups. Further selection by multivariate statistical analysis enabled shortlisting to a restricted list of 21 protein marker candidates for HER2-positive breast cancer including zinc-alpha-2-glycoprotein 1 (AZGP1), LRG1, retinol-binding protein 4 (RET4), annexin A1 (ANXA1), ganglioside GM2 activator (SAP3), Src substrate cortactin (SRC8), gelsolin (GSN), kininogen 1, CO9, clusterin (CLUS), ceruloplasmin, alpha-1-anti-glycoprotein 1 (A1AG1) and A1AT. These proteins were further validated by WB and MRM in an independent small cohort of patients $(n=32)$. As revealed by WB, the urinary levels of ZA2G, A2GL, ANXA1, SAP3, SRC8 and A1AG1 were upregulated in patients with HER2-positive breast cancer compared to healthy individuals, whereas A1AT, KNG1, GSN, CLUS urinary levels were decreased. In case of ANXA1, ZA2G and A1AG1, their increased abundance was also confirmed by MRM (61).

\section{Pancreatic cancer}

Radon et al. applied LC-MS/MS to investigate differences between the urinary proteome of 6 patients each with pancreatic cancer or chronic pancreatitis and 6 healthy individuals (62). Three proteins, lymphatic vessel endothelial hyaluronic receptor (LYVE1), trefoil factor (TFF1) and lithostathine-1alpha (REG1A), were identified as candidate biomarkers $(\boldsymbol{p}<0.05)$. Their value was subsequently investigated in an independent multicentre cohort by ELISA. All three biomarker candidates were combined into a panel, following by adjustment for creatinine and age using logistic regression and subsequently validated in a set of 49 PDAC patients and 28 healthy controls by ELISA. The generated biomarker panel discriminated PDAC patients from healthy controls with an AUC value of 0.92. Moreover, the urinary levels of all three biomarkers (LYVE-1, TFF1 and REG1A) were significantly increased in stages I-II PDAC patients $(n=15)$ compared to chronic pancreatitis $(n=26)$. The panel revealed an AUC value of 0.85 with a sensitivity and specificity of $>85 \%$ and $50 \%$, respectively (62).

\section{Studies performed in serum/ plasma}

\section{Small cell lung carcinoma and Non-small cell lung cancer, Lung nodules}

As the currently applied routine methods for lung cancer screening are radiography based like chest Xrays and low-dose computed tomography (LDCT) (63), several studies have investigated the value of serum and/or plasma-based biomarkers in improving lung cancer diagnosis. Ahn et al. aimed to identify changes in fucosylated glycoproteins in sera of patients with small-cell lung carcinoma (SCLC) in comparison to healthy controls, using LC-MS/MS (label-free and iTRAQ labeling). First, fucosylated glycoproteins were enriched using agarose-bound Aleuria aurantia lectin (AAL) columns, followed by SDS-PAGE and LC-MS/MS analysis of pooled sera from 5 healthy individuals, 5 patients with limited stage SCLC disease, and 5 patients with extensive stage disease. The same samples were also analysed 
using iTRAQ labeling. A total of 186 proteins were identified by using these approaches and were further prioritized as follows: 1) After removing common contaminant serum proteins (i.e. trypsin, albumin, keratin, and haemoglobin), uncharacterized proteins, and immunoglobulins, and testing for the existence of glycosylation sites, 87 proteins were selected; 2) Of those, only proteins identified in both (label-free and iTRAQ) approaches and exhibited greater than 1.3- (in iTRAQ) or 1.5-fold (label-free) abundance changes in SCLC compared to the healthy individuals were selected for further analysis. As a result, 66 proteins were shortlisted, for 62 of which, spectral information was available in the Peptide Atlas database, enabling selecting target peptides and transitions for further verification studies by LCMRM-MS. Following this latter analysis using the same sample set as in the discovery phase, four fucosylated proteins: upregulated amyloid p component (APCS) and complement component 9 (C9), and downregulated kallistatin (SERPINA4) and PON1 were selected and subjected for further validation by WB and the hybrid lectin ELISA (HLE) detection system to quantify the level of fucosylation (63). In WB, APCS and C9 serum levels were increased, whereas PON1 serum levels were decreased and kallistatin exhibited no significant difference in its serum levels in 29 patients with SCLC compared to 29 healthy controls (63). In HLE, fucosylated APCS and C9 were increased in the sera of patients with SCLC ( $n=29$ extensive stage disease patients) compared to the healthy controls ( $n=29)$, exhibiting AUC values of 0.88 and 0.69 , respectively, whereas fucosylated kallistatin was decreased exhibiting an AUC value of 0.67 . Surprisingly and in contrast to the results from the discovery experiments (see above), the fucosylated PON1 levels were significantly increased in SCLC patients compared to healthy controls (63).

In case of NSCLC, Pecot et al. investigated the added value of a previously established serum proteomic signature comprised of 7 peaks using MALDI-MS in combination with the clinical data and chest computed tomography (CT) results, in two cohorts of patients with lung nodules (64). In cohort 1 ( $n=265$ patients), the chest CT imaging variables (size and shape) and the clinical results exhibited an AUC of 0.86 in discriminating lung cancer from other pulmonary nodules, whereas in cohort 2 including patients with smaller lung nodules $(n=114)$, the respective AUC value was 0.61. Combination of the 7-peak signature score with the clinical and chest CT data did not change the AUC in cohort 1. However, in cohort 2 , the AUC value increased from 0.61 to 0.69 , which was found to be statistically significant $(\boldsymbol{p}=0.0003)(64)$.

VeriStrat ${ }^{\circledR}$ is a commercially available serum-based proteomic assay developed by Taguchi et al. using a MALDI-MS to predict the clinical outcome in NSCLC patients after treatment with EGFR tyrosine kinase inhibitors (TKI) (65). The assay is based on the measurement of 8 peak MS features $(\mathrm{m} / \mathrm{z}$ $5843.241, \mathrm{~m} / \mathrm{z}$ 11445.75, $\mathrm{m} / \mathrm{z}$ 11529.52, $\mathrm{m} / \mathrm{z} 11685.37, \mathrm{~m} / \mathrm{z}$ 11759.16, $\mathrm{m} / \mathrm{z}$ 11903.24, $\mathrm{m} / \mathrm{z} 12452.38, \mathrm{~m} / \mathrm{z}$ 12579.85), initially detected by MALDI-MS and associated with treatment outcome (65). Unfortunately, no sequence information for the MS peak features is available. This approach was used in several studies to stratify NSCLC patients in advance to therapeutic intervention (66-69). In a prospective phase III trial, Gregorc et al. investigated the predictive ability of the VeriStrat assay in NSCLC patients after 
erlotinib administration (67). In their study, the VeriStrat assay classified $68 \%$ of the 129 patients in a chemotherapy (pemetrexed or docetaxel) treatment group and $72 \%$ of 134 patients in a erlotinib treatment group, as having a good clinical outcome. The authors found no significant difference in overall survival (OS) between the good and poor outcome prediction groups irrespective of chemotherapy and erlotinib administration. Vice versa, if the comparison in OS rates was based on differences between chemotherapy and erlotinib, the result was also negative in the case of patients stratified for good outcome (median OS 10.9 months vs 11.0 months, respectively, HR=1.06 [95\% CI, $0.77-1.46], \boldsymbol{p}=0.71)$. Surprisingly, patients with poor outcome prediction exhibited significantly shorter OS rates when treated with erlotinib than with chemotherapy (median OS 3.0 months vs 6.4 months, respectively, $\mathrm{HR}=1.72$, [95\% CI, 1.08-2.74], $\boldsymbol{p}=0.02$ ). Based on these results, the authors conclude that the VeriStrat assay might have some prognostic value, in patients with poor outcome (67). Kuiper et al. evaluated VeriStrat in 50 patients with advanced stage NSCLC treated with a combination of erlotinib and sorafenib. The groups of patients with predicted good and poor outcome were significantly different in OS (HR=0.30, log-rank $\boldsymbol{p}=0.009)$ and in progression-free survival (PFS) (HR=0.40, log-rank $\boldsymbol{p}=0.035$ ) (68). Based on this study, the authors concluded that VeriStrat may enable enriching advanced NSCLC patients who would benefit from erlotinib and sorafenib combination therapy (68). Dingemans et al. applied VeriStrat to investigate the treatment effect of sorafenib (phase II trial) in serum samples from 55 treated NSCLC patients (66). The prediction of the treatment outcome was good in 32 patients, poor in 21, and indeterminate in two patients. The VeriStrat assay was found predictive of prolonged PFS in patients with a good prediction outcome, compared to patients with poor prediction outcome (2.6 months vs 1.5 months; HR=1.4; 95\% CI, 1.0-1.9; $\boldsymbol{p}=0.029$ ). Patients with a predicted good outcome exhibited longer median OS rates than patients with a predicted poor outcome (6 months vs 2.5 month, $\mathrm{HR}=1.3$; 95\% CI, 0.9-1.7; $\boldsymbol{p}=0.17$ ), but this difference was not significant (66). Mok et al. applied VeriStrat in a study comparing the combination of ficlatuzumab plus gefitinib with gefitinib monotherapy in a pulmonary adenocarcinoma cohort $(n=183)$, which was enriched for EFGR tyrosine kinase inhibitor-sensitizing mutations (69). VeriStrat classified these 183 patients into 148 with good, 34 with poor and one with indeterminate treatment outcome. There were no significant differences in PFS and OS between treatment arms in the group of patients with good treatment outcome, whereas there was a significant improvement in the group of patients with poor treatment outcome in the ficlatuzumab+gefitinib arm as compared to gefitinib alone for PFS (7.4 months vs 2.3 months; HR=0.46, 95\% CI: $0.23-0.91, \boldsymbol{p}=0.02$ ) and OS (23.9 months vs 5.8 months; HR=0.41, 95\% CI: $0.18-0.90, \boldsymbol{p}=0.04$ ) (69). These different clinical trials suggest that VeriStrat may to some degree be predictive of outcome. However, as pointed out by Taguchi et al., it appears that the accuracy of the prediction by VeriStrat is insufficient to guide treatment, and its value in prediction of the drug response was until now not demonstrated convincingly (65).

In a study conducted by Kim et al. multiplexed liquid chromatography-selected reaction monitoring (LC-SRM) was applied to screen 72 plasma samples from NSCLC patients from early to late stage 
disease (70). Seventeen candidate NSCLC biomarkers were identified with at least a 2-fold change in NSCLC compared to healthy controls and further evaluated by ELISA ( $\mathrm{n}=144$ samples). Among them, zyxin demonstrated the highest specificity towards NSCLC (AUC $=0.96)$ and was proposed as an early diagnostic biomarker for detection of NSCLC (70).

For the identification of cancerous pulmonary nodules, $\mathrm{Li}$ et al. investigated proteins expressed on the cell surface or secreted from lung cancer tumor cells in comparison to non-malignant lung cells (71). Specimens were collected from freshly resected lung tumors using organelle isolation techniques. In parallel, an extensive literature search for lung cancer biomarkers was performed. Only biomarkers that provided the evidence of presence in blood were considered. A total of 388 protein candidates were defined and subjected to MRM-MS analysis in a discovery set of 143 plasma samples from patients with benign and stage IA lung cancer. After data normalization and selection, a total of 125 proteins were shortlisted and subjected to Monte Carlo cross validation (MCCV) to define robust and cooperative proteins that were found to be most frequently represented in the different evaluations (72). As a result, 13 proteins were selected including: LRG1, transforming growth factor-beta-induced protein ig-h3 (BGH3), COL1A1, tetranectin (TETN), THBS1, fructose-1,6-biphosphate aldolase (ALDOA), 78 kDa glucose-regulated protein (GRP78), immunoglobulin superfamily containing leucine-rich repeat protein 2 (ISLR), ferritin light chain (FRIL), galectin-3-binding protein (LG3BP), peroxiredoxin-1 (PRDX1), fibrinogen alpha chain (FIBA), Golgi apparatus protein 1 (GSLG1) (71). The 13-protein classifier was tested in an independent set of plasma samples ( $\mathrm{n}=52$ malignant and $\mathrm{n}=52$ benign lung nodules) providing a negative predictive value (NPV) of 90\% (71). Based on these results, Vachani et al. developed an 11-protein classifier consisting of 5 diagnostic proteins (ALDOA, COL1A1, FRIL, LG3BP, THBS1) retrieved from the 13-protein classifier (71) and an additional 6 to be used for normalization GSN, scavender receptor cysteine-rich type I protein M130 (C163A), lumican (LUM), mannan-binding lectin serine protease I (MASP1), pigment epithelium-derived factor (PEDF) and receptor-type tyrosine protein phosphatase (PTPRJ) which were defined in (73) and reported to enable reducing pre-analytical and analytical variations in MS-based protein quantification. The performance of the 11-protein classifier was tested by MRM-MS and it exhibited a NPV of $90 \%$ at a reference value of 0.36 , corresponding to sensitivity and specificity of $92 \%$ and $20 \%$, respectively, discriminating benign ( $n=63$ ) and malignant ( $n=78)$ lung nodules (74).

\section{Breast cancer}

Chung et al. used surface-enhanced laser desorption/ionization time-of-flight (SELDI-TOF) MS to identify serum biomarkers for breast cancer in a set of serum samples from 99 breast cancer patients and 51 healthy subjects (75). Fifty one potentially relevant MS peaks were identified by clustering analysis. These peaks were subjected to forward and reverse binary logistic regression analysis with 10-fold crossvalidation and resulted in the generation of a biomarker model based on a combination of five peaks $(\mathrm{m} / \mathrm{z} 3808, \mathrm{~m} / \mathrm{z}$ 6624, $\mathrm{m} / \mathrm{z}$ 8916, $\mathrm{m} / \mathrm{z}$ 13870, and $\mathrm{m} / \mathrm{z}$ 28268). Using MALDI-MS/MS for amino acid sequencing, the peaks were identified as fragments of apolipoprotein $\mathrm{H}(\mathrm{APOH})$, APOCI, complement 
C3a, transthyretin (TTR), and APOA1. Further assessment of this 5-biomarker panel by WB was conducted in an independent set of 100 breast cancer serum samples and 70 healthy subjects, exhibiting an AUC value of 0.94 (75).

Correa et al. applied LC-MS/MS to investigate proteomic differences between plasma samples from four major breast cancer molecular subtypes: luminal A (HER2-negative, $n=55$ ), luminal B (HER2positive, n=18), HER2-subtype (HER2-positive, n=19) and triple negative (TN, HER2-positive subtype, $\mathrm{n}=15)$ and plasma samples from healthy donors $(\mathrm{n}=120)(76)$. The comparison revealed $186,155,175$, and 172 differentially expressed proteins in the luminal A, luminal B, HER2, and TN subtypes in comparison to controls, respectively. Among these, 41 proteins were commonly downregulated in all breast cancer subtypes. Pathway analysis using Metacore ${ }^{\mathrm{TM}}$ (GeneGO Inc., Encinitas, USA) suggested that these 41 proteins reflect pathways related to cell cycle control, apoptosis, survival and signal transduction mediated by NF-kb. Further shortlisting based on literature data and in silico analyses resulted in selecting CLUS, killin, interleukin-1 receptor-associated kinase 1-binding protein 1 (IKBP1), breast carcinoma amplified sequence 3 (BCAS3), iroquois-class homeodomain protein IRX-1 (IRX1), IRX4 and IRX5 for further WB validation in a set of 37 plasma samples. BCAS3, IRX1 and IRX5 were found to be overexpressed in breast cancer plasma samples in comparison to healthy controls; unfortunately no information on the results from the investigation of the other candidates was provided (76).

\section{Ovarian cancer}

Several studies have been conducted in serum from ovarian cancer patients to replace or complement CA125 as the gold standard biomarker - in ovarian cancer diagnosis. Wu et al. conducted two studies to discover potential glycoprotein biomarkers in serum from ovarian cancer patients using a lectin array strategy to detect ovarian cancer-specific glycosylation changes $(77,78)$. In the first study, the glycosylation changes were investigated in 12 serum samples from patients with benign tumor types and 22 serum samples from stage III ovarian cancer patients, using Aleuria aurantia lectin chromatography, followed by ExacTag isobaric labeling, trypsin digestion and LC-MS/MS analysis. Five glycoproteins: corticosteroid-binding globulin (CBG), complement factor B (CFAB), N-acetylmuramoyl-L-alanine amidase (PGRP2), thyroxine-binding globulin (THBG) and histidine-rich glycoprotein (HRG) were identified as being significantly altered in ovarian cancer compared to benign disease $(\boldsymbol{p}<0.05)$. CBG, HRG and CFAB were further investigated by ELISA in an independent cohort of serum samples $(n=85)$. Serum amyloid P-component (SAP) was also included in analysis because it was previously identified as being significantly changed in pancreatic cancer. All 4 fucosylated proteins were significantly increased in cancer, $(\boldsymbol{p}<0.05)$, however, only SAP remained increased in respect to their degree of fucosylation (77). In the second study, the abundance of CLUS, LRG1, hemopexin (HEMO), vitamin D-binding protein (VDB), and complement factor $\mathrm{H}(\mathrm{CFH})$ was found to be significantly altered in the serum of patients with ovarian cancer $(n=22)$ compared to benign diseases $(n=12)(78)$. CLUS and LRG1 were verified as biomarkers for ovarian cancer in an independent sample set $(n=88)$ using ELISA, 
showing slightly better performance ( $\mathrm{AUC}=0.84$ ) in distinguishing stage III ovarian cancer patients $(\mathrm{n}=26)$ from benign diseases $(\mathrm{n}=30)$ than CA125 alone (AUC=0.81) (78).

Russell et al. identified 90 proteins differentially expressed between ovarian cancer (Type I ovarian cancer, $n=19$ and type II ovarian cancer, $n=27$ ) and controls with no history of ovarian cancer and no diagnosis of cancer on collection date $(\mathrm{n}=23)$ using iTRAQ-LC-MS/MS (79). After targeted mass spectrometry (MRM-MS) analysis of twenty of these candidates, protein Z (PROZ) was identified as a potential early biomarker for ovarian cancer. Further validation by ELISA was conducted in an independent set of 80 serum samples, (Type I ovarian cancer, n=19, type II ovarian cancer, n=30 and 31 normal controls, $n=31$ ). In the ROC analysis, the combination of PROZ with CA-125 resulted in an AUC increase from 0.77 to 0.81 for type I and from 0.76 to 0.82 for type II ovarian cancer compared to CA125 alone (79).

\section{Hepatocellular carcinoma}

MALDI-TOF profiling of serum samples from patients with liver cirrhosis and HCC enabled identification of changes in the glycosylation of A1AT isoforms (80). These changes were further examined by lectin-fluorophore-linked immunosorbent assay (FLISA) in a cohort of 458 patients. In this analysis, fucosylated A1AT could distinguish between HCC and liver cirrhosis with an AUC of 0.87, whereas alpha-fetoprotein (AFP) as the most widely used biomarker for HCC diagnosis, provided only an AUC value of $0.76(80)$. He et al. employed iTRAQ-MALDI-MS/MS for the discovery of serum peptides associated with HCC in serum from 10 patients with AFP-negative hepatitis B virus (HBV)related HCC, 10 patients with HBV alone and 10 healthy control subjects (81). A total of 24 differentially regulated proteins were identified as associated with AFP-negative HBV-related HCC. Gene Ontology analysis of the 24 proteins revealed a prominent network involved in enzyme inhibition, with GSN in its centre. Therefore, GSN was selected for validation by WB in an independent cohort of 24 samples from AFP-negative HBV-related HCC cases, HBV and healthy controls subjects $(\mathrm{n}=8$ for each group). The results indicated a significant ( $\boldsymbol{p}<0.01)$ association of GSN with HCC (81).

Using LC-MS/MS profiling of plasma samples from liver cirrhosis and HCC patients, Shang et al., identified significantly upregulated OPN levels in HCC compared to cirrhosis. Further validation by ELISA in an independent cohort of 173 samples showed that OPN had better performance than AFP in discriminating $\mathrm{HCC}$ and cirrhosis ( $\mathrm{AUC}=0.76$ for $\mathrm{OPN}$ compared to $\mathrm{AUC}=0.71$ for $\mathrm{AFP}$ ). The combination of OPN and AFP further increased the AUC value to 0.82 ( $\boldsymbol{p}<0.05)$ (82). Da Costa et al. performed plasma proteome analysis in 30 samples from patients with HCC, chronic liver disease or HBV infection (10 samples per group) to identify plasma biomarkers that can outperform AFP (83). Mass spectrometry profiling revealed latent-transforming growth factor $\beta$ binding-protein 2 (LTBP2) and OPN as significantly elevated in HCC cases compared to the controls. Both proteins were further validated by ELISA in an independent set of 684 plasma samples, including $183 \mathrm{HCC}, 274$ chronic liver disease and 227 asymptomatic controls (83). The combination of LTBP2 and OPN exhibited an AUC 
value of 0.85 in distinguishing HCC from chronic liver disease in subjects with AFP plasma levels below $20 \mathrm{ng} / \mathrm{mL}(83)$.

\section{Colorectal carcinoma}

LC-MS/MS analysis of plasma samples resulted in the identification of five proteins significantly elevated in CRC cases ( $n=90)$ compared to controls without history on cancer diagnosis $(n=90)$, which are microtubule-associated protein RP/EB family member 1 (MAPRE1), IGFBP2, ENO1, protein disulfide-isomerase A3 (PDIA3) and mesencephalic astrocyte-derived neurotrophic factor (ARMET) (84). Further validation by ELISA in an independent set of serum samples (58 CRC cases and 58 agematched controls) confirmed upregulation of these proteins in CRC. The AUCs for IGFBP2, LRG1, MAPRE1 and CEA ranged from 0.71 to 0.78 , while their combination into a multimarker panel provided an AUC of 0.84, corresponding to 59\% sensitivity and 95\% specificity in CRC detection (84). Aiming at identifying prognostic biomarkers for CRC progression, 2DE and MALDI-TOF-MS was employed to analyse plasma samples from CRC patients (85). In a set of 60 samples (30 colorectal adenomas and $30 \mathrm{CRC}$ ), differences in their expression levels between cases and controls were observed for the plasma proteins interleukin-8 (IL-8), interferon gamma-induced protein 10 (IP-10), and tumor necrosis factor (TNF) alpha between cases and controls. Further validation by multiplex bead assays revealed that all three proteins are significantly elevated in plasma of CRC patients compared to patients with premalignant lesions (85).

Jones et al. developed a plasma-based protein marker panel for CRC diagnosis by LC-MRM-MS. An assay was established for 187 biomarker candidates selected from the literature, using 337 peptides monitored through 674 simultaneously measured MRM transitions in a discovery set of immunodepleted plasma samples from 69 CRC cases and 69 controls. Further analysis in the discovery set using the elastic net feature selection and random forest classifier assembly resulted in the establishment of an MRM-based assay simultaneously assessing the following 13 protein markers: A1AG1, A1AT, AMY2B, CLUS, CO9, mitochondrial delta(3,5)-delta(2,4)-dienoyl-CoA isomerase (ECH1), FRIL, GSN, OSTP, selenium-binding protein 1 (SBP1), seprase (SEPR), spondin-2 (SPON2), and TIMP1. Validation in an independent cohort of 136 samples ( $n=68 \mathrm{CRC}$ and $\mathrm{n}=68$ normal controls) exhibited an AUC value of 0.91 with $87 \%$ sensitivity and $81 \%$, specificity in CRC detection of this 13 protein marker panel (86).

\section{Pancreatic cancer}

Conducting an analysis of pools of plasma samples from patients with pancreatic cancer, chronic pancreatitis or non-pancreatic disease controls by 2DE and LC-MS/MS, Pan et al. (87) found differential abundance of TIMP1, ICAM1 and AZGP1 in cancer. Further validation by ELISA in a cohort of 138 samples revealed that a biomarker panel consisting of TIMP1 and ICAM1 could distinguish pancreatic cancer from disease-matched controls including chronic pancreatitis with an AUC value of 0.80 . In comparison to these controls, the plasma levels of TIMP1 and ICAM1 were significantly increased in case of pancreatic cancer. In the same study, AZGP1 was significantly elevated in plasma from chronic 
pancreatitis compared to non-pancreatic disease and was proposed as biomarker candidate for chronic pancreatitis (AUC=0.83) (87). Antibody-based reverse phase protein assay (RPPA) and LC-MS/MS were combined to identify plasma biomarkers for early detection of invasive ductal adenocarcinoma of the pancreas (IDACP) (88). The authors investigated 260 genes previously reported as being upregulated in IDACP cells (89) and selected 130 candidate proteins for RPPA analysis based on known functional relevance to availability of specific antibodies. The RPPA assay was performed in serum samples from 164 IDACP patients and 106 healthy controls. In this analysis, 23 proteins exhibited AUC values higher than 0.8 out of which complement $\mathrm{C} 2$ (C2b) and IGFBP2 as well as IGFBP1, IGFBP3, C-reactive protein (CRP) and adiponectin (as being associated with cancer risk) were further selected for analysis by LC-MS/MS. Validation of the biomarker candidates was performed in a set of 38 IDACP patients and 65 healthy controls. IGFBP2 and IGFBP3 were significantly higher $(\boldsymbol{p}=0.0012)$ or lower $(\boldsymbol{p}<0.001)$, respectively, in IDACP patients compared to controls, with AUC values of 0.71 and 0.77 , respectively, rates which were lower than CA19-9 (AUC=0.84) (88).

\section{Gastric cancer}

Aiming at identifying plasma biomarkers associated with gastric cancer, Uen et al. investigated glycoprotein profiles in plasma samples obtained from 30 patients with gastric cancer and 30 healthy subjects by combining Concanavalin A (Con A) affinity chromatography and LC-MS/MS (90). Differential abundance of LRG1 and inter-alpha-trypsin inhibitor heavy chain H3 (ITIH3) was detected and further examined in a validation set of 60 gastric cancer patients and 60 normal controls. The later validation study involved analysis of Con A-captured plasma by immunoblotting with the LRG1 and ITIH3 antibodies. The AUC value for gastric cancer detection based on Con A-bound LRG1 glycoprotein was 0.65. In case of Con A-bound ITIH3 glycoprotein, the AUC was 0.75 (90). Yoo et al. compared the proteome of serum samples from gastric cancer patients $(n=6)$ and normal controls $(n=3)$ to establish a biomarker test for the diagnosis of gastric cancer using LC-MS/MS followed by label-free quantitation (91). Between 215 and 260 proteins were identified in the samples. Thirty one candidate biomarkers were selected based on > 2-fold changes in spectral ion counting, and subjected to further MRM-MS analysis in an independent set of 89 samples. Vitronectin, clusterin isoform 1, THBS1 and tyrosine-protein kinase SRMS were found significantly altered in gastric cancer compared to normal controls. In this respect, the highest AUC values in discriminating advanced gastric cancer stage patients from normal controls with 0.83 and 0.94 were obtained for vitronectin and clusterin isoform 1 , respectively (91).

\section{Prostate cancer}

In a phase II trial, Templeton et al. investigated biomarkers predicting response to everolimus treatment (phase II trial) in serum samples from 28 patients with metastatic castration-resistant prostate cancer (mCRPC) using SRM-MS (92). Forty candidate peptide biomarkers, originating from 37 different proteins were measured. The candidates were previously associated with changes in glycoprotein abundance after PTEN loss with involvement in the activity of the PI3K/Akt signaling pathway. The 
concentrations of 13 out of the 40 peptides were significantly associated with PFS at week 12 after initiation of everolimus therapy as the primary endpoint. Among them, high serum concentrations of carboxypeptidase M (CPM) and APOB were most predictive for PFS in this patient cohort with accuracies of $82 \%$, sensitivities of $77 \%$ and $85 \%$, and specificities of $87 \%$ and $80 \%$ for CPM and APOB, respectively (92).

\section{Oral squamous cell carcinoma}

Chai et al., compared serum proteins from patients with node-positive and node-negative OSCC using quantitative iTRAQ-LC-MS/MS approach (93). A total of 282 serum proteins were identified and quantified (93). Among them, the four candidate biomarkers: GSN, fibronectin, angiotensinogen (AGT), and haptoglobin (HP) were selected based on an observed $>2$-fold change between node-positive and node-negative patients. Their further validation by WB was conducted in an independent group of serum samples from patients with node-positive $(n=16)$ and node-negative OSCCs $(n=12)$. The WB analysis revealed that all four protein candidates were significantly upregulated in node-positive compared to node-negative OSCCs $(\boldsymbol{p}<0.05$ for fibronectin and $\boldsymbol{p}<0.01$ for GSN, AGT and HP) (93).

\section{E. Studies performed in other biofluids}

\section{Cholangiocarcinoma}

Lankisch et al. used CE-MS to study proteomic profiles in bile. For differentiation of primary sclerosis cholangitis (PSC) and CC, a 22 peptide marker model, including fragments of keratin type I, haemoglobin subunit $\alpha$ and $\beta, 14-3-3$ protein zeta/delta and actin cytoplasmic I, was established and cross-validated in a training set composed of 18 patients with PSC and 16 patients with CC (11). Among the peptides included in the model, the levels of fragments of haemoglobin subunit $\alpha, 14-3-3$ protein zeta/delta and actin cytoplasmic I were increased, whereas those of keratin type I were decreased in CC. Applied to an independent validation set of patients (18 PSC, 25 CC), the 22-peptide marker model demonstrated an AUC of 0.87 , with a specificity of $78 \%$ and sensitivity of $84 \%$ in CC detection. The obtained peptide model demonstrates a benefit in diagnosing of CC in patients with PSC especially as supplement to other endoscopic and imaging methods, such as endoscopic retrograde cholangiopancreatography enabling tissue sampling to perform cytology or magnetic resonance visualization of the biliary ducts by magnetic resonance cholangiopancreatography (11).

\section{Gastric cancer}

Xiao et al. conducted a study in saliva of gastric cancer patients to search for biomarkers most applicable for early diagnosis (94). Cystatin B (CSTB), triosephosphate isomerase (TPI1), and DMBT1 were identified using LC-MS/MS analysis of Tandem mass tags (TMT) labeled samples and verified by ELISA in an independent cohort of 20 cancer cases and 20 normal controls. All three proteins were downregulated in saliva from gastric cancer patients compared to the control subjects. The combination of these three biomarkers to a multimarker panel demonstrated an AUC value of 0.93 , and sensitivity 
and specificity values of $85 \%$ and $80 \%$, respectively, for the early diagnosis of gastric cancer in saliva samples (94).

\section{Lung cancer}

Yu et al. employed LC-MS/MS to screen the sputum protein content of sputum samples from 6 early stage lung cancer patients and 5 cancer-free controls (95). Eight biomarker candidates for lung cancer were identified: ENO1, membrane protein DAP10 (DAP10), guanine nucleotide exchange factor (GEFs), low density lipoprotein receptor related protein-deleted in tumor (LRP1B), hemopexin (HPX), transmembrane secretory component (poly-Ig receptor), lactoferrin precursor and high molecular weight salivary mucin (MG1). ENO1 was further evaluated using ELISA in an independent set of 35 lung cancer cases and 36 controls where it exhibited an AUC value of 0.71 for distinguishing the NSCLC patients from controls (95).

\section{Ovarian cancer}

Using 2DE-MALDI-TOF-MS, Wang et al. compared the protein profiles between tumor 23 tumor interstitial fluid (TIF) and 19 normal interstitial fluids (NIF) samples obtained from tissue biopsies, with the aim to identify potential ovarian cancer biomarkers (96). Among the identified proteins, the levels of stress-induced phosphoprotein 1 (STIP1), leucine aminopeptidase 3 (LAP3), type I keratin 16, macrophin 1 isoform 2 (MACF1), brain-derived neurotrophic factor (BDNF) isoform b preproprotein (BDNF1), and triose-phosphate isomerase 1 (TPI) were elevated, while ubiquitin carboxyl-terminal esterase L1 (UCHL1) and transferrin were reducedin TIF in comparison to NIF. Increased abundance in serum STIP1 was confirmed by ELISA with significant increase in ovarian cancer patients $(n=43)$ compared with age-matched normal controls $(\mathrm{n}=43)(\mathrm{AUC}=0.93, \boldsymbol{p}<0.000001)(96)$.

\section{Oral cancer}

Jou et al. and Wu et al. investigated saliva as a source of potential oral cancer biomarkers. In the former (Jou et al.) study, the protein profile of pooled salivary samples from 41 patients with oral squamous cell carcinoma (OSCC) and 30 OSCC-free control subjects was analysed using 2DE-MALDI-TOF-MS (97). This approach revealed elevated transferrin levels in OSCC, an observation which was subsequently validated by ELISA in saliva samples of patients with different stages of OSCC progression (stage T1 $(n=17)$, stage T2 $(n=15)$, stage T3 or T4 $(n=9))$ as well as and OSCC-free individuals $(\mathrm{n}=30)$ providing an AUC value of 0.95 for detecting OSCC in T1, 0.94 in T2, and 0.91 in T3/T4 patients (97). In the second study, Wu et al. investigated proteome profiles of saliva from healthy volunteers $(n=10)$, individuals with oral pre-malignant disorders (OPMD, $n=9$ ) including oral submucous fibrosis, erythroplakia, hyperkeratosis/epithelial hyperplasia and epithelial dysplasia and OSCC patients $(\mathrm{n}=10)$ using SDS-PAGE coupled with LC-MS/MS (98). Among the identified candidates, resistin (RETN) was subjected to further validation in an independent cohort of 285 saliva samples ( $n=99$ healthy individuals, $n=87$ OSCC patients and $n=99$ non-cancerous patients with OPMD) using ELISA. The AUC value provided by the RETN levels was 0.72 for discriminating OSCC patients from healthy individuals and OPMD groups (98). 


\section{Mesothelioma}

Mundt et al. performed LC-MS/MS using iTRAQ labeling to screen the effusion proteome of mesothelioma and lung adenocarcinoma patients and identify mesothelioma biomarkers (99). More than 1300 proteins were identified in pleural effusions from patients with malignant mesothelioma $(n=6)$, lung adenocarcinoma $(n=6)$, or benign mesotheliosis $(n=7)$. Among them, seven candidates: aldo-keto reductase 1B10 (AKR1B10), APOCI, galectin 1 (Gal-1), myosin-VIIb, superoxide dismutase 2 (SOD2), tenascin C, and THBS1 were further investigated by ELISA in an independent set of patients with mesothelioma $(n=37)$, metastatic carcinomas $(n=25)$ or benign disorders $(n=16)$. The AUC values of the seven biomarker candidates for the discrimination of mesothelioma patients from those with benign disorders were reported by the authors to be in the range of 0.54 (tenascin $\mathrm{C}$ and THBS1) to 0.81 (Gal1). Similar results were obtained for the discrimination of mesothelioma patients from those with metastatic cancers with AUC values being in the range of 0.54 for THBS1 to 0.93 for Gal-1 (99).

\section{PROTEOMICS PLATFORMS IN CANCER RESEARCH}

As shown by the retrieved studies, LC-MS/MS is the most widely applied discovery method, followed by 2DE in combination with MALDI-MS (Figure 2). LC-MS/MS is particularly effective for largescale protein identification of highly complex samples, providing high resolution proteomics data (100). A major advantage of LC-MS/MS is that it is easy to use and protocols for sample preparation and analysis that have been extensively tested and are available. Hence their application on a technical level can be straightforward. A further advantage is the high resolution that under ideal conditions enables routine identification of $>10000$ peptides in one sample using a shallow gradient (101). A disadvantage is that information on the protein (including all PTMs) is not fully preserved, the identified tryptic peptides can generally not be traced to a specific protein isoform and therefore differences in isoforms or PTMs that may well serve as biomarkers cannot be assessed in the typical routine application (101). Apart from LC separation, 2DE is frequently employed as separation technique prior to MS analysis, typically coupled with MALDI-TOF-MS/MS. The combination of methodologies is based on spot excision, trypsinization and subsequent offline ionization, allowing for identification of the proteins contained in the different gel spots. Importantly, 2DE enables to detect protein isoforms, and indicates post-translational modifications that change the isoelectric point $(\mathrm{pI})$ and/or molecular mass of intact proteins $(102,103)$. The limitations of this approach include the moderate reproducibility of 2DE and the high demand in skills, the requirement to cut out each single spot from the gel, process and analyse each spot separately (clearly limiting throughput), and the difficulties in separation of low abundance or hydrophobic proteins (such as membrane proteins).

For the discovery but also for validation of low molecular proteome (peptidomic) biomarkers, CE-MS has been successfully applied $(11,58,60,104,105)$. This technique involves separation of small proteins and peptides in narrow-bore fused silica capillaries based on their electrophoretic mobility, under the applied electric field (105). Subsequently, the analytes are ionized (usually by electrospray ionization - 
ESI) followed by MS analysis. CE can be coupled to MS by using either a sheath-liquid interface or without. The sheath-liquid interface method enables robust and efficient analysis and is comparable to LC-MS micro- or nano-ionspray interfaces (104-107). The sheathless interface methods should theoretically eliminate analyte dilution, thus providing higher sensitivity and stability (107). However, these theoretical advantages could never be demonstrated convincingly. Therefore, sheath-flow interfaces are generally used, as a stable and sufficiently sensitive (detection limits in the high amol range) approach. To implement the peptide sequencing, CE has been coupled with different platforms e.g. MALDI-TOF-TOF, FT-ICR (Fourier transform ion cyclotron resonance) (108) and Orbitrap (109). Advantages of CE-MS are the high stability and reproducibility that enabled comparable analysis of $>40000$ samples to date (110), and the separation of all peptides contained in a sample (no loss of peptides in the "void"). Disadvantages include the limited sample volume (in general <200 nl) that can be injected, and the relatively short separation time of about 15-20 minutes that cannot be extended, limiting the number of peptides that can be analysed in a sample. Advantages and disadvantages are well described in Klein et al. (109), where the authors present data on the direct comparison of LCMS/MS and CE-MS/MS.

The targeted proteomic approaches like MRM, SRM and parallel reaction monitoring (PRM) are typically applied for large scale verification of protein biomarkers. As evident from the studies presented above, MRM has been employed for the validation of proteomic biomarkers obtained from plasma and serum specimens. Moreover, the SRM methodology was presented in combination with stable isotope dilution (SID) method for validation the potential biomarkers in ovarian cancer. Targeted protein quantitation by MRM or SRM was applied for biomarker verification as an attractive alternative to ELISAs, as presented in multiple studies and together with CE-MS have become promising alternative approaches for large scale validation (Figure 3) (19, 29, 41, 71, 74, 92, 111, 112). A further advancement in targeted proteomics was the development of PRM by the group of Josh Coon (113). In this approach the third quadrupole of a triple quadrupole instrument is replaced by a high resolution and accurate mass analyzer to permit the parallel detection of all target product ions in one high resolution analysis. As demonstrated by the authors, PRM yields quantitative data over a wider dynamic range than SRM due to its high $\mathrm{m} / \mathrm{z}$ selectivity.

Another recent advance in proteomics analysis was the introduction of the data independent acquisition (DIA) approach named SWATH. This innovative approach achieves quantitation of several hundred proteins without the use of labeled standards.

Two principal approaches have been used for quantification: either by using unlabeled samples or by employing specific labeling. The more widely used approach in the retrieved studies is the unlabeled approach, often employing ion-counting, normalized either to the total counts in the sample (20), or to specific internal standards $(57,58,60)$ or spectral counting $(38)$. Chemical labeling methods like isotope-coded affinity tags ICAT $(40)$ and iTRAQ $(37,52,63)$ for LC-based approaches, as well as DIGE (for 2DE) have been employed in studying proteomic biomarkers linked with cancer development 
and progression, as described above. The advantage of those methods is that analysis of several samples is multiplexed within a single MS run, limiting intra-run variability. However, pooling of the samples increases the probability of errors resulting from accidental variabilities in the individual sample processing, prior to mixing (114). As reported recently (115), in direct comparison of the two approaches, the number of identified proteins was significantly higher in the unlabeled approach. A further disadvantage of the labeling approaches is that while the abundance of a specific protein can be compared within the samples contained in the analysis, further comparison with other datasets is at least challenging, in contrast to unlabeled approaches where e.g. ion-counting especially in reference to internal standards can serve very well to compare data from multiple experiments (116).

Regardless from the applied MS technique, the reproducibility and analytical robustness of the platform applied should be known, and well described. It also seems essential that well established SOPs are in place, to ensure validity of the data. Especially in the discovery phase such rigorous demands are essential, to avoid "discovering" a large number of artefacts, due to variability in the platform performance. As an example, a flow-chart for the well established CE-MS platform is presented in Figure 6. As described in more detail for example in (117), data on analytical performance should be available including reproducibility (short-term and intermediate repeatability), stability, interference, quantification capabilities (limits of detection), and inter-laboratory variability.

\section{FUNCTIONAL ANNOTATION OF MAIN BIOMARKER FINDINGS}

As shown by the retrieved biomarker studies, a number of proteins seem to be associated with different cancer etiologies, potentially indicating common underlying mechanisms (like e.g. loss of p53 function or activation of the MAPK pathway). This is also well reflected by recent reports on general tumor biomarkers $(118,119)$. In this systematic analysis, 19 proteins were revealed as significantly correlated with at least two cancer types. When investigating these proteins in more detail, they seem to be involved in several mechanisms during tumorigenesis processes that are reflecting cancer-associated pathways (120) (Table 3). Among them, OPN, IGFBP-2 and LRG1 were consistently upregulated, while CLUS was downregulated. OPN is a multifunctional cytokine that facilitates cell-matrix interactions and promotes tumor progression, and was consistently observed upregulated regardless of the cancer primary site (121). Similarly, IGFBP-2 stimulates proliferation and inhibits apoptosis in cancer cells in general (122) and is also frequently identified in increased levels in the body fluids of tumor-bearing patients. Serum LRG1 has been classified as an "acute-phase protein" involved in inflammatory response and was reported highly expressed in ovarian, breast and gastric cancer $(61,90,123)$. CLUS is a novel regulator of TGF- $\beta$ signaling by modulating Smad2/3 proteins (124) and was reported to be involved in many pathological processes including tumorigenesis $(61,78)$. Moreover, extracellular matrix (ECM) related proteins like Annexin I and TIMP1 were also identified in increased abundance throughout the different cancer studies, involving different cancer types, techniques and biological fluids. These findings may reflect invasion of the tumor, which requires degradation of ECM. 
To obtain a broader overview on the function of proteomics-derived biomarkers in the context of tumour biology and to identify biological processes reflected by the aforementioned biomarkers, the complete list of 141 proteins (Supplementary Table S3) that were identified and validated in the context of the 72 presented studies was analysed in silico. Gene Ontology enrichment analysis was performed for these proteins using ClueGO software, emphasizing on the evaluation of GO Biological Processes (Figure 4) (125). The analysis resulted in 425 statistically significant GO terms. The network illustrates each biological process as individual GO term, while edges between pathways denote an approximation of biological interaction between the pathways based on the cross-pathway feature overlap. Manual classification based on the GO hierarchical structure sub-classified the above mentioned 425 significant terms in 53 general biological processes, as presented in Supplementary Table S3. Among the 53 biological processes, signaling, metabolic pathways and pathways related to immune response, migration and ECM remodeling were most prominent (Supplementary Table S3). The biological processes were further shortlisted based on their relevance to cancer. This assessment indicates that several biological processes reflecting cancer-associated pathways (120) are affected, like angiogenesis, cell migration and invasion, inflammation and cancer related immune reactionsas depicted in Figure 4. Among the latter: 1) angiogenesis was represented by five significant GO terms, 2) apoptosis with 13 GO terms 3) cell adhesion with $13 \mathrm{GO}$ terms, 4) cell migration with $12 \mathrm{GO}$ terms, 5) cytokine production with 23 terms, 6) collagen processes and ECM remodeling with 6 terms in total, 7) immune and inflammatory response with 32 terms in total, 8) metabolic processes with 44 significant GO terms. The functional relevance of the protein biomarkers, when combined and annotated in silico, underline the general validity of the published proteomics data.

\section{OUTLOOK AND FURTURE PERSPECTIVES}

\section{First indications of success}

Importantly, several proteins have been approved by the FDA for use as cancer biomarkers. For instance, CA-125, CA19-9 and PSA tumor markers are routinely applied in clinical oncology. Considering, however, that cancer is a complex and highly heterogeneous disease, a single biomarker in general likely lacks accuracy in detecting all subtypes and stages of cancer. One strategy to overcome the shortcomings of single biomarkers is to apply a combination of biomarkers that better reflect disease heterogeneity (37). As evident from this review, this strategy has been applied in multiple studies, in each case with success, compared to the single biomarkers. Based on these reports, it is evident that proteomic approaches hold promise for discovering robust biomarker panels (Figure 5).

The application of MS-based approaches has gained attention for biomarker validation, as CE-MS and targeted proteomic approaches, such as MRM, SRM and PRM can be applied for multiplex large-scale verification of protein biomarkers. In fact, a first large clinical trial guided by proteome analysis is currently ongoing, although not in the field of oncology. In this trial, PRIORITY (126), patients are stratified for risk to develop diabetic nephropathy using CE-MS analysis of urinary peptides (127). 
While the study is still ongoing and consequently no results are available yet, the approach demonstrates well the applicability of proteome analysis in the routine clinical setting, and hopefully paves the way for broader application of MS-based proteomics in the management of cancer patients.

As in the PRIORITY trial, and in many of the presented studies, particularly in the case of colorectal cancer, hepatocellular carcinoma and ovarian cancer, a combination of commonly applied biomarkers together with novel candidates significantly improved sensitivity and specificity of detection and have been found to have a clear potential in clinical diagnosis and prognosis, likely enabling improvement in patient management.

\section{Challenges and shortcomings}

However, although proteomics studies have contributed with a long list of potential cancer biomarkers, the vast majority of them has not been successfully implemented in clinical studies. When investigating the studies, shortcomings that have already been indicated in the past (Figure 7, described also below) $(128,129)$ seem to be responsible for this frequently observed failure in implementation. Because the purpose of a biomarker is its application/implementation, any valid biomarker study must present a convincing case and the evidence required for actual implementation. This implies defining a specific context-of-use. Unfortunately, this requirement is frequently not met.

Moreover, other major shortcomings in the proteomic studies are, on one hand, the small sample size, hence very limited study power, and on the other hand the frequently "relaxed" application of statistical assessment that result in low validity/credibility of the data. Additionally, the study design is frequently not guided by the targeted clinical use: the comparison between e.g. cancer patients and healthy individuals typically does not reflect the clinical situation. In addition, the requirements for a specific application are frequently not even taken into account.

We want to highlight the relevance of such considerations by using $\mathrm{BCa}$ as example (130): the number of new BCa cases per year is estimated at 20 people out of 100000 people. Even an excellent assay with a specificity of $99 \%$ and $100 \%$ sensitivity would result in 50 false positive cases for one detected true case. However, in reality we record sensitivities and specificities in the range of $70-80 \%$, which correspond to detection of 15 out of the 20 true cases detected, and 25,000 people that are falsely diagnosed diseased (false positives). This clearly indicates that the aim to develop a biomarker to be used for BCa screening in the general population will most likely result in failure. Consequently, testing a biomarker for $\mathrm{BCa}$ in cancer cases versus normal healthy individuals does not result in relevant data. In a selected population of risk for $\mathrm{BCa}$ (e.g. patients with hematuria -not caused by other diseases- that will subsequently undergo cytoscopy), approximately 10 out of 100 patients may harbour a tumor (131, 132). A biomarker that shows $90 \%$ sensitivity and even only $50 \%$ specificity would still enable sparing cystoscopy for 45 patients, at the expense of only one undetected tumor. Hence, testing in a population that will undergo cystoscopy with the aim to guide application of this invasive procedure seems 
appropriate (130). This example showcases an application where a biomarker can be applied in a meaningful way (based on realistic expectations for performance).

A principal problem in biomarker research is the fact that it is still easier to publish underpowered "discovery studies", while well powered validation studies are frequently rejected, based on the argument of lack of novelty. As a result, "potential biomarkers" are constantly "discovered", but not properly validated, hence never meet their purpose: to be translated into a reliable assay to improve patient management. The above principal aspects in the biomarker research and implementation are schematically summarized in Figure 7.

\section{Potential solutions and suggestions}

Based on these facts and observations, biomarker research in oncology needs to focus on increasing impact at the clinical practice, at performing properly powered validation studies, driven by the specific clinical context and need. In this context, the clinical parameters that are currently applied as gold standards in cancer diagnosis have to be taken into consideration and the proposed biomarkers need to be superior or at least demonstrate an added benefit to the current practice. Moreover, the potential biomarker should have an impact on disease management (the mere information of a tumor that is present, or of poor prognosis, without any means to improve on this condition, appears of no value) and should be linked to the molecular pathophysiology. As a result of the last statement and to give an example: it is difficult to envision how highly abundant plasma proteins identified in urine i.e. apolipoproteins and A1AT can be specific for a malignant tumor. It is more likely that the above proteins reflect associated kidney disease and proteinuria.

As evident from this review and also indicated in several articles, by now a plethora of potential biomarkers is available (133). The next logical step should be a research focus towards testing their actual value, also likely combine them together to increase their performance. As thorough testing requires substantial efforts and well characterized cohorts of ideally >1000 individuals (depending on the specific context of use, investigating biomarkers guiding treatment in a rare disease with high prevalence in a preselected population will require less patients than testing screening in the general population), such challenges can probably best be met by larger consortia. Along these lines the establishment of the Early Detection Research Network (EDRN) in the US is a very promising step into this direction. Similar initiatives are yet lacking in other regions of the world, but a slow shift in the funding from underpowered discovery to well powered validation studies in e.g. the Cancer Research U.K. (CRUK) and by the European Commission (H2020) is detectable.

In parallel, increasing power of individual observations and establishing biological relevance of proteomics data through integration with other-omics, should be targeted. Even for classical biomarkers (such as HER2, EGFR) the evidence by now suggests that a comprehensive investigation at multiple molecular levels may be needed to increase accuracy in tumor subtyping (134). Future personalized medicine approaches will likely involve the evaluation of a combination of -omics features estimating 
on one hand the cancer risk (likely based on features at the mutational /genomic level) but also the 'cancer activity' (based on the cancer protein and metabolite characteristics). Such an integrative approach will pave the way not only towards more powerful biomarker profiles but also towards the identification of optimal therapeutic targets. In conclusion, placing emphasis not only -or just- on the acquisition of more information at the proteomics level, but rather on interpreting and evaluating collected results according to the specific clinical settings appears as the appropriate way forward in biomarker research.

Without any doubt, biomarkers are urgently needed in oncology not only for early detection but, even more, to maximize benefit from currently available (and under development) treatment modalities (through stratification /predictive biomarkers). Therefore, coordinated activities of proteomics researchers not only with physicians but, when applicable (for example case of predictive markers) also with pharmaceutical companies should be actively pursued and positively embraced, having the potential to significantly shorten the path to successful outcome, including most importantly, bringing to the patients the best possible treatment. 


\section{ACKNOWLEDGEMENT}

This work was supported by the Chromatin3D (MSCA-ITN- 622934) project, BioMedBC (H2020MSCA-IF-2016- 752755) and PCaProTreat, (H2020-MSCA-IF-2017- 800048), funded by the European Commission.

\section{ABBREVIATIONS}

2D, Two dimensional electrophoresis; 2D-DIGE, 2D differential gel electrophoresis; 2DE, Two dimensional electrophoresis; Aab, Autoantibodies; A1AG1, Alpha-1-anty-glycoprotein 1; A1AT, Alpha-1-antitrysin; AFP, Alpha-fetoprotein;AGR2, Anterior gradient protein 2 homolog; GT, Angiotensinogen; AHNAK, Neuroblast differentiation-associated protein AHNAK; AHSG, Alpha-2HS-glycoprotein; AKR1B10, Aldo-keto reductase 1B10; ALDOA, Fructose-1,6-biphosphate aldolase; ALL, Aleuria aurantia lectin; ANTXR1, Anthrax toxin receptor 1; ANXA1, Annexin 1;APCS, Amyloid p component; APOCI, Apolipoprotein C-I; APOE, Apolipoprotein E; APOH, Apolipoprotein H; ARMET, Mesencephalic astrocyte-derived neurotrophic factor; AUC, Area under the curve; ZGP1, Zinc-alpha-2-glycoprotein; B2M, Beta-2-microglobulin; BBD, Bening biliary disorders; BCa, Bladder cancer; BCAS3, Breast carcinoma amplified sequence 3; BDNF1, Brain-derived neurotrophic factor; BPH, Benign prostatic hyperplasia; 163A, Scavender receptor cysteine-rich type I protein M130; C9, Complement component 9; CA125, Cancer antigen 125; CA19-9, Cancer antigen 19-9; CA2, Carbonic anhydrase 2; CBG, Corticosteroid-binding globulin; CC, Cholangiocarcinoma; ccRCC, Clear-cell type of renal cell carcinoma; CD14, Monocyte differentiation antigen CD14; CDH1, E-Cadherin; CEA, Carcinoembryonic antigen; CE-MS, Capillary electrophoresis coupled to mass spectrometry; CFAB, Complement factor B; CFH, Complement factor H; CGN, Cingulin; CLUS, Clusterin; COL1A1, Collagen type I alpha 1; COL1A2, Collagen type I alpha 2; COL3A1, Collagen type III alpha 1; Con A, Concanavalin A; CPM, Carboxypeptidase M; CRABP2, Cellular retinoic acid-binding protein 2; CRC, Colorectal cancer; CSC, Cell Surface Capture; CSTB, Cystatin B; CT, Computed chest tomography; CYFRA 21-1, Cytokeratin-19 fragment; DAP10, Membrane protein DAP10; DMBT1, Deleted in human brain tumor protein 1; DNM2, Dynamin-2;DSG2, Desmoglein-2; DSP, Desmoplakin; ECH1, Delta(3,5)-Delta(2,4)-dienoyl-CoA isomerase; ECM, Extracellular matrix; EDRN, Early Detection Research Network; e-FABP5, Epidermal fatty acid-binding protein; EFEMP2, EGF-containing fibulinlike extracellular matrix protein 2; EGFR, Epidermal growth factor receptor; EIF3J, Eukaryotic translation initiation factor 3 subunit J; ENO1, $\alpha$-enolase; ESCC, Esophageal squamous cell carcinoma; ESI, Electrospray ionization; EVs, Extracellular vesicles; FABP5, Fatty acid binding protein 5; FDA, Food and Drug Administration; FGA, Fibrinogen alpha chain; FGB, Fibrinogen beta chain; FISH, Fluorescence In Situ Hybridization; FLISA, Lectin-fluorophore-linked immunosorbent assay; FRIL, Ferritin light chain; FST, Follistatin; FT-ICR, Fourier Transform Ion Cyclotron Resonance; G3BP2, Ras-GTPase activating protein-binding protein 2; G6PD, Glucose-6-phosphate dehydrogenase; Gal-1, Galectin 1; GBP1, Guanylate-binding protein 1; GDF15, Growth/differentiation factor 15; GDIR, Rho- 
GDP-dissociation inhibitor 2; GEFs, Guanine nucleotide exchange factor; GeLC-MS/MS, In-gel tryptic digestion followed by liquid chromatography-tandem mass spectrometry; GLUT1, Glucose transporter member 1; GM2, Protein-glutamine gamma-glutamyltransferase 2; GO, Gene Ontology; GP73, Golgi membrane protein-1; GRN, Granulin; GRP78, 78 kDa glucose-regulated protein; GSN, Gelsolin; GSLG1, Golgi apparatus protein 1; GSTO1, Glutathione s-transferase omega-1; GST-Pi, GlutathioneS-transferase Pi (GST-Pi); HBV, Hepatitis B virus; HCC, Hepatocellular carcinoma; HEMO, Hemopexin; HGB, Haemoglobin subunit beta; HLE, Hybrid lectin ELISA; HMGB1, High-mobility group box-1; HNC, Head and neck cancer tissues; HNOSCC, Head and neck cancer/oral squamous cell carcinoma; HNSCC, Head and neck cell carcinoma; HP, Haptoglobin; HPX, Hemopexin; HRG1, Histidine-rich glycoprotein; HSP27, Heat shock protein beta-1; HSP70, Heat shock protein 70; HSP709B, Heat shock protein 70-9B; HSPE1, $10 \mathrm{kDa}$ heat shock protein; HSPG2, Basement membranespecific heparan sulfate proteoglycan core protein; HYOU1, Hypoxia up-regulated protein 1; ICAM1, Intercellular adhesion molecule 1; ICAM5, Intercellular adhesion molecule 5; ICAT, Isotope-coded affinity tags; IDACP, Invasive ductal adenocarcinoma of pancreas; IGFBP2, Insulin-like growth factorbinding protein 2; IGFBP7, Insulin-like growth factor-binding protein 7; IHC, Immunohistochemistry; IKBP1, Interleukin-1 receptor-associated kinase 1-binding protein 1; IL-8, Interleukin-8; IMPDH, Inosine-5'-monophosphate dehydrogenase; iMRM, MRM coupled with immunoprecipitation; IP-10, Interferon gamma-induced protein 10; IPA, Ingenuity Pathway Analysis; IRX1, Iroquois-class homeodomain protein IRX-1; ISG15, Interferon-induced 17-kDa protein; ISLR, Immunoglobulin superfamily containing leucine-rich repeat protein 2; ITIH3, Inter-alpha-trypsin inhibitor heavy chain H3; iTRAQ, Isobaric tag for relative and absolute quantitation; KLK6, Kallikrein 6; LAMC2, Laminin 2; LAP3, Leucine aminopeptidase 3; LC-MS/MS, Liquid chromatography tandem mass spectrometry; LC-SRM, Liquid chromatography-selected reaction monitoring; LDCT, Low-dose computed tomography; LEI, Leukocyte elastase inhibitor; LFQ, Label free quantification; LG3BP, Galectin-3binding protein; LIF, Leukemia inhibitory factor; LNM, Lymph-node metastasis; LRG1, Leucine-rich alpha-2-glycoprotein; LRP1B, Low density lipoprotein receptor related protein-deleted in tumor; LTBP2, Latent-Transforming Growth Factor $\beta$ Binding-Protein 2; LUM, Lumican; LYVE1, Lymphatic vessel endothelial hyaluron receptor; MACF1, Type I keratin 16 macrophin 1 isoform 2; MALDI-TOFMS, Matrix assisted laser desorption ionization-time of flight mass spectrometry; MAPRE1, Microtubule-associated protein RP/EB family member 1 ; MASP1, Mannan-binding lectin serine protease I; MCCC2, Mitochondrial methylcrotonoyl-CoA carboxylase beta chain; MCCV, Monte Carlo cross validation; mCRCP, Metastatic castration-resistant prostate cancer; MDK, Midkine; MG1, Highmolecular-weight salivary mucins; MMP14, Metalloproteinase 14; MMP2, Matrix metalloproteinase-2; MPE, Malignant pleural effusions; MPM, Malignant pleural mesothelioma; MRI, Magnetic resonance imaging; MRM-MS, Multiple reaction monitoring mass spectrometry; MS, Mass spectrometry; MS/MS, Tandem mass spectrometry; MudPIT, Multidimensional protein identification technology; MYL6, Myosin light polypeptide 6; NGAL, Neutrophil gelatinase-associated lipocalin; NIF, Normal interstitial 
fluid; NPV, Negative predictive value; NSCLC, Non-small cell lung cancer; OCIAD1, Ovarian carcinoma immuno-reactive antigen domain containing protein 1; OPMD, Oral pre-malignant disorders; OPN, Osteopontin; OS, Overall survival; OSCC, Oral squamous cell carcinoma; PAI-3, Plasma serine protease inhibitor; PCa, Prostate cancer; PDAC, Pancreatic ductal adenocarcinoma; PDCD4, Programmed Cell Death 4; PDIA3, Protein disulfide-isomerase A3; PEDF, Pigment epithelium-derived factor; PFS, Progression-free survival; PGAM1, Phosphoglycerate mutase 1; PGK1, Phosphoglycerate kinase 1; PGRP2, N-acetylmuramoyl-L-alanine amidase; pI, Isoelectric point; PLAU, Urokinase; PMA, Phorbol myristate acetate; PON1, Serum paraoxonase/arylesterase 1; PPA2, Inorganic pyrophosphatase 2 mitochondrial; PRDX1, Peroxiredoxin-1; PRM, Parallel reaction monitoring; ProEGF, Pro-epidermal growth factor; PROS1, Protein S; PROZ, Protein Z; PSA, Prostate-specific antigen; PSC, Primary sclerosis cholangitis; PTPRJ, Receptor-type tyrosine-protein phosphatase eta; RACK1, Guanine nucleotide-binding protein subunit beta 2-like 1; RCC, Renal cell carcinoma; REG1A, Lithostathine-1alpha; RET4, Retinol-binding protein 4; RETN, Resistin; RPPA, Reverse phase protein assay; S100A8/A9, Calprotectin; SAA4, Serum amyloid A-4 protein; SAP, Serum amyloid P-component; SAP3, Ganglioside GM2 activator; SBP1, Selenium-binding protein 1; SCC-Ag, Squamous cell carcinoma antigen; SCLC, Small-cell lung carcinoma; SDF-1, Stromal cell-derived factor 1; SELDITOF MS, Surface-enhanced laser desorption/ionization time-of-flight; SEPR, Seprase; SERPINA3, Serpin peptidase inhibitor clade A; SERPINA4, Kallistatin; SERPINB9, Serpin B9; SERPINI1, Serpin Family I Member I; SFN, 14-3-3 protein sigma; SID, Stable isotope dilution; SLC3A2, 4F2 cell-surface antigen heavy chain; SLP2, Stomatin like protein 2; SM22, Smooth muscle protein; SOD2, Superoxide dismutase 2; SPON2, Spondin-2; SRC8, Src substrate cortactin; SRM, Selected reaction monitoring; STIP1, Stress-induced phosphoprotein 1; STMN1, Stathmin; SWATH, Sequential window acquisition of all theoretical spectra; TACSTD2, Tumor-associated calcium-signal transducer 2; TAGLN2, Transgelin-2; TCP1 $\beta$, T-complex protein 1 subunit $\beta$; TETN, Tetranectin; TFF1, Treofil factor 1 ; TFF3, Trefoil factor 3; TFP1, Tissue factor pathway inhibitor; TGFB1, Transforming growth factor betainduced; THBG, Thyroxine-binding globulin; THBS1, Thrombospondin-1; TIF, Tumor interstitial fluid; TIMP1, Tissue inhibitor of metalloproteinases 1; TKI, Tyrosine kinase inhibitors; TMT, Tandem mass tags; TNF $\alpha$, Tumor necrosis factor alpha; tPA, tissue-type plasminogen activator; TPI1, Triosephosphate isomerase 1; TPM3, Tropomyosin 3 chain; TTR, Transthyretin; TXN, Thioredoxin; UBC, Urothelial bladder cancer; UCHL1, Ubiquitin carboxyl-terminal esterase L1; VDB, Vitamin D-binding protein; WB, Western blot; WTL, Whole tissue lysate. 


\section{FIGURES}

Figure 1

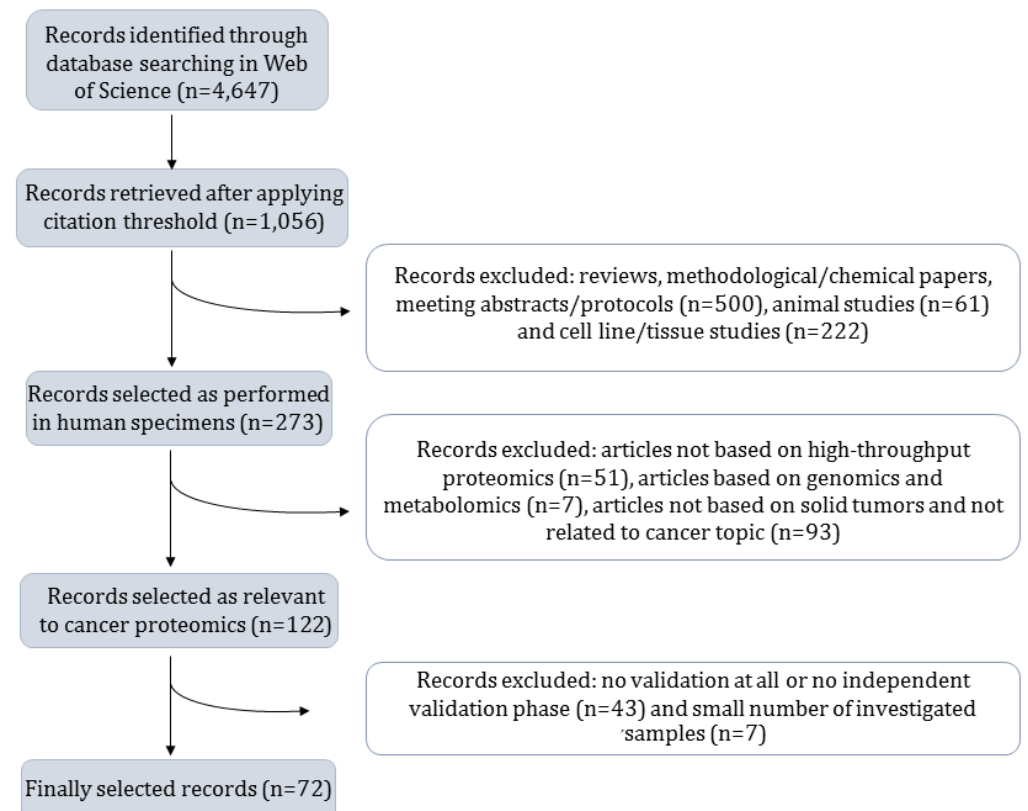

Figure 1. Schematic representation of the literature search performed in the Web of Science database. The detailed exclusion criteria are given along with the number of studies that were excluded in each selection step.

Figure 2

A. Discovery

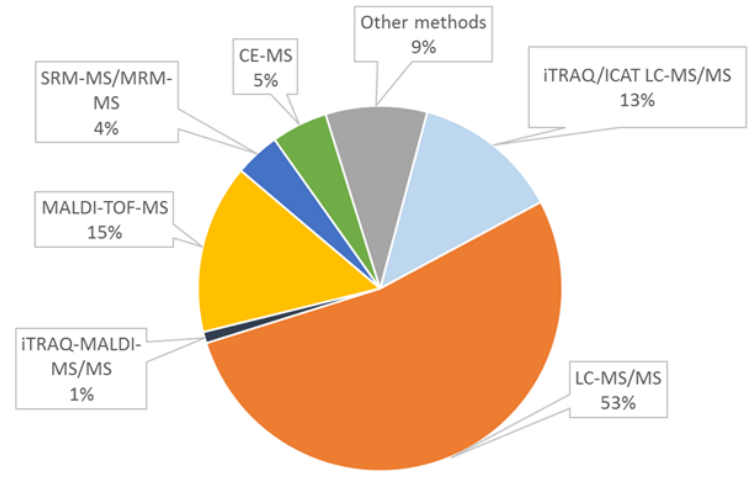

B. Validation

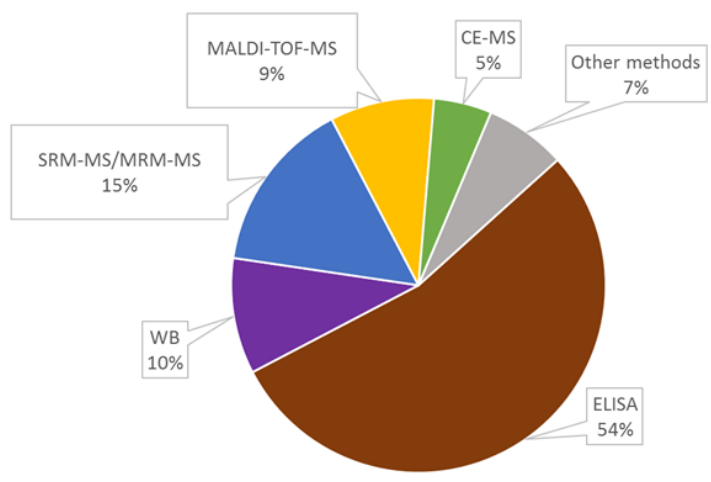

Figure 2. Distribution of the proteomic techniques that were applied in the selected studies for: A. discovery phase and $\mathbf{B}$. validation phase. 
Figure 3

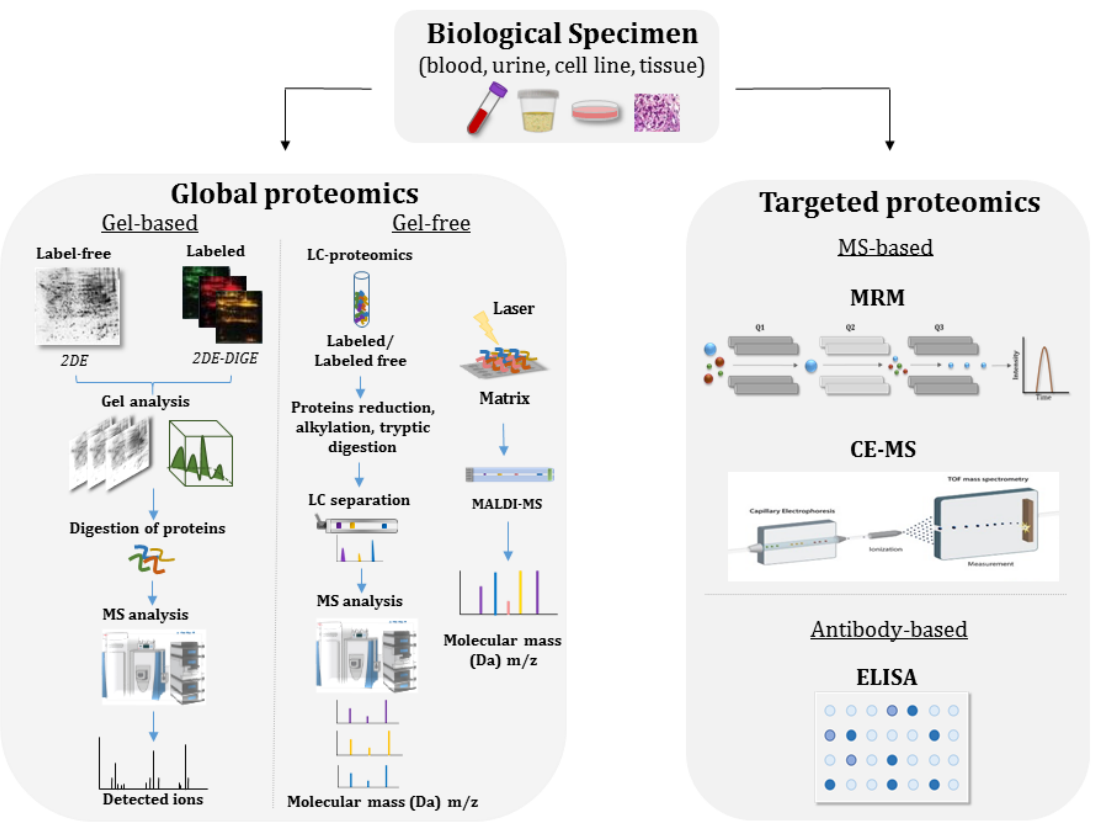

Figure 3. Outline of the commonly used proteomics strategies. Global proteomics (left panel) include MS-based approaches for the identification of potential protein biomarkers. Protein separation prior to MS can be achieved by either gel-based or gel-free proteomics strategies; Targeted proteomics (right panel) include antibody-based approaches like ELISA and highly selective quantitative MS-based approaches like MRM.

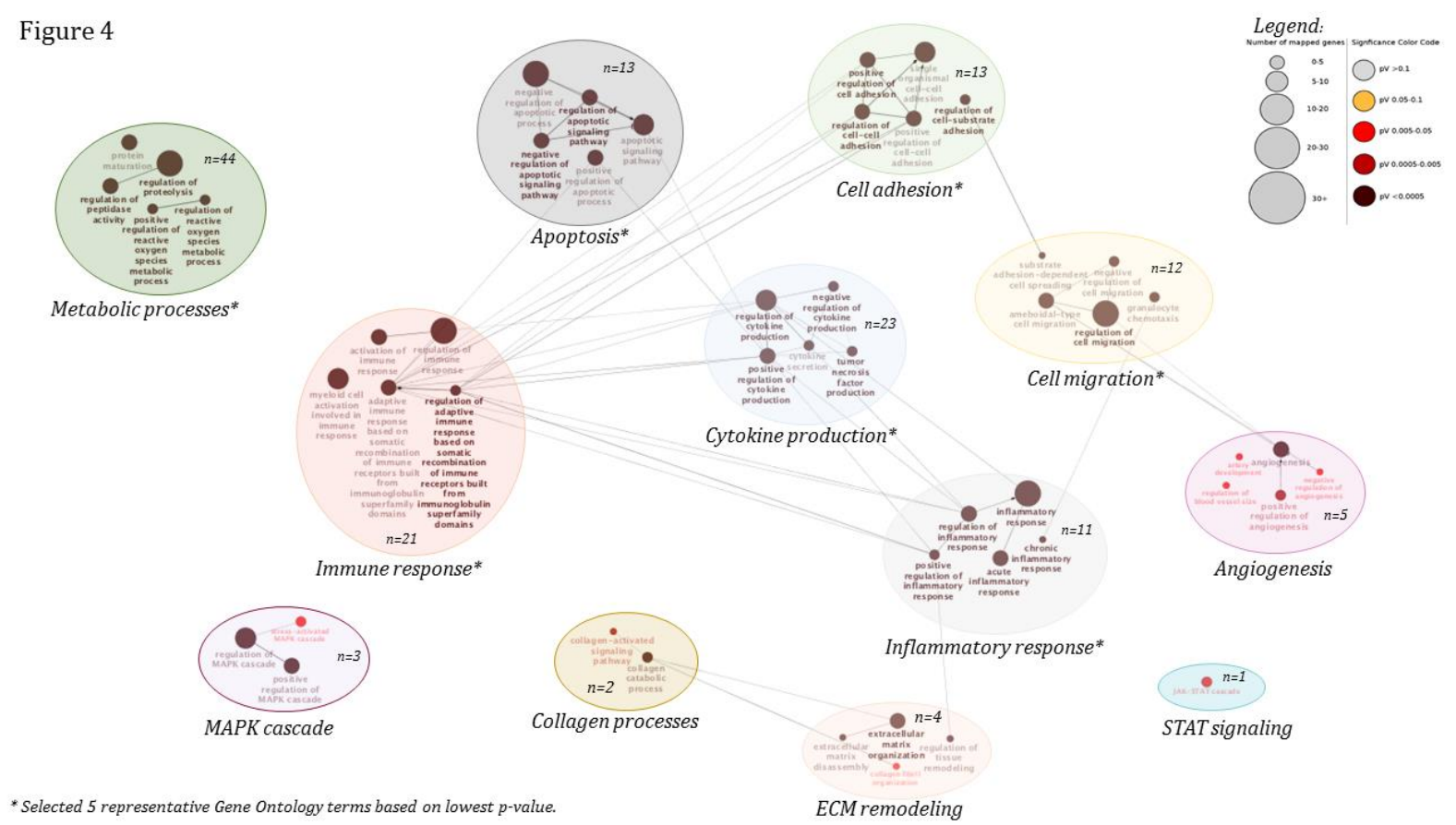

Figure 4. Representation of several cancer related biological processes as defined based on grouping of GO significant terms/GO biological processes after in silico pathway enrichment analysis. A functionally grouped network was created in Cytoscape Software (version 3.5.1) by iterative merging of initially defined GO significant groups based on the predefined kappa score threshold $(\geq 0.4)$. The 
network represents each significant term/pathway as individual node $(\boldsymbol{p}<0.05)$. The edges (links) between terms/pathways denote an approximation of biological interaction between the pathways based on the cross-pathway feature overlap. The size of the nodes is proportional to the number of protein symbols that are involved in each GO terms, while the colour gradient reflects the enrichment significance of the terms. For easing the visualization, for the processes where more than five significant GO terms were involved, the top five most significant pathways/ terms are shown.

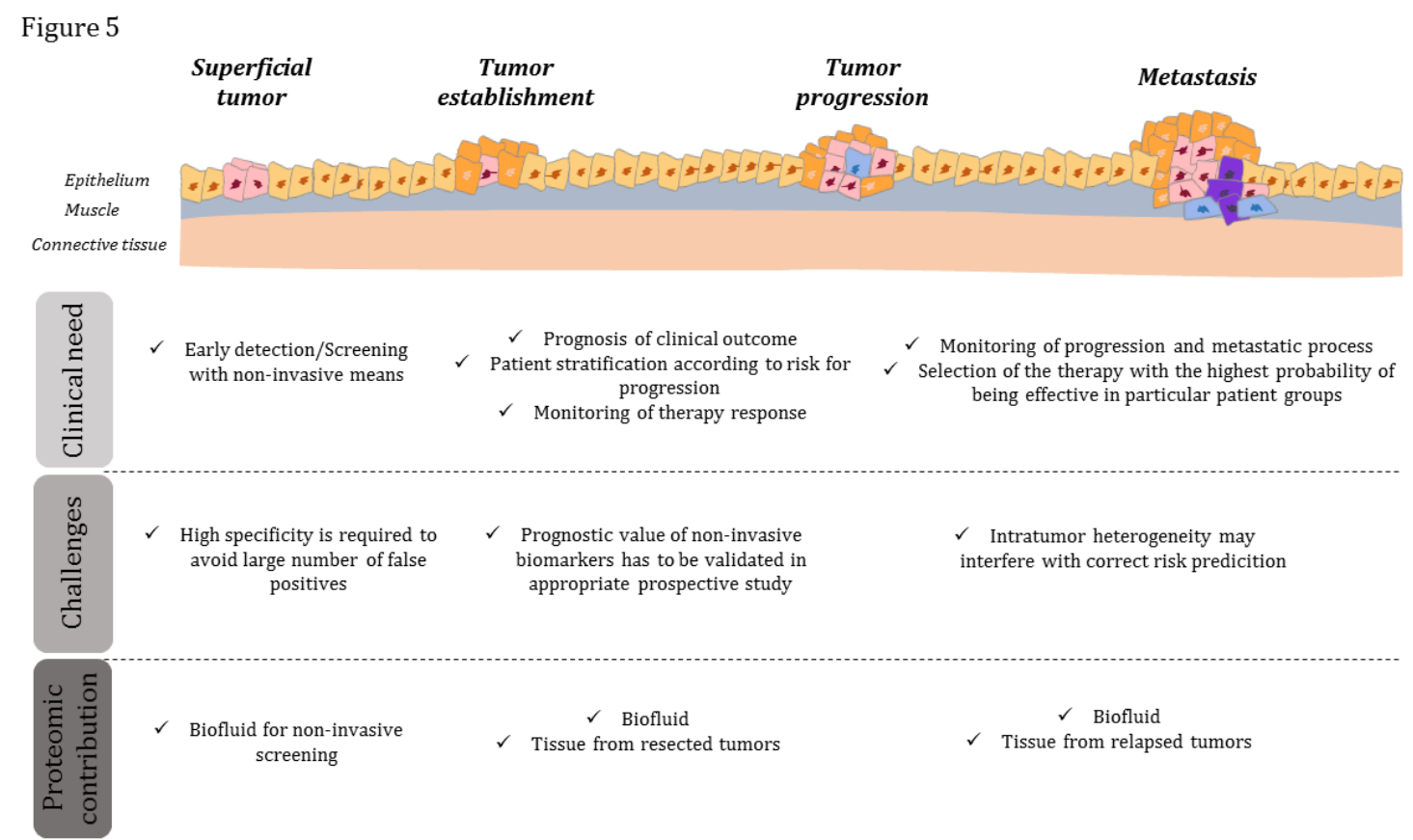

Figure 5. Overview of the main clinical contexts and the contribution of proteomics to cancer research. Proteomic techniques can be employed to address different clinical needs such as early diagnosis of cancer, prognosis, monitoring of tumor progression and metastasis. Cancer research is associated with challenges, involving limited specificity when screening the early cancer stages but also increased cancer heterogeneity mainly present in later cancer stages. 
Figure 6

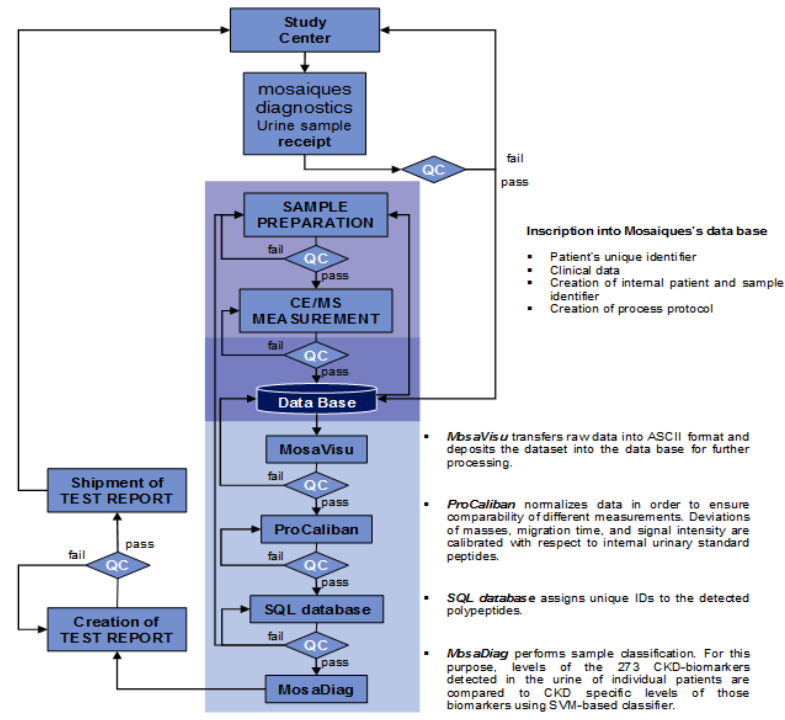

Figure 6. Workflow of the CE-MS analysis and data evaluation. The complete procedure of the CE-MS application in clinical proteomics includes the protocol for efficient and reproducible sample preparation, software solutions that enable efficient extraction of the data and the identification of internal calibrants that enable re-calibration of the datasets. Reprinted with permission from (135).

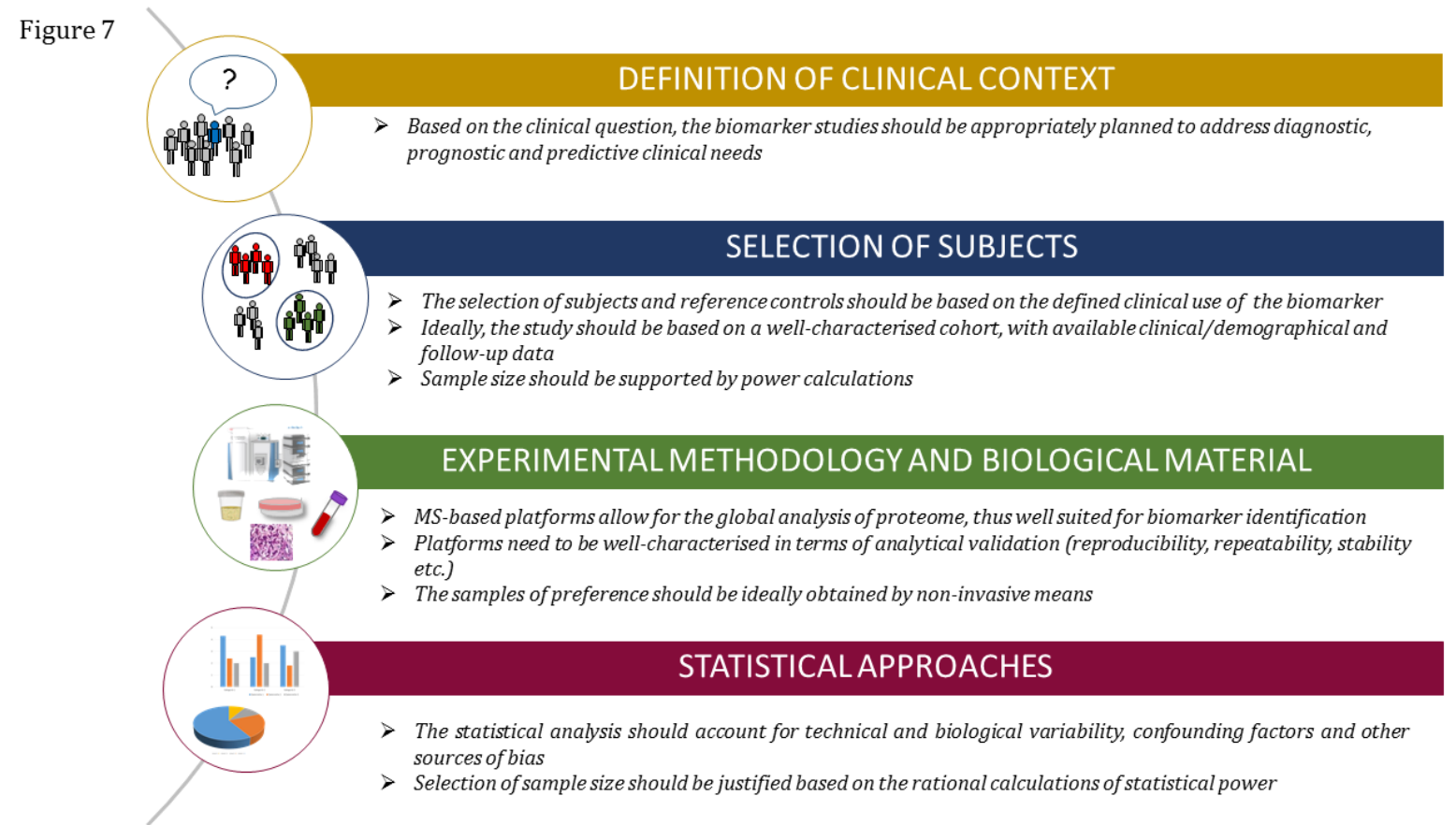

\section{Figure 7.}

General concept and analytical strategies for the generation of a successful biomarker study design. Principle aspects that should be addressed in biomarker study design include among others a clearly defined clinical need, selection of appropriate experimental methodology to address the clinical question, recruitment of a number of patients to support a well-powered study, established sample selection protocols and a statistical evaluation plan. 


\section{TABLES}

\section{Table 1. Cancer screening programmes for adults recommended by The American Cancer} Society

Women of age between 40 to 44 should have the choice to start the annual breast cancer screening with mammograms

Women of age between 45 to 54 should get mammograms every year

Women 55 and older could switch to mammograms every 2 years, or can continue yearly screening

All women should be familiar with the known benefits, limitations and potential harms linked to cancer screening. They also should provide physical breast examinations

Starting at age of 50, both men and women should follow one of these testing plans:

- $\quad$ test that find polyps and cancer: flexible sigmoidoscopy every 5 years, or colonoscopy every 10 years, or double-contrast barium enema every 5 years, or CT colonography every 5 years;

- $\quad$ test that mostly find cancer: yearly guaiac-based fecal occult blood test (gFOBT), or yearly fecal immunochemical test (FIT), or stool DNA test (sDNA), every 3 years

Cervical cancer testing should start at the age of 21

Women between the ages of 21 and 29 should have a Pap test done every year

Women between the ages of 30 and 65 should have a Pap test plus an HPV test done every 5 years

Women over age 65 who have had regular cervical cancer testing in the past 10 years with normal results should not be tested for cervical cancer. Women with a history of a serious cervical pre-cancer should continue to be tested for at least 20 years after the diagnosis, even if testing goes past age 65

All women who have been vaccinated against HPV should still follow the screening recommendations for their age groups

At the time of menopause, all women should be told about the risks and symptoms of endometrial cancer.

Women should report any unexpected vaginal bleeding or spotting to their doctors

Screening guidelines should be performed for those who are at high risk of lung cancer due to cigarette smoking. Screening might be right: for patients at the age between 55 and 74, who are in good health, have at least a 30 pack-year smoking history and are either still smoking or have quit smoking within the past 15 years

Screening is done with an annual low-dose CT scan (LDCT) of the chest

Starting at age of 50, men should talk to a health care provider about the pros and cons of testing so they can decide if testing is the right choice for them. If patient decides to be tested, he should get a PSA blood test with or without rectal exam. How often patient should be tested will depend on PSA level 
Table 2. List of FDA-approved proteomic and genomic cancer biomarkers.

\begin{tabular}{lccccl}
$\begin{array}{l}\text { Cancer } \\
\text { type }\end{array}$ & $\begin{array}{c}\text { Biomarker } \\
\text { type }\end{array}$ & $\begin{array}{c}\text { Biomarker } \\
\text { target }\end{array}$ & Specimen & Method & \multicolumn{1}{c}{ Clinical use } \\
& & Pro2PSA & Serum & Immunoassay & $\begin{array}{l}\text { Guidance } \\
\text { discrimination of }\end{array}$ \\
& & & & $\begin{array}{l}\text { in } \\
\text { prostate cancer from } \\
\text { benign conditions }\end{array}$ \\
& & & &
\end{tabular}

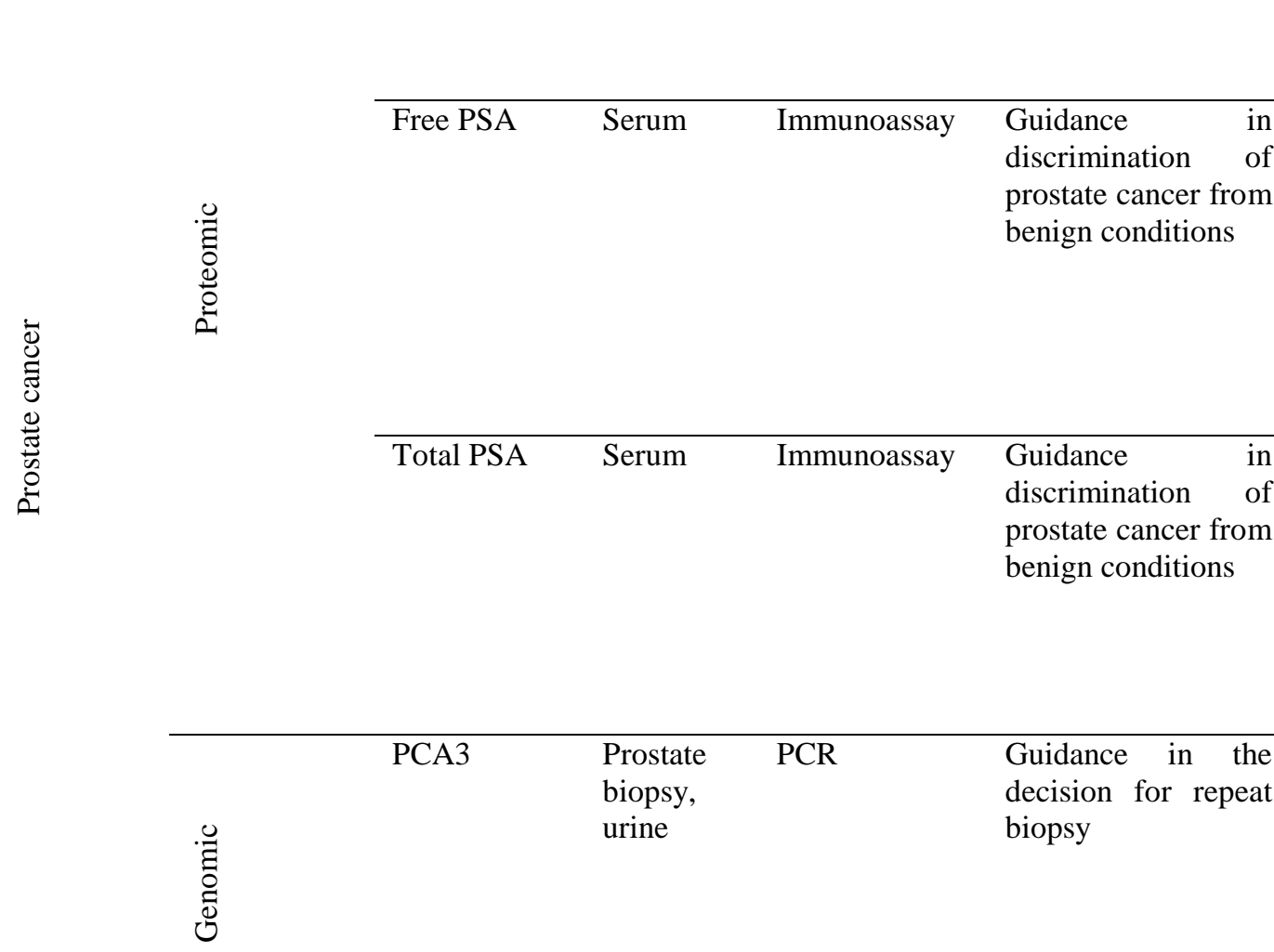

Study sample size: $\mathrm{n}=462$ benign and $\mathrm{n}=430 \quad$ cancer patients (136) performance* At 4-10 ng/ml PSA range and at $97 \%$ sensitivity, specificity is $6 \%$. Study sample size: $\mathrm{n}=117$ patients without cancer and $\mathrm{n}=35 \quad$ cancer patients (137) At 2-10 ng/ml PSA range and at $81.9 \%$ sensitivity, specificity is $16.8 \%$. Study sample size: $\mathrm{n}=220$ prostate cancer patients (138)

Study sample size: $\mathrm{n}=12$ tissue biopsies and $\mathrm{n}=12$ urine samples. At PCA3 score 5 and at $83 \%$ sensitivity, specificity is $21 \%$ (139)

\begin{tabular}{|c|c|c|c|c|c|c|}
\hline \multirow[t]{2}{*}{ 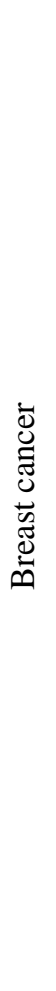 } & \multirow[t]{2}{*}{ 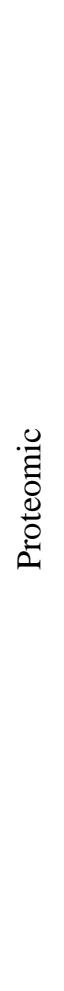 } & $\begin{array}{l}\text { Circulating } \\
\text { tumor cells } \\
\text { (EpCAM, } \\
\text { CD45, } \\
\text { cytokeratins } \\
8,18+, 19+)\end{array}$ & Blood & $\begin{array}{l}\text { Immunomag- } \\
\text { netic capture/ } \\
\text { immune- } \\
\text { fluorescence }\end{array}$ & $\begin{array}{lr}\text { Monitoring } & \text { of } \\
\text { patients } & \text { with } \\
\text { metastatic } & \text { breast } \\
\text { cancer } & \end{array}$ & $\begin{array}{l}\text { PFS Analysis: } \text { Cut- } \\
\text { off: a circulating } \\
\text { tumor cells (CTC) } \\
\text { count of }>5 \text { per } 7.5 \\
\text { mL of blood. The } \\
\text { Favorable group } \\
\text { (n=90, patients } \\
\text { with }<5 \text { CTC) and } \\
\text { the Unfavorable } \\
\text { group (n=87, } \\
\text { patients with >5 } \\
\text { CTC). The the } \\
\text { difference in PFS } \\
\text { between the two } \\
\text { groups is highly } \\
\text { significant (Log- } \\
\text { rank p }=0.0001 \text {, } \\
\text { Cox HR=1.9547, } \\
\boldsymbol{p}=0.0001)(140)\end{array}$ \\
\hline & & $\begin{array}{l}\text { Estrogen } \\
\text { receptor (ER) }\end{array}$ & $\begin{array}{l}\text { FFPE } \\
\text { tissue }\end{array}$ & $\begin{array}{l}\text { Immunohisto- } \\
\text { chemistry }\end{array}$ & $\begin{array}{l}\text { Prognosis, response } \\
\text { to therapy }\end{array}$ & $\begin{array}{l}\text { At the cut-off of } \\
\text { Allred score of } \\
\text { greater than } 2 \\
\text { (corresponding to } \\
\text { as few as } 1 \% \text { to } \\
10 \% \text { weakly }\end{array}$ \\
\hline
\end{tabular}




\begin{tabular}{|c|c|c|c|c|}
\hline & & & & $\begin{array}{l}\text { positive cells) and } \\
\text { at } 98.8 \% \\
\text { sensitivity, } \\
\text { specificity is } 100 \% \\
\text { Study sample size: } \\
\mathrm{n}=90 \text { breast cancer } \\
\text { tissue (141) }\end{array}$ \\
\hline $\begin{array}{l}\text { Progesterone } \\
\text { receptor }(\mathrm{PR})\end{array}$ & $\begin{array}{l}\text { FFPE } \\
\text { tissue }\end{array}$ & $\begin{array}{l}\text { Immunohisto- } \\
\text { chemistry }\end{array}$ & $\begin{array}{l}\text { Treatment } \\
\text { monitoring }\end{array}$ & $\begin{array}{l}\text { At the cut-off of } \\
\text { Allred score of } \\
\text { greater than } 2 \\
\text { (corresponding to } \\
\text { as few as } 1 \% \text { to } \\
\text { 10\% weakly } \\
\text { positive cells) and } \\
\text { at } 98.5 \% \\
\text { sensitivity, } \\
\text { specificity is } 100 \% \\
\text { (141) }\end{array}$ \\
\hline HER-2/neu & $\begin{array}{l}\text { FFPE } \\
\text { tissue }\end{array}$ & $\begin{array}{l}\text { Immunohisto- } \\
\text { chemistry }\end{array}$ & $\begin{array}{l}\text { Treatment } \\
\text { monitoring }\end{array}$ & $\begin{array}{l}\text { LSI HER-2/neu: } \\
\text { CEP } 17 \text { signal ratio } \\
\text { of } \geq 2.0 ; \text { normal } \\
\text { specimens showed } \\
\text { a ratio of }<2.0 \\
\text { Study sample size: } \\
n=18 \text { tissue slides } \\
(142)\end{array}$ \\
\hline CA15-3 & $\begin{array}{l}\text { Serum, } \\
\text { plasma }\end{array}$ & Immunoassay & $\begin{array}{l}\text { Monitoring } \text { of } \\
\text { disease progression } \\
\text { or response to } \\
\text { therapy }\end{array}$ & $\begin{array}{l}\text { At the cut-off of } 35 \\
\text { U/mL and at } 65.7 \% \\
\text { sensitivity, } \\
\text { specificity } \\
76.6 \% \text {. St } \\
\text { sample size: } \mathrm{n}=44 \\
\text { serum samples } \\
\text { from 25 women } \\
\text { diagnosed with } \\
\text { breast cancer (143) }\end{array}$ \\
\hline CA27.29 & Serum & Immunoassay & $\begin{array}{l}\text { Early detection of } \\
\text { recurrence and } \\
\text { therapy monitoring }\end{array}$ & $\begin{array}{l}\text { At the cut-off of } \\
\mathbf{1 0 U} / \mathbf{m L}, \\
\text { sensitivity is } 87 \% \\
\text { Study samples } \\
\text { size: } \mathrm{n}=603 \text { breast } \\
\begin{array}{l}\text { cancer } \quad \text { cases } \\
\text { cancer, n=194 } \\
\text { healthy controls } \\
(144)\end{array}\end{array}$ \\
\hline $\begin{array}{l}58 \text { gene RNA } \\
\text { expression } \\
\text { profile }\end{array}$ & Tumor & $\begin{array}{l}\text { nCounter } \\
\text { System }\end{array}$ & $\begin{array}{l}\text { Risk assessment of } \\
\text { distant recurrence of } \\
\text { disease }\end{array}$ & $\begin{array}{l}\text { The probability of } \\
\text { 10-year overall } \\
\text { survival: for } \\
\text { intermediate risk } \\
\text { patients - } 77.2 \% \text {; } \\
\text { distant metastases- } \\
\text { patients: } 76.4 \% \text {. } \\
\text { Study sample size: } \\
\mathrm{n}=650 \text { patients } \\
(145)\end{array}$ \\
\hline $\begin{array}{l}\text { 70-gene } \\
\text { expression } \\
\text { profile } \\
\text { (MammaPrin } \\
\text { t) }\end{array}$ & Tumor & Agendia BV & $\begin{array}{l}\text { Risk assessment of } \\
\text { distant metastasis }\end{array}$ & $\begin{array}{l}\text { Sensitivity } 91 \% \\
\text { and specificity } \\
47 \%(146)\end{array}$ \\
\hline
\end{tabular}




\begin{tabular}{|c|c|c|c|c|c|c|}
\hline \multirow{2}{*}{ 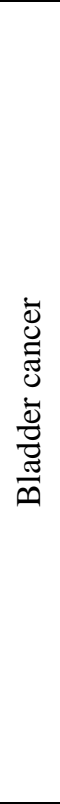 } & 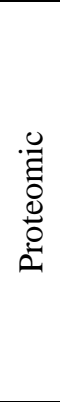 & $\begin{array}{l}\text { Nuclear } \\
\text { Miotic } \\
\text { Apparatus } \\
\text { (NuMA, } \\
\text { NMP22) }\end{array}$ & Urine & $\begin{array}{l}\text { Lateral flow } \\
\text { immunoassay }\end{array}$ & $\begin{array}{l}\text { Diagnosis } \\
\text { monitoring } \\
\text { disease }\end{array}$ & 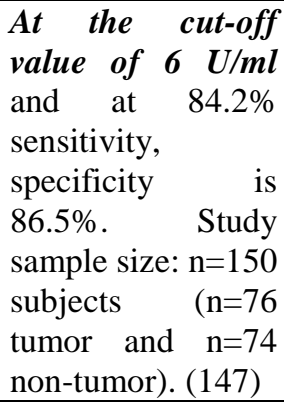 \\
\hline & 弟 & $\begin{array}{l}\text { Aneuploidy } \\
\text { for } \\
\text { chromosome } \\
\text { s } 3,7,17 \text { loss } \\
\text { of } 9 \mathrm{p} 2\end{array}$ & Urine & FISH & $\begin{array}{l}\text { Diagnosis of bladder } \\
\text { carcinoma in } \\
\text { patients } \\
\text { hematuria } \\
\text { subsequent } \\
\text { monitoring and } \\
\text { tumor recurrence }\end{array}$ & $\begin{array}{l}\text { At the cut-off of } 4 \\
\text { cells with gains of } \\
\text { multiple } \\
\text { chromosomes or } \\
12 \text { cells with } \\
\text { homozygous loss } \\
\text { of 9p21 and at } 71 \% \\
\text { sensitivity, } \\
\text { specificity is } \\
65.8 \%(148)\end{array}$ \\
\hline \multirow{3}{*}{ 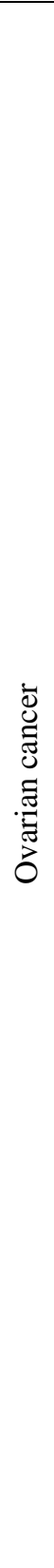 } & \multirow{3}{*}{ 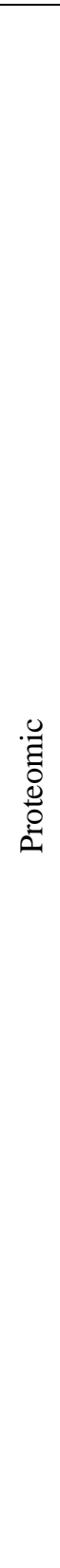 } & $\begin{array}{l}\text { ROMA } \\
(\mathrm{HE} 4+\mathrm{CA}- \\
125)\end{array}$ & Serum & Immunoassay & $\begin{array}{l}\text { Prediction } \\
\text { malignancy }\end{array}$ & $\begin{array}{l}\text { Premenopausal } \\
\text { subjects (n=240 } \\
\text { patients): At the } \\
\text { cut-off of } 1.31 \\
\text { ROMA score and } \\
\text { at } \quad 81.3 \% \\
\text { sensitivity, } \\
\text { specificity } \\
74.5 \% \\
\text { Postmenopausal } \\
\text { subjects (n=221): } \\
\text { At the cut-off of } \\
\text { 2.77 ROMA score } \\
\text { and at 90\%, } \\
\text { sensitivity, } \\
\text { specificity is } \\
76.8 \%(149)\end{array}$ \\
\hline & & $\begin{array}{l}\text { OVA1 Next } \\
\text { Generation }\end{array}$ & Serum & Immunoassay & $\begin{array}{l}\text { Prediction } \\
\text { malignancy }\end{array}$ & $\begin{array}{l}\text { Premenopausal } \\
\text { subjects ( }=276 \\
\text { patients): At the } \\
\text { clinical cut-off } \\
\text { level at } 5.0 \text { and at } \\
90.3 \% \text { sensitivity, } \\
\text { specificity is } \\
71.4 \% \text {. } \\
\text { Postmenopausal } \\
\text { subjects ( }=217 \\
\text { patients): At the } \\
\text { clinical cut-off } \\
\text { level at } 5.0 \text { and at } \\
91.8 \% \text { sensitivity, } \\
\text { specificity is } \\
65.4 \%(150)\end{array}$ \\
\hline & & HE4 & Serum & Immunoassay & $\begin{array}{l}\text { Monitoring } \\
\text { recurrence or } \\
\text { progressive disease }\end{array}$ & $\begin{array}{lr}\text { At } 18 \% & \text { HE4 } \\
\text { concentration } \text { and } \\
\text { at } & 49.2 \% \\
\text { sensitivity, } & \\
\text { specificity } & \text { is } \\
79.6 \% . & \text { Study } \\
\text { sample size: } & n=72 \\
(151) & \end{array}$ \\
\hline
\end{tabular}




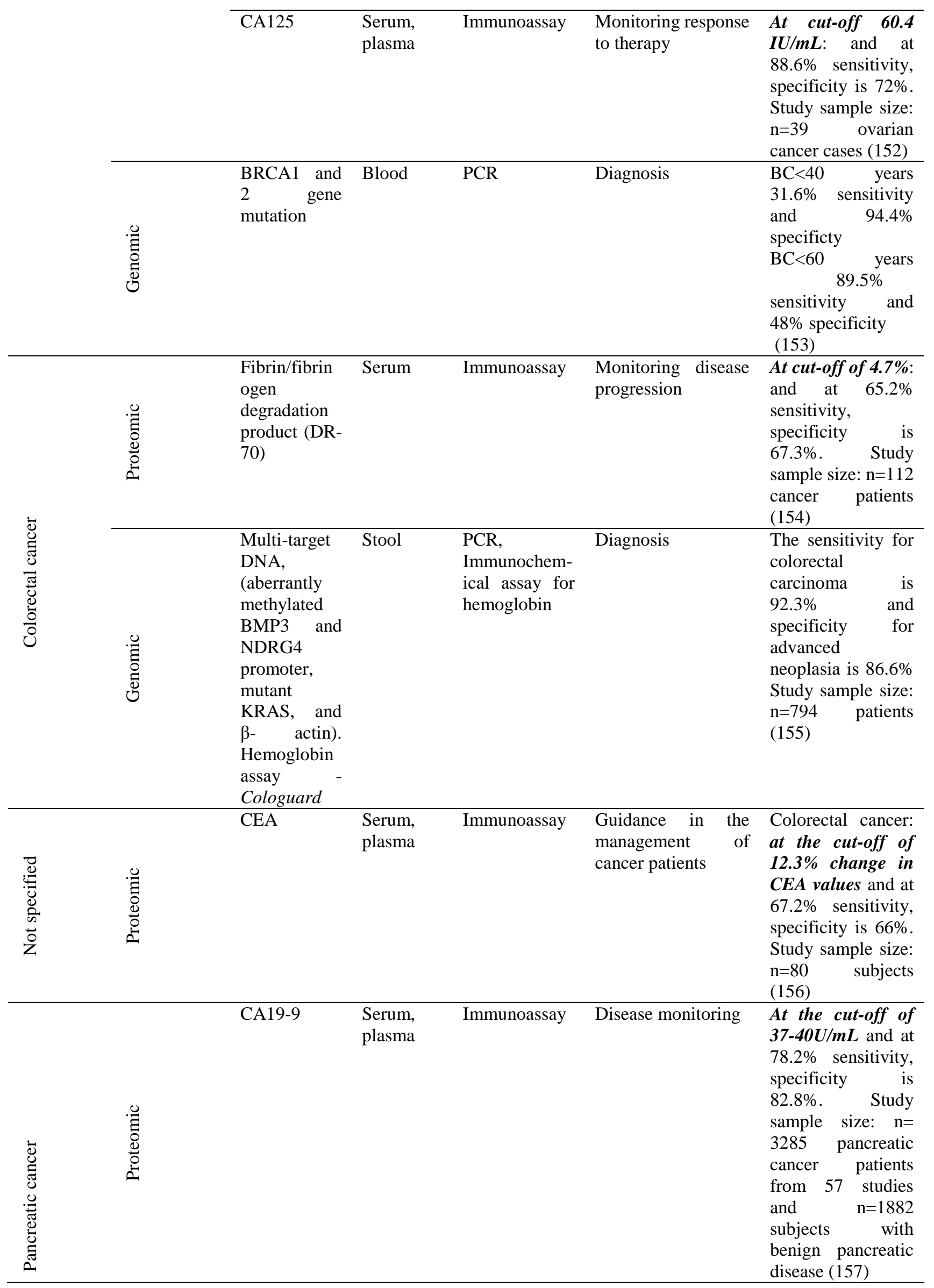




\begin{tabular}{|c|c|c|c|c|c|c|}
\hline 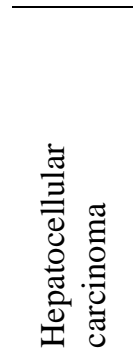 & 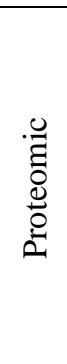 & AFP-L3\% & Serum & $\begin{array}{l}\text { Immunoassay, } \\
\text { microfluidic } \\
\text { capillary } \\
\text { electrophoresi } \\
\mathrm{s}\end{array}$ & $\begin{array}{l}\text { Risk assessment for } \\
\text { development of } \\
\text { disease }\end{array}$ & $\begin{array}{l}\text { At the cut-off of } \text { of } \\
\mathbf{1 0 \%} \text { and at } 71 \% \\
\text { sensitivity, } \\
\text { specificity is } 63 \text {. } \\
\text { Study sample size: } \\
\mathrm{n}=24 \text { chronic liver } \\
\text { disease, } \mathrm{n}=52 \\
\text { hepatocellular } \\
\text { carcinoma (158) }\end{array}$ \\
\hline
\end{tabular}

*Indicative accuracy rates are provided based on published data even though it should be noted that variations in these rates exist based on the tested clinical cohort. 
Table 3. List of the 19 common protein biomarkers (observed in at least in two cancer types) retrieved from 72 selected studies.

\begin{tabular}{|c|c|c|}
\hline \begin{tabular}{c|c} 
Protein names \\
(Uniprot Entry name)
\end{tabular} & $\begin{array}{c}\text { Type of cancer (type of } \\
\text { biofluid/regulation) }\end{array}$ & Reference \\
\hline Clusterin (CLUS) & $\begin{array}{l}\text { Breast cancer (urine/ } \downarrow \text { ) } \\
\text { Ovarian cancer (serum/ } \downarrow \text { ) }\end{array}$ & $\begin{array}{l}\text { Gajbhiye A et al. } 2016(61) \\
\text { Wu J et al. } 2013 \text { (78) }\end{array}$ \\
\hline $\begin{array}{l}\text { Leucine-rich alpha-2- } \\
\text { glycoprotein (LRG1) }\end{array}$ & $\begin{array}{l}\text { Breast cancer (urine } / \uparrow \text { ) } \\
\text { Colorectal cancer (plasma/ } \uparrow \text { ) } \\
\text { Gastric cancer (plasma } / \uparrow \text { ) } \\
\text { Bladder cancer }(\text { urine } / \uparrow \text { ) } \\
\text { Ovarian cancer }(\text { serum } / \uparrow \text { ) }\end{array}$ & $\begin{array}{l}\text { Gajbhiye A et al. } 2016(61) \\
\text { Ladd JJ et al. } 2012(84) \\
\text { Uen YH et al. } 2013(90) \\
\text { Linden M et al. } 2012(54) \\
\text { Wu J et al. } 2013(78)\end{array}$ \\
\hline Gelsolin (GSN) & $\begin{array}{l}\text { Hepatocellular carcinoma (serum/ } \downarrow \text { ) } \\
\text { Breast cancer (urine/ } \downarrow \text { ) }\end{array}$ & $\begin{array}{l}\text { He X et al. } 2014(81) \\
\text { Gajbhiye A et al. } 2016(61)\end{array}$ \\
\hline Osteopontin (OPN) & $\begin{array}{l}\text { Hepatocellular carcinoma (plasma/ } \uparrow \text { ) } \\
\text { Lung cancer (cell line, serum/ } \uparrow \text { ) } \\
\text { Cholangiocarcinoma (urine } / \uparrow \text { ) }\end{array}$ & $\begin{array}{l}\text { Shang F et al. 2012, Da Costa AN et al. } \\
2015(82,83) \\
\text { Birse CE et al. } 2015 \text { (27) } \\
\text { Metzger J et al. } 2013(60)\end{array}$ \\
\hline $\begin{array}{l}\text { Alpha-1-antitrypsin } \\
\text { (A1AT) }\end{array}$ & $\begin{array}{l}\text { Hepatocellular carcinoma (serum/ } \uparrow \text { ) } \\
\text { Bladder cancer (urine } / \uparrow \text { ) }\end{array}$ & $\begin{array}{l}\text { Comunale MA et al. } 2010(80) \\
\text { Linden M et al. 2012, Yang N et al. } 2011 \\
(53,54)\end{array}$ \\
\hline $\begin{array}{l}\text { Insulin-like growth } \\
\text { factor-binding protein } \\
2(\text { IGFBP-2) }\end{array}$ & $\begin{array}{l}\text { Colorectal cancer (plasma/ } \uparrow \text { ) } \\
\text { Lung cancer (cell line, pleural } \\
\text { effusion } \uparrow \text { ) } \\
\text { Pancreatic cancer (plasma/ } \uparrow \text { ) } \\
\end{array}$ & $\begin{array}{l}\text { Ladd JJ et al. } 2012(84) \\
\text { Yu CJ et al. } 2011 \text { (28) } \\
\text { Yoneyama et al. T } 2016(88)\end{array}$ \\
\hline $\begin{array}{l}\text { Metalloproteinase } \\
\text { inhibitor } 1 \text { (TIMP1) }\end{array}$ & $\begin{array}{l}\text { Lung cancer }(\text { cell line, serum/ } \uparrow) \\
\text { Pancreatic cancer (plasma/ } \uparrow)\end{array}$ & $\begin{array}{l}\text { Birse CE et al. } 2015(27) \\
\text { Pan S et al. } 2011(87)\end{array}$ \\
\hline $\begin{array}{l}\text { Alpha-enolase } \\
\text { (ENOA) }\end{array}$ & $\begin{array}{l}\text { Lung cancer }(\text { sputum/ } \uparrow) \\
\text { Pancreatic cancer (tissue, serum/ } \uparrow \text { ) } \\
\text { HNCSC }(\text { cell line, serum/ } \uparrow \text { ) }\end{array}$ & $\begin{array}{l}\text { Yu L et al. } 2014 \text { (95) } \\
\text { Tomaino B et al. } 2011(21) \\
\text { Ralhan R et al. } 2011(33) \\
\end{array}$ \\
\hline $\begin{array}{l}\text { Collagen alpha-1(I) } \\
\text { chain (COL1A1) }\end{array}$ & $\begin{array}{l}\text { Cholangiocarcinoma (urine/ } \uparrow \text { ) } \\
\text { Renal cell carcinoma (urine/ } \downarrow \text { ) } \\
\end{array}$ & $\begin{array}{l}\text { Metzger J et al. } 2013(60) \\
\text { Frantzi M et al. } 2014 \text { (58) } \\
\end{array}$ \\
\hline $\begin{array}{l}\text { Apolipoprotein B } \\
\text { (APO B) }\end{array}$ & $\begin{array}{l}\text { Bladder cancer }(\text { urine } / \uparrow) \\
\text { Prostate cancer }(\text { serum } / \uparrow)\end{array}$ & $\begin{array}{l}\text { Chen CL et al. } 2013 \text { (51) } \\
\text { Templeton AJ et al. } 2013 \text { (92) }\end{array}$ \\
\hline $\begin{array}{l}\text { Fibrinogen beta chain } \\
\text { (FGB) }\end{array}$ & $\begin{array}{l}\text { Bladder cancer (urine/ } \uparrow \text { ) } \\
\text { Renal cell carcinoma (urine/ } \uparrow \text { ) } \\
\end{array}$ & $\begin{array}{l}\text { Linden M et al. } 2012(54) \\
\text { Frantzi M et al. } 2014 \text { (58) } \\
\end{array}$ \\
\hline $\begin{array}{c}\text { Zinc-alpha-2- } \\
\text { glycoprotein (AZGP1) }\end{array}$ & $\begin{array}{l}\text { Breast cancer (urine } / \uparrow \text { ) } \\
\text { Pancreatic cancer (plasma/ } \uparrow \text { ) }\end{array}$ & $\begin{array}{l}\text { Gajbhiye A et al. } 2016(61) \\
\text { Pan S et al. } 2011(87)\end{array}$ \\
\hline Annexin A1 (ANXA1) & $\begin{array}{l}\text { Breast cancer (urine/ } \uparrow \text { ) } \\
\text { Lung cancer (cell line, serum/ } \uparrow \text { ) }\end{array}$ & $\begin{array}{l}\text { Gajbhiye A et al. } 2016(61) \\
\text { Farlow EC et al. } 2010(26)\end{array}$ \\
\hline $\begin{array}{c}\text { Deleted in malignant } \\
\text { brain tumors } 1 \text { protein } \\
\text { (DMBT1) }\end{array}$ & $\begin{array}{l}\text { Gastric cancer (saliva/ } \downarrow \text { ) } \\
\text { Renal cell carcinoma (urine/ } \downarrow \text { ) } \\
\end{array}$ & $\begin{array}{l}\text { Xiao H et al. } 2016(94) \\
\text { Frantzi M et al. } 2014 \text { (58) }\end{array}$ \\
\hline $\begin{array}{l}\text { Collagen alpha-2(I) } \\
\text { chain (COL1A2) }\end{array}$ & $\begin{array}{l}\text { Cholangiocarcinoma (urine } / \uparrow \text { ) } \\
\text { Renal cell carcinoma (urine } / \uparrow \text { ) }\end{array}$ & $\begin{array}{l}\text { Metzger J et al. } 2013(60) \\
\text { Frantzi M et al. } 2014 \text { (58) }\end{array}$ \\
\hline $\begin{array}{l}\text { Collagen alpha-1(III) } \\
\text { chain (COL3A1) }\end{array}$ & $\begin{array}{l}\text { Cholangiocarcinoma (urine } / \uparrow \text { ) } \\
\text { Renal cell carcinoma (urine/ } \uparrow \text { ) }\end{array}$ & $\begin{array}{l}\text { Metzger J et al. } 2013(60) \\
\text { Frantzi M et al. } 2014 \text { (58) } \\
\end{array}$ \\
\hline & Cholangiocarcinoma (urine/ $\downarrow$ ) & Metzger J et al. 2013 (60) \\
\hline
\end{tabular}




\begin{tabular}{|c|l|l|}
$\begin{array}{c}\text { CD99 antigen-like } \\
\text { protein 2 (CD99) }\end{array}$ & Renal cell carcinoma (urine/ $\downarrow$ ) & Frantzi M et al. 2014 (58) \\
\hline $\begin{array}{c}\text { Hemoglobin subunit } \\
\text { beta (HGB) }\end{array}$ & $\begin{array}{l}\text { Cholangiocarcinoma (bile/ } \uparrow) \\
\text { Renal cell carcinoma (urine/ } \uparrow)\end{array}$ & $\begin{array}{l}\text { Lankisch TO et al. 2011 (11) } \\
\text { Frantzi M et al. 2014 (58) }\end{array}$ \\
\hline 14-3-3-zeta & $\begin{array}{l}\text { Cholangiocarcinoma (bile/ } \uparrow) \\
\text { HNCSC }(\text { cell line, serum/ } \uparrow)\end{array}$ & $\begin{array}{l}\text { Lankisch TO et al. 2011 (11) } \\
\text { Ralhan R et al 2011 (33) }\end{array}$ \\
\hline
\end{tabular}


XII. SUPPLEMENTARY TABLES

Supplementary Table S1. List of the 1056 identified records through database searching in Web of Science after applying the citation threshold. The literature search was most recently updated in July 2017.

Supplementary Table S2. List of 72 finally selected studies. The studies are categorized based on the type of biological specimen under investigation. For each publication, selected features are extracted and provided, including: a) the name of biomarker candidates/panels of biomarkers, b) the sample types, c) the biomarker performance, d) the levels of differential expression, e) sample size and f) the clinical context of use.

Supplementary Table S3. Functional analysis of differentially expressed proteins. For elucidating molecular pathways being associated to cancer, the differentially expressed proteins retrieved from 72 selected studies were subjected to the Cytoscape's plug-ins ClueGo and CluePedia. GO Biological processes served as the clustering criterion using a two-sided hypergeometric test followed by Bonferroni correction (significance level of 0.05 ) for identifying significantly affected pathways/terms. 


\section{REFERENCE LIST}

1. Ferlay J, Soerjomataram I, Dikshit R, et al. Cancer incidence and mortality worldwide: sources, methods and major patterns in GLOBOCAN 2012. Int J Cancer. 2015;136(5):E359-E86.

2. Thun MJ, DeLancey JO, Center MM, Jemal A, Ward EM. The global burden of cancer: priorities for prevention. Carcinogenesis. 2010;31(1):100-10.

3. Cox J MM. Is proteomics the new genomics? Cell. 2007.

4. Ocak S CP, Massion PP. Mass spectrometry-based proteomic profiling of lung cancer. Proc Am Thorac Soc. 2009.

5. Kolch W, Mischak H, Pitt AR. The molecular make-up of a tumour: proteomics in cancer research. Clinical Science. 2005;108(5):369-83.

6. Aebersold R, Mann M. Mass-spectrometric exploration of proteome structure and function. Nature. 2016;537(7620):347-55.

7. Huang Y ZH. Protein Array-based Approaches for Biomarker Discovery in Cancer. Genomics Proteomics Bioinformatics. 2017;15(2):73-81.

8. Kohler K, Seitz H. Validation Processes of Protein Biomarkers in Serum-A Cross Platform Comparison. Sensors. 2012;12(9):12710-28.

9. Kulasingam V, Diamandis EP. Strategies for discovering novel cancer biomarkers through utilization of emerging technologies. Nat Clin Pract Oncol. 2008;5(10):58899.

10. Etzioni R, Urban N, Ramsey S, et al. The case for early detection. Nature Reviews Cancer. 2003;3(4):243-52.

11. Lankisch TO, Metzger J, Negm AA, et al. Bile Proteomic Profiles Differentiate Cholangiocarcinoma from Primary Sclerosing Cholangitis and Choledocholithiasis. Hepatology. 2011;53(3):875-84.

12. Brown AP, Wendler DS, Camphausen KA, Miller FG, Citrin D. Performing nondiagnostic research biopsies in irradiated tissue: A review of scientific, clinical, and ethical considerations. Journal of Clinical Oncology. 2008;26(24):3987-94.

13. Karakasis K, Burnier JV, Bowering V, Oza AM, Lheureux S. Ovarian Cancer and BRCA1/2 Testing: Opportunities to improve Clinical Care and Disease Prevention. Frontiers in Oncology. 2016;6.

14. Gown AM. Current issues in ER and HER2 testing by IHC in breast cancer. Modern Pathology. 2008;21:S8-S15.

15. Kulasingam V, Prassas I, Diamandis EP. Towards personalized tumor markers. Npj Precision Oncology. 2017;1.

16. Chace DH, Kalas TA. A biochemical perspective on the use of tandem mass spectrometry for newborn screening and clinical testing. Clinical Biochemistry. 2005;38(4):296-309.

17. White NMA, Masui O, DeSouza LV, et al. Quantitative proteomic analysis reveals potential diagnostic markers and pathways involved in pathogenesis of renal cell carcinoma. Oncotarget. 2014;5(2):506-18. 
18. Hamelin C, Cornut E, Poirier F, et al. Identification and verification of heat shock protein 60 as a potential serum marker for colorectal cancer. Febs Journal. 2011;278(24):4845-59.

19. Surinova S, Choi M, Tao S, et al. Prediction of colorectal cancer diagnosis based oncirculating plasma proteins. Embo Molecular Medicine. 2015;7(9):1166-78.

20. Kosanam H, Prassas I, Chrystoja CC, et al. Laminin, gamma 2 (LAMC2): A Promising New Putative Pancreatic Cancer Biomarker Identified by Proteomic Analysis of Pancreatic Adenocarcinoma Tissues. Molecular \& Cellular Proteomics. 2013;12(10):2820-32.

21. Tomaino B, Cappello P, Capello M, et al. Circulating Autoantibodies to Phosphorylated alpha-Enolase are a Hallmark of Pancreatic Cancer. Journal of Proteome Research. 2011;10(1):105-12.

22. Pang J, Liu WP, Liu XP, et al. Profiling Protein Markers Associated with Lymph Node Metastasis in Prostate Cancer by DIGE-based Proteomics Analysis. Journal of Proteome Research. 2010;9(1):216-26.

23. Zhang JT, Wang KJ, Zhang JZ, et al. Using Proteomic Approach to Identify TumorAssociated Proteins as Biomarkers in Human Esophageal Squamous Cell Carcinoma. Journal of Proteome Research. 2011;10(6):2863-72.

24. Hou GX, Lou XM, Sun YL, et al. Biomarker Discovery and Verification of Esophageal Squamous Cell Carcinoma Using Integration of SWATH/MRM. Journal of Proteome Research. 2015;14(9):3793-803.

25. Chen CL, Chung T, Wu CC, et al. Comparative Tissue Proteomics of Microdissected Specimens Reveals Novel Candidate Biomarkers of Bladder Cancer. Molecular \& Cellular Proteomics. 2015;14(9):2466-78.

26. Farlow EC, Patel K, Basu S, et al. Development of a Multiplexed Tumor-Associated Autoantibody-Based Blood Test for the Detection of Non-Small Cell Lung Cancer. Clinical Cancer Research. 2010;16(13):3452-62.

27. Birse CE, Lagier RJ, FitzHugh W, et al. Blood-based lung cancer biomarkers identified through proteomic discovery in cancer tissues, cell lines and conditioned medium. Clinical Proteomics. 2015;12.

28. Yu CJ, Wang CL, Wang CI, et al. Comprehensive Proteome Analysis of Malignant Pleural Effusion for Lung Cancer Biomarker Discovery by Using Multidimensional Protein Identification Technology. Journal of Proteome Research. 2011;10(10):467182.

29. Cerciello F, Choi M, Nicastri A, et al. Identification of a seven glycopeptide signature for malignant pleural mesothelioma in human serum by selected reaction monitoring. Clinical Proteomics. 2013;10.

30. Ralhan R, DeSouza LV, Matta A, et al. iTRAQ-Multidimensional Liquid Chromatography and Tandem Mass Spectrometry-Based Identification of Potential Biomarkers of Oral Epithelial Dysplasia and Novel Networks between Inflammation and Premalignancy. Journal of Proteome Research. 2009;8(1):300-9.

31. Ralhan R, Desouza LV, Matta A, et al. Discovery and verification of head-and-neck cancer biomarkers by differential protein expression analysis using iTRAQ labeling, multidimensional liquid chromatography, and tandem mass spectrometry. Molecular \& Cellular Proteomics. 2008;7(6):1162-73. 
32. Kashat L, So AKC, Masui O, et al. Secretome-Based Identification and Characterization of Potential Biomarkers in Thyroid Cancer. Journal of Proteome Research. 2010;9(11):5757-69.

33. Ralhan R, Masui O, DeSouza LV, et al. Identification of proteins secreted by head and neck cancer cell lines using LC-MS/MS: Strategy for discovery of candidate serological biomarkers. Proteomics. 2011;11(12):2363-76.

34. Sepiashvili L, Hui A, Ignatchenko V, et al. Potentially Novel Candidate Biomarkers for Head and Neck Squamous Cell Carcinoma Identified Using an Integrated Cell Line-based Discovery Strategy. Molecular \& Cellular Proteomics. 2012;11(11):140415.

35. Xue H, Li BJ, Zhang J, et al. Identification of Serum Biomarkers for Colorectal Cancer Metastasis Using a Differential Secretome Approach. Journal of Proteome Research. 2010;9(1):545-55.

36. Barderas R, Mendes M, Torres S, et al. In-depth Characterization of the Secretome of Colorectal Cancer Metastatic Cells Identifies Key Proteins in Cell Adhesion, Migration, and Invasion. Molecular \& Cellular Proteomics. 2013;12(6):1602-20.

37. Loei H, Tan HT, Lim TK, et al. Mining the Gastric Cancer Secretome: Identification of GRN as a Potential Diagnostic Marker for Early Gastric Cancer. Journal of Proteome Research. 2012;11(3):1759-72.

38. Yao L, Lao WF, Zhang Y, et al. Identification of EFEMP2 as a Serum Biomarker for the Early Detection of Colorectal Cancer with Lectin Affinity Capture Assisted Secretome Analysis of Cultured Fresh Tissues. Journal of Proteome Research. 2012;11(6):3281-94.

39. Fujita K, Kume H, Matsuzaki K, et al. Proteomic analysis of urinary extracellular vesicles from high Gleason score prostate cancer. Scientific Reports. 2017;7.

40. Saraon P, Musrap N, Cretu D, et al. Proteomic Profiling of Androgen-independent Prostate Cancer Cell Lines Reveals a Role for Protein S during the Development of High Grade and Castration-resistant Prostate Cancer. Journal of Biological Chemistry. 2012;287(41):34019-31.

41. Chen CL, Lai YF, Tang P, et al. Comparative and Targeted Proteomic Analyses of Urinary Microparticles from Bladder Cancer and Hernia Patients. Journal of Proteome Research. 2012;11(12):5611-29.

42. Bryan RT, Regan HL, Pirrie SJ, et al. Protein shedding in urothelial bladder cancer: prognostic implications of soluble urinary EGFR and EpCAM. British Journal of Cancer. 2015;112(6):1052-8.

43. Mange A, Dimitrakopoulos L, Soosaipillai A, et al. An integrated cell line-based discovery strategy identified follistatin and kallikrein 6 as serum biomarker candidates of breast carcinoma. Journal of Proteomics. 2016;142:114-21.

44. De Marchi T, Liu NQ, Stingl C, et al. 4-protein signature predicting tamoxifen treatment outcome in recurrent breast cancer. Molecular Oncology. 2016;10(1):24-39.

45. Yu CJ, Chang KP, Chang YJ, et al. Identification of Guanylate-Binding Protein 1 as a Potential Oral Cancer Marker Involved in Cell Invasion Using Omics-Based Analysis. Journal of Proteome Research. 2011;10(8):3778-88.

46. Rhodes DR, Yu JJ, Shanker K, et al. ONCOMINE: A cancer microarray database and integrated data-mining platform. Neoplasia. 2004;6(1):1-6. 
47. Giovannini C, Minguzzi M, Genovese F, et al. Molecular and proteomic insight into Notch1 characterization in hepatocellular carcinoma. Oncotarget. 2016;7(26):3960926.

48. Huang DW, Sherman BT, Lempicki RA. Systematic and integrative analysis of large gene lists using DAVID bioinformatics resources. Nature Protocols. 2009;4(1):44-57.

49. Wu CC, Hsu CW, Chen CD, et al. Candidate Serological Biomarkers for Cancer Identified from the Secretomes of 23 Cancer Cell Lines and the Human Protein Atlas. Molecular \& Cellular Proteomics. 2010;9(6):1100-17.

50. Chen YT, Chen HW, Domanski D, et al. Multiplexed quantification of 63 proteins in human urine by multiple reaction monitoring-based mass spectrometry for discovery of potential bladder cancer biomarkers. Journal of Proteomics. 2012;75(12):3529-45.

51. Chen CL, Lin TS, Tsai CH, et al. Identification of potential bladder cancer markers in urine by abundant-protein depletion coupled with quantitative proteomics. Journal of Proteomics. 2013;85:28-43.

52. Chen YT, Chen CL, Chen HW, et al. Discovery of Novel Bladder Cancer Biomarkers by Comparative Urine Proteomics Using iTRAQ Technology. Journal of Proteome Research. 2010;9(11):5803-15.

53. Yang N, Feng S, Shedden K, et al. Urinary Glycoprotein Biomarker Discovery for Bladder Cancer Detection Using LC/MS-MS and Label-Free Quantification. Clinical Cancer Research. 2011;17(10):3349-59.

54. Linden M, Lind SB, Mayrhofer C, et al. Proteomic analysis of urinary biomarker candidates for nonmuscle invasive bladder cancer. Proteomics. 2012;12(1):135-44.

55. Yang HC, Fogo AB, Kon V. Kidneys: key modulators of high-density lipoprotein levels and function. Current Opinion in Nephrology and Hypertension. 2016;25(3):174-9.

56. Schanstra JP, Zurbig P, Alkhalaf A, et al. Diagnosis and Prediction of CKD Progression by Assessment of Urinary Peptides. Journal of the American Society of Nephrology. 2015;26(8):1999-2010.

57. Frantzi M, van Kessel KE, Zwarthoff EC, et al. Development and Validation of Urinebased Peptide Biomarker Panels for Detecting Bladder Cancer in a Multi-center Study. Clinical cancer research : an official journal of the American Association for Cancer Research. 2016;22(16):4077-86.

58. Frantzi M, Metzger J, Banks RE, et al. Discovery and validation of urinary biomarkers for detection of renal cell carcinoma. Journal of Proteomics. 2014;98:44-58.

59. Klein J, Eales J, Zurbig P, et al. Proteasix: A tool for automated and large-scale prediction of proteases involved in naturally occurring peptide generation. Proteomics. 2013;13(7):1077-82.

60. Metzger J, Negm AA, Plentz RR, et al. Urine proteomic analysis differentiates cholangiocarcinoma from primary sclerosing cholangitis and other benign biliary disorders. Gut. 2013;62(1):122-30.

61. Gajbhiye A, Dabhi R, Taunk K, et al. Urinary proteome alterations in HER2 enriched breast cancer revealed by multipronged quantitative proteomics. Proteomics. 2016;16(17):2403-18. 
62. Radon TP, Massat NJ, Jones R, et al. Identification of a Three-Biomarker Panel in Urine for Early Detection of Pancreatic Adenocarcinoma. Clinical Cancer Research. 2015;21(15):3512-21.

63. Ahn JM, Sung HJ, Yoon YH, et al. Integrated Glycoproteomics Demonstrates Fucosylated Serum Paraoxonase 1 Alterations in Small Cell Lung Cancer. Molecular \& Cellular Proteomics. 2014;13(1):30-48.

64. Pecot CV, Li M, Zhang XJ, et al. Added Value of a Serum Proteomic Signature in the Diagnostic Evaluation of Lung Nodules. Cancer Epidemiology Biomarkers \& Prevention. 2012;21(5):786-92.

65. Taguchi F, Solomon B, Gregorc V, et al. Mass spectrometry to classify non-small-cell lung cancer patients for clinical outcome after treatment with epidermal growth factor receptor tyrosine kinase inhibitors: A multicohort cross-institutional study. Journal of the National Cancer Institute. 2007;99(11):838-46.

66. Dingemans AMC, Mellema WW, Groen HJM, et al. A Phase II Study of Sorafenib in Patients with Platinum-Pretreated, Advanced (Stage IIIb or IV) Non-Small Cell Lung Cancer with a KRAS Mutation. Clinical Cancer Research. 2013;19(3):743-51.

67. Gregorc V, Novello S, Lazzari C, et al. Predictive value of a proteomic signature in patients with non-small-cell lung cancer treated with second-line erlotinib or chemotherapy (PROSE): a biomarker-stratified, randomised phase 3 trial. Lancet Oncology. 2014;15(7):713-21.

68. Kuiper JL, Lind JSW, Groen HJM, et al. VeriStrat (R) has prognostic value in advanced stage NSCLC patients treated with erlotinib and sorafenib. British Journal of Cancer. 2012;107(11):1820-5.

69. Mok TSK, Geater SL, Su WC, et al. A Randomized Phase 2 Study Comparing the Combination of Ficlatuzumab and Gefitinib with Gefitinib Alone in Asian Patients with Advanced Stage Pulmonary Adenocarcinoma. Journal of Thoracic Oncology. 2016;11(10):1736-44.

70. Kim YJ, Sertamo K, Pierrard MA, et al. Verification of the Biomarker Candidates for Non-small-cell Lung Cancer Using a Targeted Proteomics Approach. Journal of Proteome Research. 2015;14(3):1412-9.

71. Li XJ, Hayward C, Fong PY, et al. A Blood-Based Proteomic Classifier for the Molecular Characterization of Pulmonary Nodules. Science Translational Medicine. 2013;5(207).

72. $\mathrm{Xu}$ QS, Liang YZ. Monte Carlo cross validation. Chemometrics and Intelligent Laboratory Systems. 2001;56(1):1-11.

73. Li XJ, Lee LW, Hayward C, et al. An integrated quantification method to increase the precision, robustness, and resolution of protein measurement in human plasma samples. Clinical Proteomics. 2015;12.

74. Vachani A, Pass HI, Rom WN, et al. Validation of a Multiprotein Plasma Classifier to Identify Benign Lung Nodules. Journal of Thoracic Oncology. 2015;10(4):629-37.

75. Chung LP, Moore K, Phillips L, et al. Novel serum protein biomarker panel revealed by mass spectrometry and its prognostic value in breast cancer. Breast Cancer Research. 2014;16(3).

76. Correa S, Panis C, Binato R, et al. Identifying potential markers in Breast Cancer subtypes using plasma label-free proteomics. Journal of Proteomics. 2017;151:33-42. 
77. Wu J, Xie XL, Liu YS, et al. Identification and Confirmation of Differentially Expressed Fucosylated Glycoproteins in the Serum of Ovarian Cancer Patients Using a Lectin Array and LC-MS/MS. Journal of Proteome Research. 2012;11(9):4541-52.

78. Wu J, Xie XL, Nie S, Buckanovich RJ, Lubman DM. Altered Expression of Sialylated Glycoproteins in Ovarian Cancer Sera Using Lectin-based ELISA Assay and Quantitative Glycoproteomics Analysis. Journal of Proteome Research. 2013;12(7):3342-52.

79. Russell MR, Walker MJ, Williamson AJK, et al. Protein Z: A putative novel biomarker for early detection of ovarian cancer. International Journal of Cancer. 2016;138(12):2984-92.

80. Comunale MA, Rodemich-Betesh L, Hafner J, et al. Linkage Specific Fucosylation of Alpha-1-Antitrypsin in Liver Cirrhosis and Cancer Patients: Implications for a Biomarker of Hepatocellular Carcinoma. Plos One. 2010;5(8).

81. He X, Wang Y, Zhang W, et al. Screening differential expression of serum proteins in AFP-negative HBV-related hepatocellular carcinoma using iTRAQ -MALDI-MS/MS. Neoplasma. 2014;61(1):17-26.

82. Shang SF, Plymoth A, Ge SK, et al. Identification of osteopontin as a novel marker for early hepatocellular carcinoma. Hepatology. 2012;55(2):483-90.

83. da Costa AN, Plymoth A, Santos-Silva D, et al. Osteopontin and latent-TGF beta binding-protein 2 as potential diagnostic markers for HBV-related hepatocellular carcinoma. International Journal of Cancer. 2015;136(1):172-81.

84. Ladd JJ, Busald T, Johnson MM, et al. Increased Plasma Levels of the APC-Interacting Protein MAPRE1, LRG1, and IGFBP2 Preceding a Diagnosis of Colorectal Cancer in Women. Cancer Prevention Research. 2012;5(4):655-64.

85. Choi JW, Liu H, Shin DH, et al. Proteomic and cytokine plasma biomarkers for predicting progression from colorectal adenoma to carcinoma in human patients. Proteomics. 2013;13(15):2361-74.

86. Jones JJ, Wilcox BE, Benz RW, et al. A Plasma-Based Protein Marker Panel for Colorectal Cancer Detection Identified by Multiplex Targeted Mass Spectrometry. Clinical Colorectal Cancer. 2016;15(2):186-+.

87. Pan S, Chen R, Crispin DA, et al. Protein Alterations Associated with Pancreatic Cancer and Chronic Pancreatitis Found in Human Plasma using Global Quantitative Proteomics Profiling. Journal of Proteome Research. 2011;10(5):2359-76.

88. Yoneyama T, Ohtsuki S, Honda K, et al. Identification of IGFBP2 and IGFBP3 As Compensatory Biomarkers for CA19-9 in Early-Stage Pancreatic Cancer Using a Combination of Antibody-Based and LC-MS/MS-Based Proteomics. Plos One. 2016;11(8).

89. Nakamura T, Furukawa Y, Nakagawa H, et al. Genome-wide cDNA microarray analysis of gene expression profiles in pancreatic cancers using populations of tumor cells and normal ductal epithelial cells selected for purity by laser microdissection. Oncogene. 2004;23(13):2385-400.

90. Uen YH, Lin KY, Sun DP, et al. Comparative proteomics, network analysis and posttranslational modification identification reveal differential profiles of plasma Con Abound glycoprotein biomarkers in gastric cancer. Journal of Proteomics. 2013;83:197213. 
91. Yoo MW, Park J, Han HS, et al. Discovery of gastric cancer specific biomarkers by the application of serum proteomics. Proteomics. 2017;17(6).

92. Templeton AJ, Dutoit V, Cathomas R, et al. Phase 2 Trial of Single-agent Everolimus in Chemotherapy-naive Patients with Castration-resistant Prostate Cancer (SAKK 08/08). European Urology. 2013;64(1):150-8.

93. Chai YD, Zhang LF, Yang Y, et al. Discovery of potential serum protein biomarkers for lymph node metastasis in oral cancer. Head and Neck-Journal for the Sciences and Specialties of the Head and Neck. 2016;38(1):118-25.

94. Xiao H, Zhang Y, Kim Y, et al. Differential Proteomic Analysis of Human Saliva using Tandem Mass Tags Quantification for Gastric Cancer Detection. Scientific Reports. 2016;6.

95. Yu L, Shen J, Mannoor K, Guarnera M, Jiang F. Identification of ENO1 As a Potential Sputum Biomarker for Early-Stage Lung Cancer by Shotgun Proteomics. Clinical Lung Cancer. 2014;15(5):372-+.

96. Wang TH, Chao A, Tsai CL, et al. Stress-induced Phosphoprotein 1 as a Secreted Biomarker for Human Ovarian Cancer Promotes Cancer Cell Proliferation. Molecular \& Cellular Proteomics. 2010;9(9):1873-84.

97. Jou YJ, Lin CD, Lai CH, et al. Proteomic identification of salivary transferrin as a biomarker for early detection of oral cancer. Analytica Chimica Acta. 2010;681(12):41-8.

98. Wu CC, Chu HW, Hsu CW, Chang KP, Liu HP. Saliva proteome profiling reveals potential salivary biomarkers for detection of oral cavity squamous cell carcinoma. Proteomics. 2015;15(19):3394-404.

99. Mundt F, Johansson HJ, Forshed J, et al. Proteome Screening of Pleural Effusions Identifies Galectin 1 as a Diagnostic Biomarker and Highlights Several Prognostic Biomarkers for Malignant Mesothelioma. Molecular \& Cellular Proteomics. 2014;13(3):701-15.

100. Yates JR, Ruse CI, Nakorchevsky A. Proteomics by Mass Spectrometry: Approaches, Advances, and Applications. Annual Review of Biomedical Engineering. Annual Review of Biomedical Engineering. 112009. p. 49-79.

101. Thakur SS, Geiger T, Chatterjee B, et al. Deep and Highly Sensitive Proteome Coverage by LC-MS/MS Without Prefractionation. Molecular \& Cellular Proteomics. $2011 ; 10(8)$.

102. Monteoliva L AP. Differential proteomics: an overview of gel and non-gel based approaches. Brief Funct Genomic Proteomic. 2004;Nov;3(3):220-39.

103. Strohkamp S, Gemoll T, Habermann JK. Possibilities and limitations of 2DE-based analyses for identifying low-abundant tumor markers in human serum and plasma. Proteomics. 2016;16(19):2519-32.

104. Kolch W, Neususs C, Peizing M, Mischak H. Capillary electrophoresis - Mass spectrometry as a powerful tool in clinical diagnosis and biomarker discovery. Mass Spectrometry Reviews. 2005;24(6):959-77.

105. Mischak H, Coon JJ, Novak J, et al. Capillary electrophoresis-mass spectrometry as a powerful tool in biomarker discovery and clinical diagnosis: an update of recent developments. Mass Spectrometry Reviews. 2009;28(5):703-24. 
106. Stalmach A, Albalat A, Mullen W, Mischak H. Recent advances in capillary electrophoresis coupled to mass spectrometry for clinical proteomic applications. Electrophoresis. 2013;34(11):1452-64.

107. Pontillo CF, Szymon; Borras, Daniel M. CE-MS-based proteomics in biomarker discovery and clinical application. PROTEOMICS CLINICAL APPLICATIONS 2014;9(3-4).

108. Chalmers MJ, Mackay CL, Hendrickson CL, et al. Combined top-down and bottomup mass spectrometric approach to characterization of biomarkers for renal disease. Analytical Chemistry. 2005;77(22):7163-71.

109. Klein J, Papadopoulos T, Mischak H, Mullen W. Comparison of CE-MS/MS and LCMS/MS sequencing demonstrates significant complementarity in natural peptide identification in human urine. Electrophoresis. 2014;35(7):1060-4.

110. Nkuipou-Kenfack E, Zurbig P, Mischak H. The long path towards implementation of clinical proteomics: Exemplified based on CKD273. Proteomics Clinical Applications. 2017;11(5-6).

111. Elschenbroich S, Ignatchenko V, Clarke B, et al. In-Depth Proteomics of Ovarian Cancer Ascites: Combining Shotgun Proteomics and Selected Reaction Monitoring Mass Spectrometry. Journal of Proteome Research. 2011;10(5):2286-99.

112. Tsai TH, Song EW, Zhu R, et al. LC-MS/MS-based serum proteomics for identification of candidate biomarkers for hepatocellular carcinoma. Proteomics. 2015;15(13):2369-81.

113. Peterson AC, Russell JD, Bailey DJ, Westphall MS, Coon JJ. Parallel Reaction Monitoring for High Resolution and High Mass Accuracy Quantitative, Targeted Proteomics. Molecular \& Cellular Proteomics. 2012;11(11):1475-88.

114. Li Z, Adams RM, Chourey K, et al. Systematic Comparison of Label-Free, Metabolic Labeling, and Isobaric Chemical Labeling for Quantitative Proteomics on LTQ Orbitrap Velos. Journal of Proteome Research. 2012;11(3):1582-90.

115. Latosinska A, Vougas K, Makridakis M, et al. Comparative Analysis of Label-Free and 8-Plex iTRAQ Approach for Quantitative Tissue Proteomic Analysis. Plos One. 2015;10(9).

116. Jantos-Siwy J, Schiffer E, Brand K, et al. Quantitative Urinary Proteome Analysis for Biomarker Evaluation in Chronic Kidney Disease. Journal of Proteome Research. 2009;8(1):268-81.

117. Mischak H, Vlahou A, Ioannidis JPA. Technical aspects and inter-laboratory variability in native peptide profiling: The CE-MS experience. Clinical Biochemistry. 2013;46(6):432-43.

118. Belczacka I, Latosinska A, Siwy J, et al. Urinary CE-MS peptide marker pattern for detection of solid tumors. Scientific Reports. 2018;8.

119. Cohen JD, Li L, Wang YX, et al. Detection and localization of surgically resectable cancers with a multi-analyte blood test. Science. 2018;359(6378):926-+.

120. Hanahan D, Weinberg RA. Hallmarks of Cancer: The Next Generation. Cell. 2011;144(5):646-74.

121. Rittling SR, Chambers AF. Role of osteopontin in tumour progression. British Journal of Cancer. 2004;90(10):1877-81. 
122. Park KH, Gad E, Goodell V, et al. Insulin-like Growth Factor-Binding Protein-2 Is a Target for the Immunomodulation of Breast Cancer. Cancer Research. 2008;68(20):8400-9.

123. Andersen JD, Boylan KLM, Jemmerson R, et al. Leucine-rich alpha-2-glycoprotein-1 is upregulated in sera and tumors of ovarian cancer patients. Journal of Ovarian Research. 2010;3.

124. Lee KB, Jeon JH, Choi I, et al. Clusterin, a novel modulator of TGF-beta signaling, is involved in Smad2/3 stability. Biochemical and Biophysical Research Communications. 2008;366(4):905-9.

125. Bindea G, Mlecnik B, Hackl H, et al. ClueGO: a Cytoscape plug-in to decipher functionally grouped gene ontology and pathway annotation networks. Bioinformatics. 2009;25(8):1091-3.

126. Lindhardt M, Persson F, Currie G, et al. Proteomic prediction and Renin angiotensin aldosterone system Inhibition prevention Of early diabetic nephRopathy in TYpe 2 diabetic patients with normoalbuminuria (PRIORITY): essential study design and rationale of a randomised clinical multicentre trial. Bmj Open. 2016;6(3).

127. Pontillo $\mathrm{C}$, Mischak H. Urinary peptide-based classifier CKD273: towards clinical application in chronic kidney disease. Clinical Kidney Journal. 2017;10(2):192-201.

128. Mischak H, Allmaier G, Apweiler R, et al. Recommendations for Biomarker Identification and Qualification in Clinical Proteomics. Science Translational Medicine. 2010;2(46).

129. Mischak H, Ioannidis JP, Argiles A, et al. Implementation of proteomic biomarkers: making it work. European Journal of Clinical Investigation. 2012;42(9):1027-36.

130. Frantzi M, Latosinska A, Fluhe L, et al. Developing proteomic biomarkers for bladder cancer: towards clinical application. Nature Reviews Urology. 2015;12(6):317-30.

131. Babjuk M, Burger M, Zigeuner R, et al. EAU Guidelines on Non-Muscle-invasive Urothelial Carcinoma of the Bladder: Update 2013. European Urology. 2013;64(4):639-53.

132. Bokarica P, Hrkac A, Gilja I. Re: J. Alfred Witjes, Thierry Lebret, Eva M. Comperat, et al. Updated 2016 EAU Guidelines on Muscle-invasive and Metastatic Bladder Cancer. Eur Urol 2017; 71: 462-75. European Urology. 2017;72(2):E45-E.

133. Vlahou A. Back to the future in bladder cancer research. Expert Review of Proteomics. 2011;8(3):295-7.

134. Eriksson P, Sjodahl G, Chebil G, Liedberg F, Hoglund M. HER2 and EGFR amplification and expression in urothelial carcinoma occurs in distinct biological and molecular contexts. Oncotarget. 2017;8(30):48905-14.

135. Mischak H VA, Ioannidis JP. Technical aspects and inter-laboratory variability in native peptide profiling: the CE-MS experience. Clin Biochem 2013;Apr;46(6):43243.

136. Catalona W.J. PAW, Sanda M.G, . A Multi-Center Study of [-2]Pro-Prostate-Specific Antigen (PSA) in Combination with PSA and Free PSA for Prostate Cancer Detection in the 2.0 to $10.0 \mathrm{ng} / \mathrm{mL}$ PSA Range. J Urol 2011;185(5): 1650-1655.

137. Lee R, Localio AR, Armstrong $\mathrm{K}$, et al. A meta-analysis of the performance characteristics of the free prostate-specific antigen test. Urology. 2006;67(4):762-8. 
138. Prcic A BE, Hiros M. Usefulness of Total PSA Value in Prostate Diseases Diagnosis. Acta Inform Med. 2016;Jun;24(3):156-61.

139. Ramos CG, Valdevenito R, Vergara I, et al. PCA3 sensitivity and specificity for prostate cancer detection in patients with abnormal PSA and/or suspicious digital rectal examination. First Latin American experience. Urologic Oncology-Seminars and Original Investigations. 2013;31(8):1522-6.

140. https://www.accessdata.fda.gov/cdrh_docs/reviews/K050245.pdf. Food and Drug Administration, CellSearch ${ }^{\mathrm{TM}}$ Circulating Tumor Cell Kit.

141. https://www.accessdata.fda.gov/cdrh_docs/reviews/K042884.pdf. Food and Drug Administration, DakoCytomation ER/PR pharmDx ${ }^{\mathrm{TM}} \mathrm{Kit}$.

142.https://www.fda.gov/ohrms/dockets/ac/01/briefing/3815b1_09_PathVysion\%20PI\%20 OCT2001.pdf. Food and Drug Administration, PathVysion ${ }^{\text {TM }}$ HER-2 DNA Probe Kit.

143. Food and Drug Administration BMaBMCotA, Systems I. https://www.accessdata.fda.gov/cdrh_docs/reviews/K033036.pdf.

144. Gion M, Mione R, Leon AE, et al. CA27.29: a valuable marker for breast cancer management. A confirmatory multicentric study on 603 cases. European Journal of Cancer. 2001;37(3):355-63.

145. https://www.accessdata.fda.gov/cdrh_docs/reviews/K130010.pdf. Food and Drug Administration, ProsignaTM Breast Cancer Prognostic Gene Signature Assay.

146. Kunz G. Use of a genomic test (MammaPrint (TM)) in daily clinical practice to assist in risk stratification of young breast cancer patients. Archives of Gynecology and Obstetrics. 2011;283(3):597-602.

147. Banos JLG, Rodrigo MHR, Juarez FMA, Garcia BM. NMP 22, BTA stat test and cytology in the diagnosis of bladder cancer: A comparative study. Urologia Internationalis. 2001;66(4):185-90.

148. https://www.accessdata.fda.gov/cdrh_docs/pdf3/P030052b.pdf. Food and Drug Administration, UroVysion Bladder Cancer Kit.

149. https://www.accessdata.fda.gov/cdrh_docs/reviews/K103358.pdf. Food and Drug Administration, ROMA ${ }^{\mathrm{TM}}$ (HE4 EIA + ARCHITECT CA 125 II $^{\mathrm{TM}}$ )

150. https://www.accessdata.fda.gov/cdrh_docs/pdf15/K150588.pdf. Food and Drug Administration, OVA1 Next Generation.

151. https://www.accessdata.fda.gov/cdrh_docs/pdf15/k151378.pdf. Food and Drug Administration, Lumipulse G HE4.

152. Moss E. L HJ, Reynolds T.M. The role of CA125 in clinical practice. J Clin Pathol 2005;Mar; 58(3): 308-312.

153. Grindedal EM HC, Karsrud I. Current guidelines for BRCA testing of breast cancer patients are insufficient to detect all mutation carriers. BMC Cancer. 2017( 2017; 17: 438).

154. https://www.accessdata.fda.gov/cdrh_docs/pdf7/K072901.pdf. Food and Drug Administration, AMDL-ELISA DR-70® (FDP)

155. Test CSD-BCCS. https://www.accessdata.fda.gov/cdrh_docs/pdf13/P130017B.pdf. Food and Drug Administration. 2014. 
156. https://www.accessdata.fda.gov/cdrh_docs/reviews/K080194.pdf. Food and Drug Administration, VIDAS ${ }^{\circ}$ CEA.

157. Poruk KE, Gay DZ, Brown K, et al. The Clinical Utility of CA 19-9 in Pancreatic Adenocarcinoma: Diagnostic and Prognostic Updates. Current Molecular Medicine. 2013;13(3):340-51.

158. Leerapun A SSV, Bida J. P. The utility of AFP-L3\% in the diagnosis of hepatocellular carcinoma: evaluation in a U.S. referral population. Clin Gastroenterol Hepatol. 2007;Mar; 5(3): 394-267. 